\title{
A Coupled Icephobic Coating and Piezoelectric Actuator System for Aircraft De-icing Applications
}

\author{
by \\ Nick Tepylo \\ A Thesis submitted to \\ the Faculty of Graduate Studies and Research \\ in partial fulfilment of \\ the requirements for the degree of \\ Master of Applied Science \\ Ottawa-Carleton Institute for \\ Mechanical and Aerospace Engineering \\ Department of Mechanical and Aerospace Engineering \\ Carleton University \\ Ottawa, Ontario, Canada
}

April 2017

Copyright (C)

2017 - Nick Tepylo 
The undersigned recommend to

the Faculty of Graduate Studies and Research

acceptance of the Thesis

\title{
A Coupled Icephobic Coating and Piezoelectric Actuator System for Aircraft De-icing Applications
}

\author{
Submitted by Nick Tepylo \\ in partial fulfilment of the requirements for the degree of \\ Master of Applied Science
}

X. Huang, Thesis Supervisor

M. Budinger, Thesis Co-Supervisor

R. Miller, Department Chair

Carleton University

2017 


\section{Abstract}

Icing on aircraft is a significant problem that can lead to catastrophic consequences. Aircraft operators are looking for solutions that require less power than today's systems. Piezoelectric de-icing systems have gathered a lot of interest in the aviation industry. Combining this technology with industrial icephobic coatings allows for the adhesion strength between the ice and aircraft surfaces to be greatly reduced, thus requiring little power to delaminate the accumulated ice.

A numerical model of a piezoelectric de-icing system on an aluminum substrate was created to determine the resonance modes of the structure. Flexural resonance modes were determined to be of interest as the shear stress generated at the ice-aluminum interface allows for the delamination of the ice sheet. At a frequency around $43 \mathrm{kHz}$, the model predicted that the ice would delaminate at voltages below $100 \mathrm{~V}$.

Experiments were conducted to ensure that the ice adhesion strength of coated and uncoated surfaces were accurate when input into the model. Wear testing was also performed to observe how the coating would degrade while in service. It was found that of the tested coatings, silicone R-1009 had the best combination of wear resistance and ice adhesion strength reduction. The silicone R-1009 coating was applied onto the de-icing system and compared against the bare substrate and it was found that the coated surface reduces the power required for delamination but does not expel the ice as the uncoated sample does. 
In memory of George Tepylo 


\section{Acknowledgments}

First and foremost, I would like to thank my thesis supervisor, Dr. Xiao Huang for her guidance and support throughout the course of this research. It is with her

support that I was able to conduct my research with both direction and purpose. Dr. Huang also provided the opportunity to undertake a portion of my thesis at ISAE Supaero in Toulouse, France.

I would like to thank my thesis co-supervisors Dr. Marc Budinger and Dr. Valérie Pommier-Budinger for welcoming me to Toulouse with open arms and for speaking primarily in English. Their guidance in the areas of electrical engineering, numerical modelling and simulation made the outcome of this work possible.

I also owe acknowledgment to faculty members Steve Truttmann, Alex Proctor, Fred Barrett, and Jianqun Wang who provided much needed support for material preparation, testing and analysis.

I would like to recognize all the people that helped me with the testing during my thesis. Pierrick Rouset, John Polansky, Chris Bassindale, Stefano Sandri, Bingjie Xiao, Achille Grellier and Rachael Machnee all contributed to this work in some capacity and the presented results would not have been obtainable without them.

Lastly, I would like to thank my parents for their never-ending encouragement and moral support throughout this journey.

And to all the people I missed or forgot to mention, thank you. 


\section{Table of Contents}

Abstract

\begin{tabular}{|l|l}
\hline Acknowledgments & v
\end{tabular}

Table of Contents $\quad$ vi

List of Tables $\quad$ xi

List of Figures $\quad$ xii

$\begin{array}{ll}\text { Nomenclature } & \text { xviii }\end{array}$

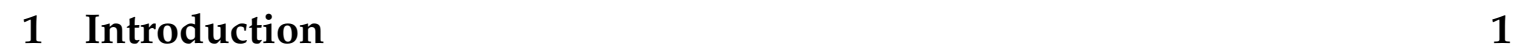

1.1 Motivation . . . . . . . . . . . . . . . . . 1

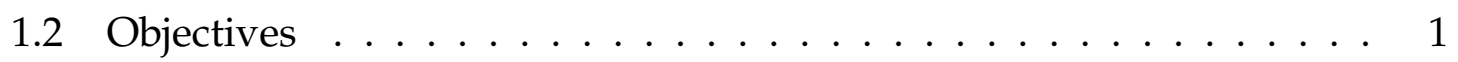

1.3 Thesis Overview $\ldots \ldots \ldots \ldots \ldots \ldots$

\begin{tabular}{|lll}
\hline 2 & Literature Review & 4
\end{tabular}

$2.1 \quad$ Ice Accretion and Properties . . . . . . . . . . . . . . . . . 4

2.1.1 Formation and Crystal Structure . . . . . . . . . . . . . . 4

2.1 .2 Properties of Ice . . . . . . . . . . . . . . 5

2.1 .3 Interaction Between Ice and a Surface . . . . . . . . . . . 7

$2.1 .3 .1 \quad$ Surface Forces . . . . . . . . . . . . 8 
2.1.3.2 Overcoming the Adhesive Force . . . . . . . . . . 9

$2.1 .4 \quad$ Ice Buildup on Structures $\ldots \ldots \ldots$

2.1 .4 .1 Types of Ice $\ldots \ldots \ldots$

2.1 .4 .2 Known Icing Conditions $\ldots . . \ldots \ldots$

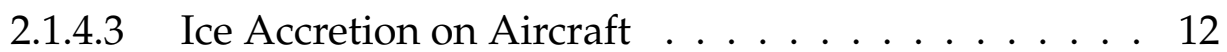

2.2 Conventional Aircraft De-icing . . . . . . . . . . . . . . . 14

2.2 .1 Definitions . . . . . . . . . . . . . . . . . . . . 14

$2.2 .2 \quad$ Pre/Post-Flight De-icing . . . . . . . . . . . . . . . . . 15

$2.2 .3 \quad$ In-Flight De-icing . . . . . . . . . . . . . . . . 16

2.2.3.1 Pneumatic De-icing Boots . . . . . . . . . . . 16

2.2.3.2 Bleed Air De-icing Systems . . . . . . . . . . . . 17

2.2.3.3 Electro-Thermal De-icing Systems . . . . . . . . . . 17

2.2.3.4 Electro-Mechanical De-icing Systems . . . . . . . . 18

2.2 .3 .5 Ultrasonic De-icing Systems . . . . . . . . . . . . 19

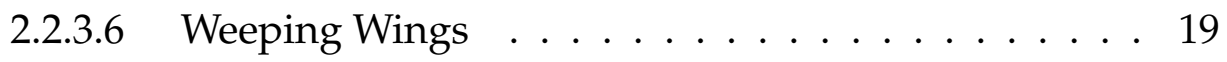

2.2 .3 .7 Passive Systems . . . . . . . . . . . . . 20

2.3 Surface Coatings and Anti-icing Applications . . . . . . . . . . 20

2.3 .1 Hydrophobic Coatings . . . . . . . . . . . . . . . . . 20

2.3 .2 Icephobic Coatings . . . . . . . . . . . . . . . . . 21

2.3.2.1 NuSil Silicone R-2180 . . . . . . . . . . . . . . . . 22

2.3.2.2 NuSil Silicone R-1009 . . . . . . . . . . . . . . . . 24

2.3 .3 Coating Processes . . . . . . . . . . . . . . . . . . . 25

2.3 .4 Parameters Affecting Ice Adhesion Strength . . . . . . . . 26

$2.3 .4 .1 \quad$ Contact Angle $\ldots \ldots \ldots \ldots$

2.3 .4 .2 Surface Roughness . . . . . . . . . . . . . . . 27

2.3 .4 .3 Temperature . . . . . . . . . . . . . 27

2.4 Piezoceramic Materials and Applications $\ldots \ldots \ldots \ldots . \ldots 28$ 
2.4 .1 Piezoelectric Materials . . . . . . . . . . . . . . . . . . . . . . . 29

2.4 .2 Use of PZT in Ultrasonic De-icing Systems . . . . . . . . . . 29

$\begin{array}{|ll|}3 & \text { Coating Procedures and Sample Preparation }\end{array}$

$3.1 \quad$ Aluminum Substrate Preparation . . . . . . . . . . . . . . . . 32

3.2 Icephobic Coating Selection $\ldots \ldots \ldots \ldots \ldots$. . . . . . . . . 34

3.3 Specific Coating Procedures . . . . . . . . . . . . . . . . 35

3.3 .1 Silicone R-2180 . . . . . . . . . . . . . . . . . . . 36

3.3 .2 Silicone R-1009 . . . . . . . . . . . . . . . . . . . . 37

3.3 .3 ETFE . . . . . . . . . . . . . . . . 38

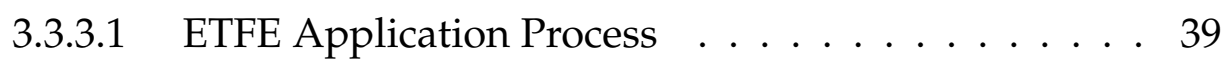

3.3.3.2 Selection of Arc Current _. . . . . . . . . . . 39

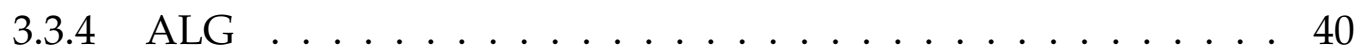

3.3 .5 Coating Surface Observations . . . . . . . . . . . . . . 42

3.4 Sample Storage $\ldots \ldots \ldots \ldots \ldots \ldots$

3.5 Bonding the Piezoelectric Actuators $\ldots \ldots \ldots \ldots$. . . . . . . 43

$3.5 .1 \quad$ Bonding the Actuator to the Substrate . . . . . . . . . . 44

3.5 .2 Verifying Electrical Conductivity . . . . . . . . . . . . 45

$\begin{array}{|ll|}4 & \text { Numerical Modelling of Ice Delamination }\end{array}$

4.1 The Numerical Model . . . . . . . . . . . . . . . . . . . . . 47

$4.1 .1 \quad$ Material Properties . . . . . . . . . . . . . . . . 48

4.1 .2 Boundary Conditions . . . . . . . . . . . . . . . . 49

4.1 .3 Element Selection . . . . . . . . . . . . . . . . . . . . . . 49

4.1 .4 Initial Mesh . . . . . . . . . . . . . . . . . . . 50

$4.2 \quad$ Mesh Convergence Study . . . . . . . . . . . . . . . . . . . . 51

$4.2 .1 \quad$ Approach . . . . . . . . . . . . . . . . . . 51

4.2 .2 Selected Mesh . . . . . . . . . . . . . . . . . . 53 
4.3 Variables Affecting Delamination $\ldots \ldots \ldots \ldots \ldots$

4.3 .1 Quality Factor . . . . . . . . . . . . . . . . . . . . . . 53

4.3 .2 Ice Thickness $\ldots \ldots \ldots \ldots$. . . . . . . . . . . 56

4.3 .3 Ice Adhesion Strength $\ldots \ldots \ldots$

$4.3 .4 \quad$ Aspect Ratio . . . . . . . . . . . . . . . . . . . . . 60

4.4 Test Points . . . . . . . . . . . . . . . . . . . . 62

$\begin{array}{|ll|}5 & \text { Experimental Results and Discussion }\end{array}$

$5.1 \quad$ Wear Testing of Polymer Coatings $\ldots \ldots \ldots$. . . . . . . . 65

5.2 Single Shear Ice Adhesion Test $\ldots \ldots \ldots \ldots$. . . . . . 71

5.2 .1 Test Setup . . . . . . . . . . . . . . . . . . . . . . . 71

5.2 .2 Adhesion Strength Results $\ldots . . . \ldots$. . . . . . . 73

5.3 Ice Adhesion Testing Using a Vertical-Axis Rotor . . . . . . . . . . . 75

$5.3 .1 \quad$ Test Setup . . . . . . . . . . . . . . . . . . . . . . 75

5.3 .2 Measurement of Parameters . . . . . . . . . . . . . 76

5.3.2.1 Accounting for Mass Loss . . . . . . . . . . . 78

$5.3 .3 \quad$ Ice Adhesion as a Function of Temperature . . . . . . . . . 79

5.3 .4 Comparison to the Single Shear Ice Adhesion Test . . . . . . . 83

5.4 Using Multiple Parameters to Evaluate Icephobic Surface Effectiveness . . . . . . . . . . . . . . . . . . . . . . 84

5.5 Testing of Piezoelectric Actuators on an Aluminum Plate . . . . . . 87

$5.5 .1 \quad$ Equipment Setup . . . . . . . . . . . . . . . . . . . 87

5.5 .2 Freezing Water onto the Plate . . . . . . . . . . . . . 89

5.5 .3 Discovery of Resonance Modes . . . . . . . . . . . . . . . 90

5.5 .4 Verification of Resonance Mode. . . . . . . . . . . . . . . . . 91

5.5 .5 Behavior at a Resonance Mode . . . . . . . . . . . . . . . 93

5.5 .6 Measurement of Quality Factor . . . . . . . . . . . . . . . 95 


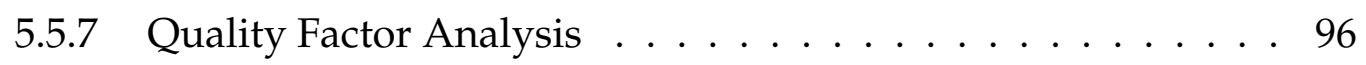

5.6 Comparing the Resonance Frequency of Coated Plates to Bare Aluminum . . . . . . . . . . . . . . . . . . . 99

5.6 .1 Using a Mechanically Activated Shaker . . . . . . . . . . . 99

5.6 .2 Using a Piezoceramic Actuator and Sensor . . . . . . . . . . 101

5.6.3 $\quad$ Measuring the Quality Factor of Bare and Coated Samples . . 103

5.7 Ice Delamination Testing . . . . . . . . . . . . . . . . . . . 105

5.7 .1 Bare Aluminum . . . . . . . . . . . . . . . . . . . 105

5.7 .2 Silicone R-1009 Coated Plate . . . . . . . . . . . . . . . 108

5.7 .3 Influence of Stiffness on Shear Stress . . . . . . . . . . . 109

$5.8 \quad$ Summary of Results . . . . . . . . . . . . . . . . . . . . . . 112

$\begin{array}{lll}6 & \text { Concluding Remarks } & 114\end{array}$

6.1 Contributions . . . . . . . . . . . . . . . . . . . . 114

$6.1 .1 \quad$ Feasibility of Coating Application . . . . . . . . . . . . 115

$6.1 .2 \quad$ Icephobic Coating Selection . . . . . . . . . . . . . . . . 115

6.1 .3 Computational Modelling of De-icing . . . . . . . . . . . 116

6.1 .4 Validation of the Ultrasonic De-icing System . . . . . . . . 117

6.2 Future Work . . . . . . . . . . . . . . . . . . . . . . . . . . . . 119

\begin{tabular}{ll}
\hline List of References & 120
\end{tabular}

\begin{tabular}{lll}
\hline Appendix A Derivation of the Numerical Model & 128
\end{tabular}

A.1 Resonance Frequency . . . . . . . . . . . . . . . . . . . . . 128

A.2 Extraction of Properties. . . . . . . . . . . . . . . . . . . . . 129

A.3 Calculation of Vibrational Properties … . . . . . . . . . 130

A.4 Calculation of Delamination Parameters . . . . . . . . . . . . . . 131 


\section{List of Tables}

1 Properties of rime, glazed and mixed ice . . . . . . . . . . . . 11

2 Applied coatings and properties . . . . . . . . . . . . . 35

3 Dimensions of the numerical model $\ldots \ldots \ldots$. . . . . . . . 48

$4 \quad$ Material properties of the numerical model . . . . . . . . . . . . 48

5 Comparing the affects of quality factor . . . . . . . . . . . 55

6 Comparing the affects of ice thickness $\ldots \ldots \ldots \ldots \ldots$

7 Comparing the affects of ice adhesion strength $\ldots \ldots \ldots$. . . . . 60

8 Size of the plates modelled . . . . . . . . . . . . . . . . 60

9 Comparing the affects of plate and actuator size . . . . . . . . . 61

$10 \quad$ Resonance modes predicted by the numerical model where delamination may occur $\ldots \ldots \ldots$. . . . . . . . . . . . . 63

$11 \quad$ Ice Adhesion Strength for Icephobic Surfaces using a Controlled Displacement . . . . . . . . . . . . . . . . . . . . . . . 74

12 Ejection shear stresses for different surfaces and temperatures . . . . 80

13 Equations of linear trend lines fitted for each surface . . . . . . . . . 81

14 Equations for the ARF function for each surface $\ldots \ldots \ldots$. . . . . 82

15 Comparison of the two ice adhesion tests $\ldots \ldots \ldots$. . . . . 83

16 Resonance modes with a high quality factor . . . . . . . . . . . 96

17 Young's modulus for aluminum, ice and silicone rubber. . . . . . . 110

18 Power required to delaminate ice on coated and uncoated plates. . . 113 


\section{List of Figures}

$1 \quad$ Tensile and compressive strengths of ice as a function of temperature. 5

2 Tensile and compressive strengths of ice as a function of the applied strain rate. . . . . . . . . . . . . . . . . . . . . 6

3 Effect of grain size on the tensile strength of ice. $\ldots \ldots \ldots \ldots$

$4 \quad$ Rime ice forms individual ice pellets (left) while glaze ice freezes into a continuous sheet (right). . . . . . . . . . . . . . . 10

5 Ice commonly builds up on the leading edge of aircraft during flight into known icing conditions. . . . . . . . . . . . . . . . 12

6 Ice accretion profile at different temperatures on a NACA 0012 airfoil. 13

$7 \quad$ Pneumatic boot not in use (left) and inflated to shed ice (right). . . . . 16

8 The contact angle of hydrophobic surface, PTFE (left) is much greater than a hydrophilic surface (right). . . . . . . . . . . . . . 21

9 Chemical structure of a polyorganosiloxane. . . . . . . . . . . 22

10 Zero Degree Cone Testing apparatus used for ice adhesion testing. . 23

11 Ice adhesion of commercially available materials tested by the Department of the Army. . . . . . . . . . . . . . . . . . . . . 24

12 Silicone R-2180 tested after extreme environmental conditioning. . . 24

13 Shear stress of icephobic coatings manufactured by NuSil Technology. 25

14 Piezoelectric stack actuator (left) and patch actuator (right). . . . . . . 28 
15 Tensile and shear stresses in the ice and aluminum substrate for flexural and extensional modes. . . . . . . . . . . . . . . . . . . . . 31

16 The sandblasting apparatus. . . . . . . . . . . . . . . 33

17 The aluminum surface prior to sandblasting (left) and after sandblasting (right). . . . . . . . . . . . . . . 33

18 The Vulcan 3-550 furnace used for curing coatings following application. . . . . . . . . . . . . . . . . . 35

19 Silicone R-2180 Part A and Part B as received. . . . . . . . . . . . . . . 36

20 The silicone R-2180 mixture ready for application. . . . . . . . . . . . 37

21 NuSil silicone R-1009 as received (left) and prior to application (right). 38

22 Plasma spray powder feeder (left) and the preheating and spraying chamber (right). . . . . . . . . . . . . . . . 39

23 SEM micrograph showing ETFE coating microstructure. . . . . . . . 40

24 The bottle of ALG (left) and the liquid being removed in a syringe

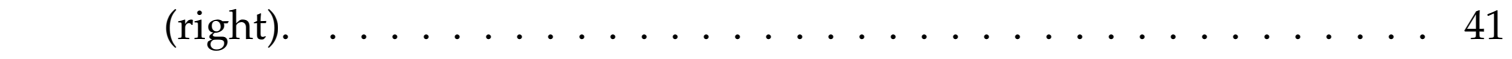

25 All the surfaces used: (a) aluminum, (b) sandblasted aluminum, (c) ALG, (d) ETFE, (e) silicone R-2180, and (f) silicone R-1009. . . . . . . . 42

26 The actuators were placed in the centre of the plate with a $2 \mathrm{~mm}$ gap between them. . . . . . . . . . . . . . . . 43

27 Tape was placed on the surface to prevent the glue from spreading past the intended area. . . . . . . . . . . . . . . . . . . . 44

28 Weights used to keep the piezoceramic in place. . . . . . . . . . . . 45

29 Aluminum sample with two piezoceramics mounted that is ready for testing. . . . . . . . . . . . . . . . . 46

$30 \quad$ Initial mesh used in the (a) x-y plane and (b) x-z plane. . . . . . . . . 50

31 Convergence of the solution varying the element size in the piezoceramic. . . . . . . . . . . . . . . . . 52 
32 Convergence of the solution varying the element size in the substrate. 52

33 Frequencies used in the calculation of quality factor. . . . . . . . . . 54

34 The flexural mode with 5 nodes and a higher order combination mode. 55

35 Shift in resonance frequency with ice thickness. . . . . . . . . . . 56

$36 \quad$ Resonance mode shapes for the flexural, torsional and shear modes used in Figure $35 \mid \ldots \ldots 7$. . . . . . . . . . . . . 57

37 Resonance mode shapes for the two node and five node flexural mode. 61

$38 \quad$ Typical deformation pattern observed for modes requiring low voltages for delamination. . . . . . . . . . . . . . . . . 62

39 Possible resonance modes that will cause delamination of a $2 \mathrm{~mm}$ thick ice sheet. . . . . . . . . . . . . . . . . . . . . . . . . 63

$40 \quad$ Possible resonance modes that will cause delamination of a $5 \mathrm{~mm}$ thick ice sheet. . . . . . . . . . . . . . . . . . . . . . . 64

41 Wear testing apparatus used for determining wear loss. . . . . . . . 66

42 Wear loss for the ALG, ETFE, silicone R-2180 and silicone R-1009 samples. . . . . . . . . . . . . . . . . . . . 67

43 Teflon flakes were deposited into the wear track. . . . . . . . . . . 68

44 Wear tests for ALG, ETFE, silicone R-2180 and silicone R-1009. . . . . 69

45 Wear track profile for the ETFE sample that was wear tested for 2

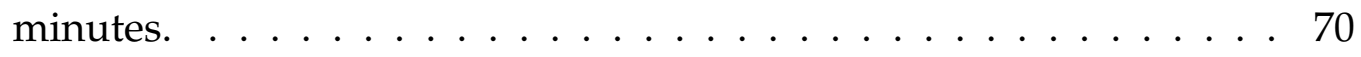

$46 \quad$ Volumetric wear loss for the ETFE samples. . . . . . . . . . . . . 71

$47 \quad$ (a) As fabricated jig used to align lap shear samples during freezing and (b) jig with one lap shear sample. . . . . . . . . . . . . . 72

48 a) Insulated chamber shown in the MTS and (b) cross-section of the insulated chamber with a loaded sample. . . . . . . . . . . . 73

49 The Vertical Axis Spin Testing Apparatus. . . . . . . . . . . . . . 76

$50 \quad$ A spline is drawn around the droplet in order to determine its area. . 77 
51 Relative mass loss due to sublimation as a function of droplet size. . 79

52 Shear stress required to eject a droplet as a function of temperature and surface. . . . . . . . . . . . . . . . . . . . . 80

53 Composite plot aiding in the selection of icephobic coatings showing both the ARF and wear resistance. . . . . . . . . . . . . . 85

54 Cracks formed on the ALG surface (left) which raised the ice adhesion strength compared to the original surface (right). . . . . . . . . 86

55 Schematic diagram showing all of the connections between the equipment used. . . . . . . . . . . . . . . . . . . 88

56 Equipment used in the experiment (a) the 4-quadrant power supply, (b) waveform generator, and (c) oscilloscope. . . . . . . . . . . . . 89

57 The sample is held level in the vice while the water freezes inside of a freezer. . . . . . . . . . . . . . . . . . . 90

58 Response using a frequency sweep for a $2 \mathrm{~mm}$ thick sheet of ice. . . . 91

59 Setup of the scanning vibrometer. . . . . . . . . . . . . . . . . . 92

60 Surface contour plot (left) and the predicted deformation from the numerical model (right) for the first resonance mode. . . . . . . . . 93

61 Sensor response and current draw for a sweep between $40 \mathrm{kHz}$ and $45 \mathrm{kHz}$ at $10 \mathrm{~V} . \ldots \ldots$. . . . . . . . . . . . . . . 994

62 Sensor response and plate temperature for a sweep between $40 \mathrm{kHz}$ and $45 \mathrm{kHz}$ at $10 \mathrm{~V} . \ldots \ldots \ldots \ldots$. . . . . . . . . . 94

63 Quality factor measurements for a $2 \mathrm{~mm}$ thick sheet of ice. . . . . . . 95

64 Extensional resonance modes for the plate obtained from the numerical model with an ice thickness of $2 \mathrm{~mm}$. . . . . . . . . . . . 97

65 Experimental displacement (left) and displacement from the numerical model (right) for the extensional mode at $26.9 \mathrm{kHz} . ~ \ldots . . . .98$ 
66 A linear correlation exists between the quality factor and resonance frequency when excluding extensional modes. . . . . . . . . . . . . . 98

67 The shaker with a coated plate as seen from the top (left) and side views (right). . . . . . . . . . . . . . . . . . . . 100

68 Sweep using the vibrometer and shaker on coated and uncoated plates. . . . . . . . . . . . . . . . . . 100

69 Corresponding resonance modes found using the shaker for the bare aluminum plate. . . . . . . . . . . . . . . . 100

70 Sweep using the piezoelectric actuator and sensor on coated and uncoated plates where the circled peaks correspond to the resonance modes illustrated in Figure $71 \mid$. . . . . . . . . . . . . . . . 101

71 Corresponding resonance modes found using the piezoelectric actuator and sensor. . . . . . . . . . . . . . . . . . . . 102

72 Corresponding resonance modes found using the numerical model with no ice. . . . . . . . . . . . . . . . . 103

73 Quality factor for the bare aluminum (blue), ETFE (red), and silicone R-1009 (green) plates. . . . . . . . . . . . . . . . . . . . . . 104

74 Quality factor for the bare aluminum and silicone R-1009 plates measured with the ceramic patch and vibrometer. . . . . . . . . . 105

75 Sequence of delamination of a $2 \mathrm{~mm}$ sheet of ice off of an aluminum plate. . . . . . . . . . . . . . . . . 107

76 Delamination attempt for a $5 \mathrm{~mm}$ sheet of ice. . . . . . . . . . . . . . . 108

77 Difference in crack depth depending on ice thickness. . . . . . . . . . 108

78 The normal and shear stress distributions in composite beams consisting of aluminum, coating and ice. . . . . . . . . . . . . . 110

79 Deformation (in $\mathrm{mm}$ ) of the plate, coating and ice for the first flexural mode. . . . . . . . . . . . . . . . . . . . . 111 
$80 \quad$ Interface shear stress between the ice and coating along the plate for different coating stiffnesses. . . . . . . . . . . . . . . . . . . 111 


\section{Nomenclature}

\section{Latin Characters}

\begin{tabular}{|c|c|c|}
\hline Symbol & Description & Units \\
\hline$a$ & Plate length & {$[\mathrm{m}]$} \\
\hline$A$ & Area & {$\left[\mathrm{m}^{2}\right]$} \\
\hline C & Structural damping matrix & {$\left[\frac{\mathrm{kg}}{\mathrm{s}}\right]$} \\
\hline$C_{0}$ & Capacitance & {$[\mathrm{F}]$} \\
\hline$E$ & Young's modulus & {$[\mathrm{GPa}]$} \\
\hline$f$ & Frequency & {$[\mathrm{Hz}]$} \\
\hline$F$ & Force vector & {$[\mathrm{N}]$} \\
\hline$h$ & Thickness & {$[\mathrm{m}]$} \\
\hline$i$ & Current & {$[\mathrm{A}]$} \\
\hline$I$ & Second moment of area & {$\left[\mathrm{m}^{4}\right]$} \\
\hline$k$ & Shear coupling factor & {$[-]$} \\
\hline$K$ & Structural stiffness matrix & {$\left[\mathrm{Nm}^{2}\right]$} \\
\hline
\end{tabular}




$\begin{array}{lll}m & \text { Mass } & {[\mathrm{kg}]} \\ M & \text { Structural mass matrix } & {[\mathrm{kg}]} \\ n & \text { Vibrational mode } & {[-]} \\ N & \text { Force factor } & {\left[\frac{\mathrm{As}}{\mathrm{m}}\right]} \\ P & \text { Power } & {[\mathrm{W}]} \\ q & \text { Electrical charge } & {[\mathrm{C}]} \\ Q_{m} & \text { Quality factor } & {[-]} \\ r & \text { Distance to centre of rotation } & {[\mathrm{m}]} \\ T & \text { Temperature } & {\left[{ }^{\circ} \mathrm{C}\right]} \\ u & \text { Displacement } & {[\mathrm{m}]} \\ \dot{u} & \text { Velocity } & {\left[\frac{\mathrm{m}}{\mathrm{s}}\right]} \\ u & \text { Acceleration } & {\left[\frac{\mathrm{m}}{\mathrm{s}^{2}}\right]} \\ V & \text { Voltage } & {[\mathrm{V}]}\end{array}$

\section{Greek Characters}

\begin{tabular}{llc} 
Symbol & Description & Units \\
\hline$\epsilon$ & Strain & {$[-]$} \\
$\epsilon_{0}$ & Electrical permittivity in a vacuum & {$\left[\frac{\mathrm{F}}{\mathrm{m}}\right]$} \\
$\epsilon^{S}$ & Piezoceramic permittivity ratio & {$[-]$}
\end{tabular}




$\begin{array}{lll}\zeta & \text { Damping ratio } & {[-]} \\ v & \text { Poisson's ratio } & {[-]} \\ \rho & \text { Density } & {\left[\frac{\mathrm{kg}}{\mathrm{m}^{3}}\right]} \\ \sigma & \text { Tensile stress } & {[\mathrm{MPa}]} \\ \tau & \text { Shear stress } & {[\mathrm{MPa}]} \\ \phi & \text { Mode shape } & {[-]} \\ \omega & \text { Natural frequency } & {[\mathrm{Hz}]} \\ \Omega & \text { Rotational speed } & {\left[\frac{\mathrm{rad}}{\mathrm{s}}\right]}\end{array}$

\section{Subscripts}

\begin{tabular}{lll} 
Symbol & Description & Units \\
\hline$A l$ & Aluminum & {$[-]$} \\
$c$ & Central & {$[-]$} \\
$d$ & Droplet & {$[-]$} \\
del & Delamination & {$[-]$} \\
exp & Experimental data & {$[-]$} \\
gen & Generated & {$[-]$} \\
$i$ & Mode number & {$[-]$} \\
ice & Ice & {$[-]$}
\end{tabular}




\begin{tabular}{|c|c|}
\hline int & Interface \\
\hline$l$ & Lower bound \\
\hline $\max$ & Maximum \\
\hline med & Median \\
\hline$n$ & Neutral line \\
\hline$S$ & Surface \\
\hline$u$ & Upper bound \\
\hline$x x$ & Normal in the $\mathrm{x}$-direction \\
\hline yy & Normal in the $y$-direction \\
\hline$z z$ & Normal in the z-direction \\
\hline$x y$ & On the $x$-face in the $y$-direction \\
\hline$y z$ & On the $y$-face in the $z$-direction \\
\hline$z x$ & On the $z$-face in the $x$-direction \\
\hline
\end{tabular}




\section{List of Abbreviations}

\begin{tabular}{ll} 
Abbreviation & Description \\
\hline AC & Alternating current \\
ALG & Advanced Liquid Glass \\
AOA & Angle of attack \\
AR & Aspect ratio \\
ARF & Adhesion reduction factor \\
ASTM & American Society for Testing and Materials \\
CRREL & Cold Regions Research and Engineering Laboratory \\
EASA & European Aviation Safety Agency \\
ESC & Electronic speed controller \\
ETFE & Ethylene tetrafluoroethylene \\
FAA & Federal Aviation Administration \\
IPS & Ice protection system \\
LWC & Liquid water content \\
MTS & Material Testing System \\
NA & Neutral Axis \\
NACA & National Advisory Committee for Aeronautics \\
& Polytetrafluoroethylene \\
\hline
\end{tabular}




$\begin{array}{ll}\text { PZT } & \text { Lead zirconate titanate } \\ \text { RPM } & \text { Revolutions per minute } \\ \text { RTV } & \text { Room temperature vulcanizing } \\ \text { SB } & \text { Sandblasted } \\ \text { SEM } & \text { Scanning electron microscope } \\ \text { SLPM } & \text { Standard liters per minute } \\ \text { TMEDS } & \text { Thermo-Mechanical Expulsion Deicing System } \\ \text { VASTA } & \text { Vertical Axis Spin Testing Apparatus }\end{array}$




\section{Chapter 1}

\section{Introduction}

\subsection{Motivation}

As the use of aircraft increased throughout the twentieth century, the effects of icing became better known. Unfortunately, this was the result of numerous accidents and many lives lost. Ice can buildup on any aircraft surface below $0{ }^{\circ} \mathrm{C}$ and results in the loss of lift while increasing the drag and stall speed of the aircraft.

Ice buildup on aircraft continues to be a problem and the aerospace industry is looking for solutions to improve today's practices. Present day solutions are classified as either passive where no energy is put into the system or active in which the system must be powered. Passive systems can only be used for preventing ice buildup while active systems can remove ice accretions and prevent ice from forming. Presently-used de-icing systems either use excess energy to shed ice or have negative effects on the environment.

\subsection{Objectives}

This thesis evaluates the potential of pairing icephobic coatings with ultrasonic de-icing systems. The main expected impacts of combining these technologies are 
the decrease in energy consumption and the reduction of environmental impacts from de-icing fluids. Such a system would be beneficial to airline operators with financial savings from the reduction in operational costs and to passengers as wait times for spraying de-icing fluid would be eliminated. The purpose of this work is to develop a coupled system that uses passive icephobic coatings to lower the shear stress required for delamination and an active system to remove any accumulated ice.

This thesis sets out to address the following objectives:

1. To evaluate the potential feasibility of applying icephobic coatings onto aircraft surfaces.

2. To select an icephobic coating based on experimental ice adhesion testing.

3. To develop a system incorporating icephobic coatings with piezoelectric actuators.

4. To use numerical modelling to find optimal resonance modes for ice delamination and to reduce the power consumed by the system.

\subsection{Thesis Overview}

This thesis is organized into six chapters. A description of each chapter is provided below.

Chapter 1: Introduction - The first chapter discusses the motivations and objectives of the work performed. A brief overview of each chapter is also provided.

Chapter 2: Literature Review - This chapter provides background information on the topics of ice accretion on aircraft, conventional de-icing techniques and the various types of aircraft de-icing systems. In addition, icephobic coatings and their potential application on aircraft surfaces shall be presented. An introduction 
into ultrasonic de-icing systems will be is provided and their potential to be paired with icephobic materials is discussed.

Chapter 3, Coating Procedures and Sample Preparation - This chapter introduces the candidate coating materials for the reduction of ice adhesion to the surface and explains the reasons for their selection. The procedures for surface preparation and application of the selected coatings are described. Furthermore, the process used to bond the piezoelectric actuators to the samples is discussed.

Chapter 4 Numerical Modelling of Ice Delamination - A numerical model was created using ANSYS software. An ice sheet was modelled on an aluminum plate and the natural frequencies of the various resonance modes were determined. The stresses in the plate, piezoelectric actuators and ice sheet were found and the power required for de-icing was computed. A further explanation of the numerical model is presented in Appendix A.

Chapter 5; Experimental Results and Discussion - The numerical model presented in Chapter 4 was tested to verify its validity. In addition to this testing, the ice adhesion strength of the selected hydrophobic and icephobic coatings was determined using a shear testing apparatus. A pin-on-disk wear test was used to determine the durability of each coating. Considering the ice adhesion and wear test results, a coating was selected to apply onto the substrate. The complete deicing system was tested for power consumption and compared to similar systems.

Chapter 6 Concluding Remarks - This final chapter summarizes the work done in designing and testing an ice protection system for aircraft involving the use of icephobic coatings paired with piezoelectric actuators. Suggestions for future work are also presented. 


\section{Chapter 2}

\section{Literature Review}

\subsection{Ice Accretion and Properties}

Ice is a naturally occurring state of water. It is characterized by its solid crystalline structure and forms when water in liquid or gaseous form cools below $0{ }^{\circ} \mathrm{C}(273.15$ K) at standard atmospheric pressure.

\subsubsection{Formation and Crystal Structure}

Ice can exist in approximately 17 different phases which differ by their crystal structures [1]. The most common type of ice is referred to as type I and it forms under atmospheric pressure. There are two variants of type I ice, type $\mathrm{I}_{\mathrm{h}}$ which has a hexagonal structure and type $I_{c}$ which has a cubic arrangement of atoms [2]. Type $\mathrm{I}_{\mathrm{h}}$ ice can be formed by cooling water below $273.15 \mathrm{~K}$ at standard atmospheric pressure. Type $I_{c}$ ice is a more stable configuration of $\mathrm{I}_{h}$ ice and forms at atmospheric pressure at temperatures below $150 \mathrm{~K}\left(-123^{\circ} \mathrm{C}\right)$.

The remaining phases of ice form at elevated pressures (above 2 atmospheres) and are unlikely to form on Earth, outside of laboratory conditions. Due to the conditions required to create the various other forms of ice, the vast majority of ice 
on Earth can be assumed to be type $\mathrm{I}_{\mathrm{h}}$ ice [3].

\subsubsection{Properties of Ice}

The properties of ice can vary significantly as a function of the temperature and the tested strain rate [4]. As can be seen in Figure1, both the compressive and ultimate tensile strength of an ice sample decrease with an increase in the temperature. The limit of this curve is at $0{ }^{\circ} \mathrm{C}$ when the ice melts into the liquid phase. There can be a large discrepancy in measurements for the compressive strength even when a constant reference temperature is used for testing [5]. This phenomenon introduces the variability in material properties that can be expected in ice samples.

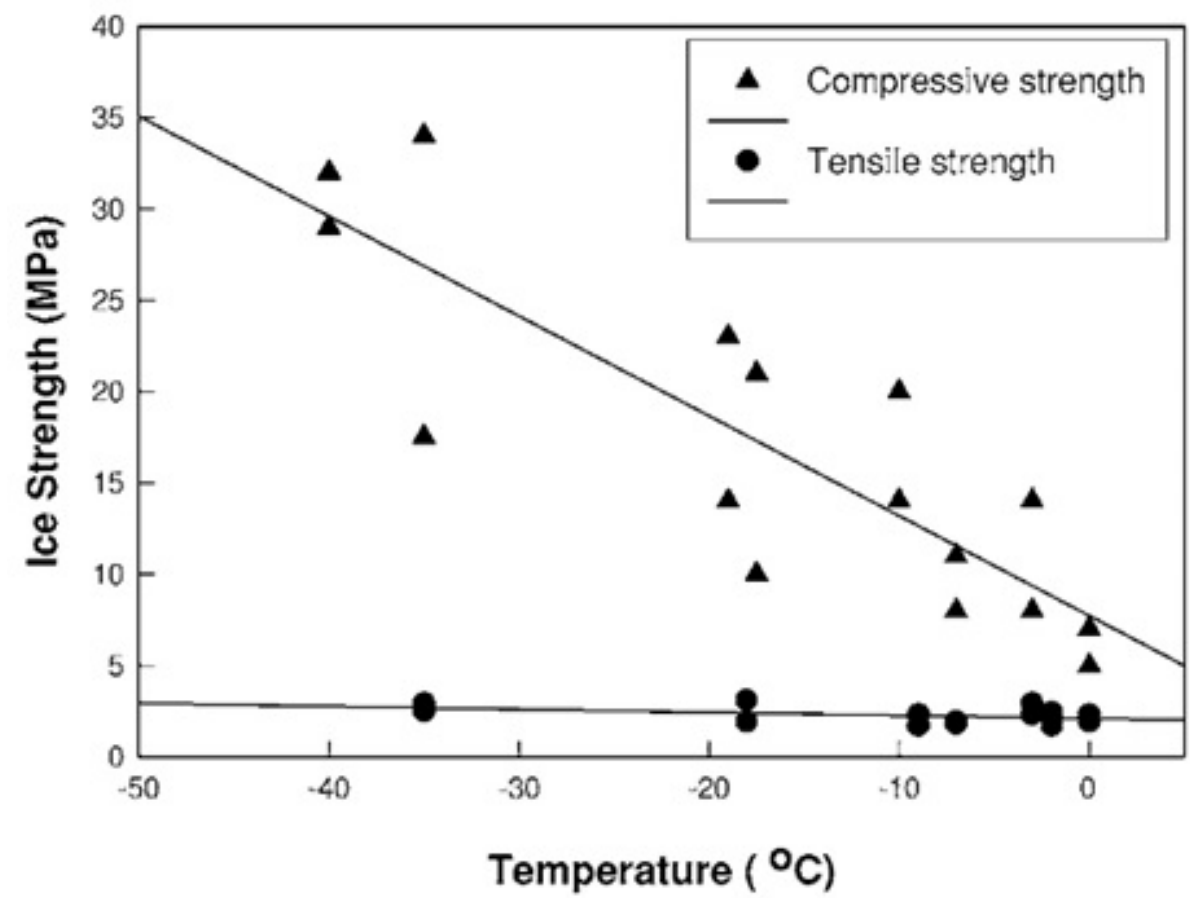

Figure 1: Tensile and compressive strengths of ice as a function of temperature [5].

Shown in Figure 2 is the dependence of the compressive and tensile strength on the axial displacement rate. As the axial displacement rate is increased at a 


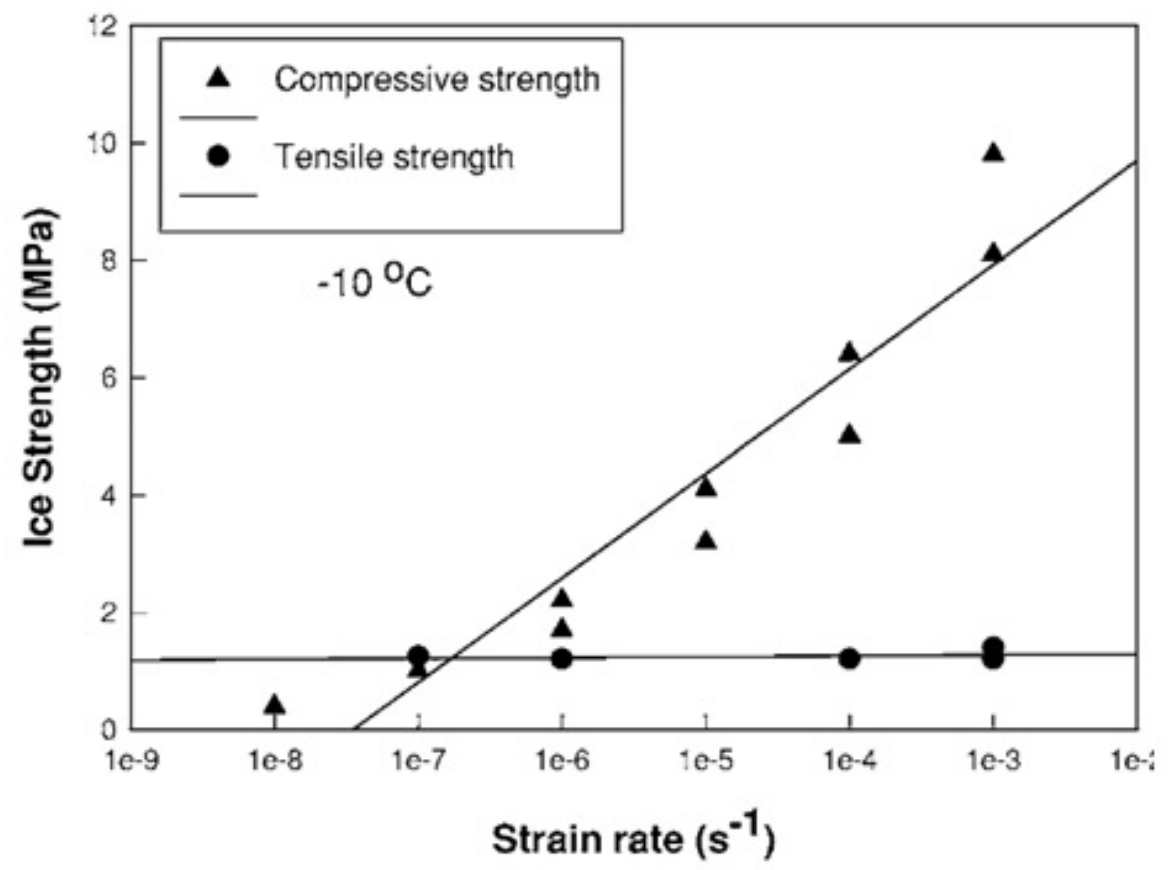

Figure 2: Tensile and compressive strengths of ice as a function of the applied strain rate [6].

constant temperature, the compressive strength of the ice samples increases linearly. The same trend can be observed for the tensile strength, however, the tensile strength of ice is fairly constant.

Grain size is another parameter that can affect the tensile strength of an ice sample. The Hall-Petch relationship used for estimating yield stress in metals can also be used for ice samples. Observed from Figure 3 , increasing the grain size causes an exponential decrease in the tensile strength of ice. This relationship suggests that failure of ice is similar to that of a metal where cracks propagate until they reach a grain boundary. Increasing the number of grain boundaries increases the tensile strength of the ice sample.

From work carried out on tensile and compressive testing on ice samples, the tensile strength of ice was found to be between 0.7 and $3.1 \mathrm{MPa}$ with an average 


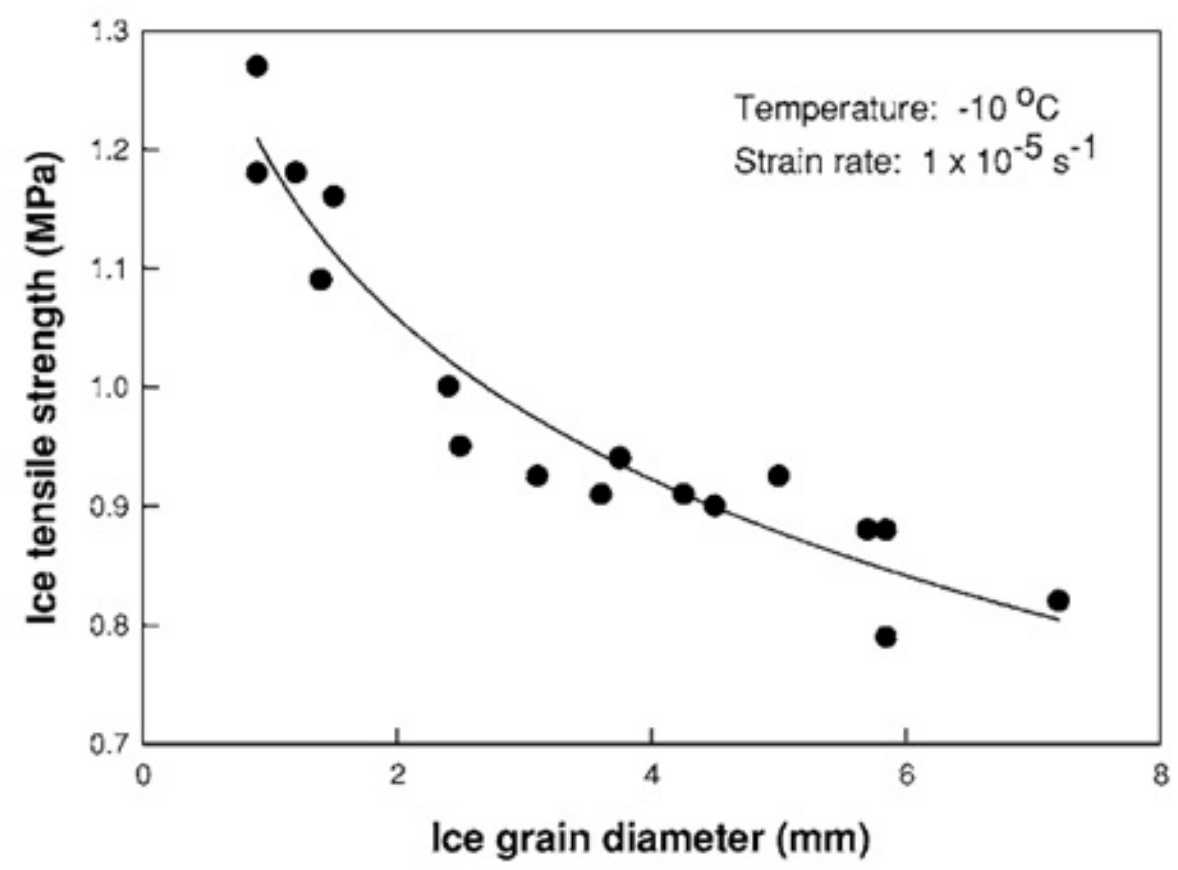

Figure 3: Effect of grain size on the tensile strength of ice [7].

value of $1.43 \mathrm{MPa}$ existing in the $-10{ }^{\circ} \mathrm{C}$ to $-20{ }^{\circ} \mathrm{C}$ range. In the same temperature range, the compressive strength was recorded to be between 5 to $25 \mathrm{MPa}$ [5].

The Young's modulus of ice samples was tested using a bi-axial bending test. It was determined that the elastic modulus of the ice samples was between 9.7 and 11.2 GPa and the Poisson's ratio was between 0.29 and 0.32 [4]. The bulk density of ice was found to be $920 \mathrm{~kg} / \mathrm{m}^{3}$ [8,9]. There are several types of ice that can form on aircraft as discussed in section 2.1.4.1 which have properties that differ from the ones listed here.

\subsubsection{Interaction Between Ice and a Surface}

In order to prevent ice accretion, it is important to understand the mechanisms that contribute to this phenomenon. 


\subsubsection{Surface Forces}

The interaction of ice with a surface can be classified as one of four mechanisms: chemical (covalent) bonding, a fluctuation in electromagnetic interaction (van der Waals forces), direct electrostatic interaction or mechanical clamping [10, 11].

A covalent bond is formed when two atoms share electrons, resulting in strong forces of attraction which hold the atoms together. There is a large difference in the electronegativities of hydrogen and oxygen atoms. For water, this results in the hydrogen atom possessing a very small share of the electron pair that forms the bond. As such, the hydrogen molecule forms a weak bond with a neighbouring hydrogen molecule (known as a hydrogen bond). Covalent bonding between the water molecules and the surface has the lowest adhesion energy of ice [10].

Van der Waals forces exist between all atoms and are caused by the changes in polarization of nearby particles. Since electrons in a bond are mobile, they can create electrical imbalances within a molecule. The fluctuation in these imbalances causes a van der Waals force.

Two spatially separated surfaces with electrical charges will generate electrostatic forces. These forces account for the largest energy component in the ice adhesion mechanism. The interaction due to electrostatic forces between a surface and ice produces energy that is significantly greater than the covalent bond energy or the van der Waals energy at the same distance [10,11].

At the microscopic level, there are many pores and voids. When water freezes onto a surface, it flows into these gaps and forms an interlocking system [12]. In order to minimize the effects of mechanical clamping, the roughness of the surface needs to be minimized. There is a direct correlation between the roughness width of a surface and the ice adhesion strength [13]. 


\subsubsection{Overcoming the Adhesive Force}

In order to break the bond that ice forms with a surface, the adhesive force must be overcome. This is usually accomplished by an applied shear force as shear is usually the weakest component of the adhesion [14]. If the shear stress required to break the bond between the ice and the surface is greater than the ultimate tensile strength of the ice, transverse cracks will propagate within the ice and lead to tensile failure, rather than ice delamination.

Numerous studies have been conducted to investigate the shear component of the ice adhesion strength on various surfaces [13-15]. There is a large variability in the results for ice adhesion strength on specific surface. On aluminum surfaces, Arianpour et al. measured the ice adhesion strength at $242 \mathrm{kPa}$ [16]. A similar measurement was obtained by Zou et al., reporting an adhesion strength of $330 \mathrm{kPa}$ [17]. At the other end of the spectrum, the adhesion strength has been measured by Ryerson to be $1576 \mathrm{kPa}$ [18].

Even though there is a large discrepancy in the measurements, it has been shown that surface coatings can reduce the adhesion strength between a surface

and the accumulated ice [19]. No coating developed to date is perfectly icephobic, as ice can adhere to any surface as long as the temperature is below $0{ }^{\circ} \mathrm{C}[20]$.

\subsubsection{Ice Buildup on Structures}

Ice accumulation on outdoor surfaces can cause severe accidents, loss of life and large economic losses. Such problems are present in many fields including aeronautics, off-shore oil platforms, power lines and wind turbines [18, 21-23]. 


\subsubsection{Types of Ice}

There are three main types of ice that can form on an aircraft: rime ice, glaze ice and mixed ice.

Rime ice occurs when small, supercooled water droplets freeze on a surface that is below the freezing temperature. Rime ice can be observed as individual droplets on a surface that do not form a continuous sheet. The formation of rime ice usually occurs between $-10{ }^{\circ} \mathrm{C}$ to $-20^{\circ} \mathrm{C}$. Rime ice can also be recognized by its milky white colour as shown in Figure 4[ [24].

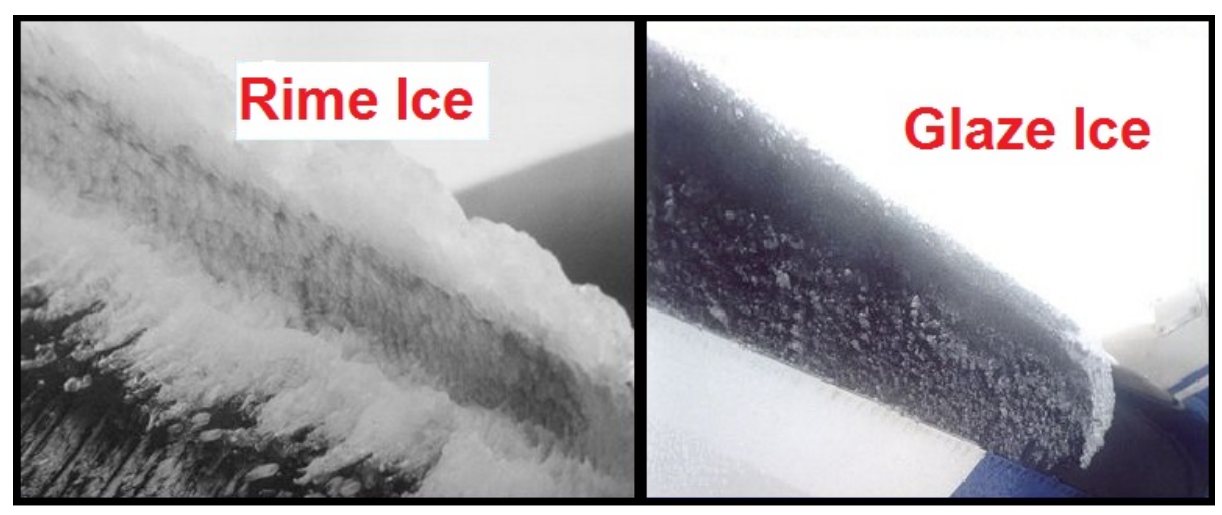

Figure 4: Rime ice forms individual ice pellets (left) while glaze ice freezes into a continuous sheet (right).

Similar to rime ice, glaze ice also occurs when supercooled water droplets come into contact with a cold surface. The difference, however, is that the water droplets are larger and glaze ice forms a sheet over the aircraft surface with very little air enclosed. Glaze ice is most likely to form during freezing rain. Glaze ice is difficult to remove due to the continuous bond it forms with the surface. When glaze ice is removed, it forms chunks which can damage the aircraft if they come loose. Glaze ice can be differentiated from rime ice as it is translucent as shown in Figure 44[24].

When different sized supercooled water droplets condense on a surface, the resulting ice layer is a mixture of glaze ice (from the large droplets) and rime ice 
(from the small droplets). This mixture is referred to as mixed ice. Mixed ice is the most common type of ice. Pure glaze ice only forms in freezing drizzle below nimbostratus clouds and pure rime ice only forms at high altitudes (lower temperatures) in either altostratus or altocumulus clouds.

The properties of rime, glazed and mixed ice are different and can be found in Table 1 [25]. Temperature and water droplet size play the biggest role in determining the type of ice that will form on a surface.

Table 1: Properties of rime, glazed and mixed ice

\begin{tabular}{|l|c|c|c|}
\hline Ice type & Density $\left(\mathbf{k g} / \mathbf{m}^{3}\right)$ & Young's Modulus (GPa) & Poisson's ratio \\
\hline Rime & 600 & 2.5 & 0.282 \\
\hline Glazed & 900 & 8.3 & 0.351 \\
\hline Mixed & 800 & 6.3 & 0.326 \\
\hline
\end{tabular}

\subsubsection{Known Icing Conditions}

Ice can form on aircraft surfaces at or below $0{ }^{\circ} \mathrm{C}$. The highest probability of ice formation is in regions where thick stratiform clouds are present or in rain when the temperature is just below $0{ }^{\circ} \mathrm{C}$. At temperatures below $-20{ }^{\circ} \mathrm{C}$, the chance of ice formation decrease significantly as the water droplets present in the clouds are already frozen. Cumuliform clouds present a major challenge to predict icing conditions as the updrafts and downdrafts can cause ice accretion on an aircraft regardless of altitude [26].

At temperatures below $-40{ }^{\circ} \mathrm{C}$ in cumulus clouds or $-30{ }^{\circ} \mathrm{C}$ in stratus clouds, the probability of ice formation is very low. Increasing the liquid water content (LWC) in the supercooled water droplets increases both the probability and severity of ice build up [27]. 


\subsubsection{Ice Accretion on Aircraft}

Aircraft icing is a significant safety concern to pilots and passengers. Between the years of 1982 and 2000, icing was attributed as the cause of 583 civil aviation accidents and over 800 deaths in the U.S. alone [28]. Figure 5 shows the ice accumulation on the wing of an aircraft. Ice can accumulate on all exposed surfaces and not just the wings. It can form in areas where de-icing boots or external hot air cannot shed the ice. Ice accretion can result in decreased lift, increased drag, reduced stall angle, decreased thrust, altered stall characteristics and even engine failure due to ice shedding [29]. Aircraft icing can occur both during flight and on the ground. It has led to many reported aircraft accidents, including Air Florida Boeing 737 (1982) and the American Eagle ATR 72 (1997) [30,31]. To ensure aircraft safety, regulatory bodies such as the Federal Aviation Administration (FAA) and European Aviation Safety Agency (EASA) have established regulations for anti-icing and de-icing of aircraft.

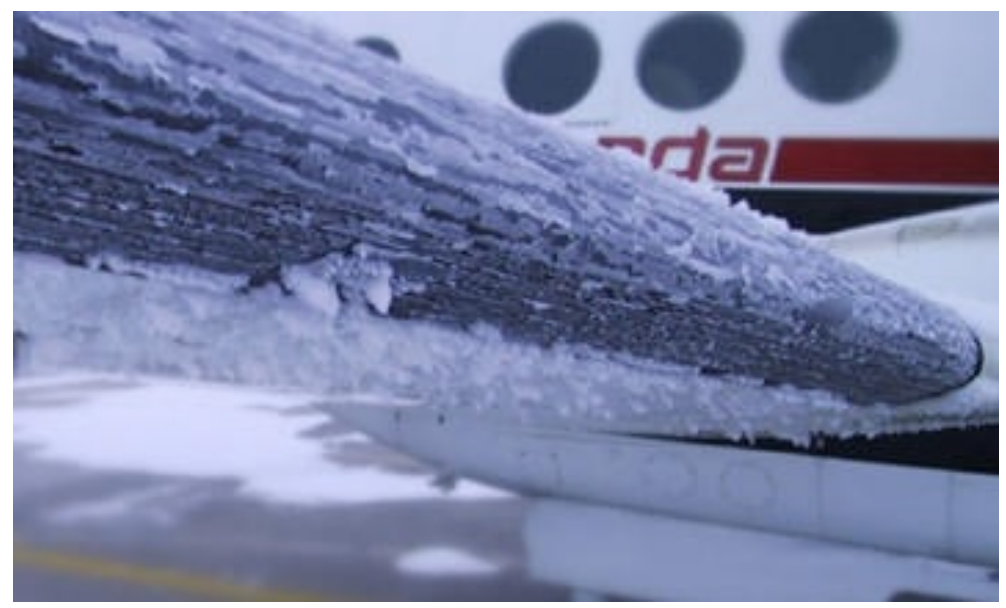

Figure 5: Ice commonly builds up on the leading edge of aircraft during flight into known icing conditions [32].

Temperature can also have an effect on the shape of the ice that accumulates on the leading edge of the wing. In a study done by Cao et al., the predicted 
and experimental results were compared for ice accretion on the leading edge of a NACA 0012 airfoil [33]. These results can be seen in Figure 6. In the first plot, the temperature is low enough $\left(-28.3^{\circ} \mathrm{C}\right)$ for the supercooled water droplets to freeze immediately upon impacting the surface. This represents a rime ice type as there is a large amount of air trapped within the accumulated ice. The second plot shows mixed ice characteristics as the temperature is higher $\left(-13.34^{\circ} \mathrm{C}\right)$. The bottom plot is a representation of glaze ice as the temperature is close to the freezing point (-6.1 $\left.{ }^{\circ} \mathrm{C}\right)[33]$.
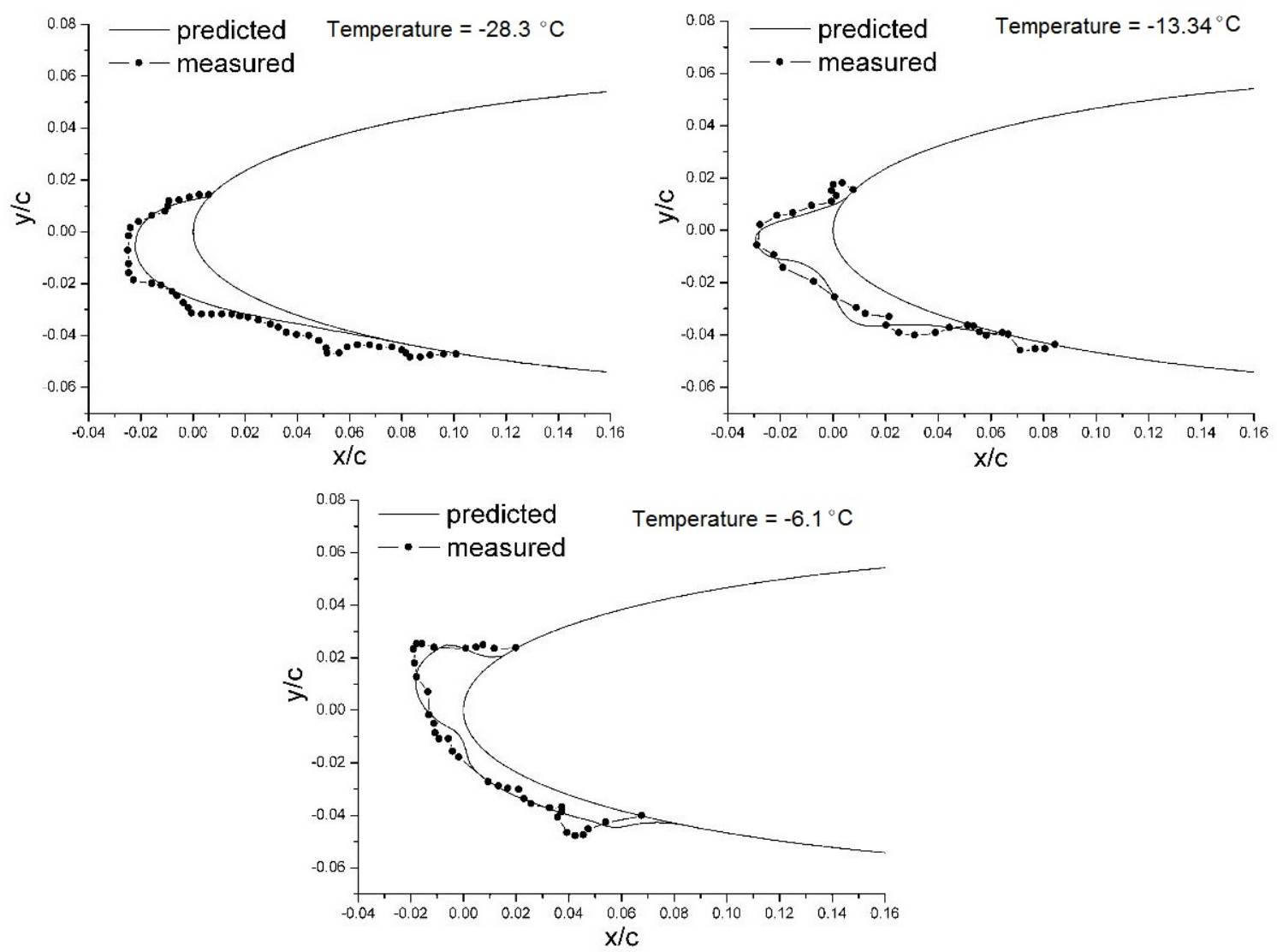

Figure 6: Ice accretion profile at different temperatures on a NACA 0012 airfoil [33].

The angle of attack (AOA) of the aircraft can also have an effect on where the ice accumulates on the wing. Increasing the AOA causes the ice to accumulate further 
back on the lower surface of the wing. The opposite is also true as ice builds up on the top surface when the AOA is decreased [33,34]. Increasing either the liquid water droplet size or the LWC in a droplet also causes an increase in the amount of ice accretion [24, 34].

\subsection{Conventional Aircraft De-icing}

Aircraft are susceptible to ice accretion both on the ground and during flight. There are different methods used for anti-icing or de-icing the aircraft depending on the stage of flight and type of aircraft.

\subsubsection{Definitions}

There are two different scenarios when it comes to protecting aircraft from ice related incidences; thus the differentiation between anti-icing and de-icing must be clearly defined.

Anti-icing is defined as the preventative process in which an aircraft surface is treated with anti-icing fluid on the ground to ensure that ice does not buildup on the surface between the time of application and takeoff. Anti-icing can also be continued in flight with the use of an on-board heating system. On the other hand, de-icing is the removal of accumulated ice which has formed on an aircraft surface using either de-icing fluid or an ice protection system (IPS) installed on the aircraft [35]. De-icing can also occur both on the ground and in the air. 


\subsubsection{Pre/Post-Flight De-icing}

The removal of ice buildup on aircraft while on the ground involves the use of heated fluids [35]. These fluids contain chemical products and have a negative impact on the environment. In order to remove ice buildup, the de-icing fluid is sprayed until the covered area is clear of any frozen snow or ice buildup. On commercial aircraft, the wings, fuselage, horizontal stabilizer, vertical stabilizer and control surfaces are typically sprayed [36]. Small general aviation aircraft are also required to be clear of any ice buildup prior to flight.

Propylene glycol and ethylene glycol are used as freezing point depressants to de-ice aircraft on the ground. These chemicals are often mixed with water to decrease its freezing temperature, which allows for them to be used in different operational ranges. Propylene glycol is more commonly used as it is less toxic than ethylene glycol, however, ethylene glycol can be used at lower temperatures [36]. These fluids also contain additives that act as corrosion inhibitors, fire retardants, defoamers and antimicrobials. There are specific regulations that govern the production, storage, and application of de-icing fluids as they are harmful to both worker health and safety and the environment when being discharged into the water system.

To prevent ice accretion, anti-icing fluids are applied to aircraft surfaces when there is a potential of freezing rain or snow occurring between the aircraft being dispatched and takeoff. A similar spray process is used as in the de-icing process, however a different fluid mixture is used. Aircraft anti-icing fluids are viscous so that they adhere to aircraft surfaces until take-off. The spray process requires a lower volume of fluid than the de-icing process. 


\subsubsection{In-Flight De-icing}

There are several types of de-icing systems used in aircraft. Each system has its own advantages and disadvantages including size, weight, power consumption and cost. Some systems can be used for both anti-icing and de-icing.

\subsubsection{Pneumatic De-icing Boots}

Some aircraft use pneumatic de-icing boots which are made of rubber and placed externally in the leading edge of the aircraft as shown in Figure 7 The boots can inflate rapidly, changing the shape of the wing. This change in shape causes the ice to delaminate and break away from the wing. The boots can then be deflated, returning to their original size. Pneumatic boots are most commonly found on piston-powered and smaller commercial aircraft that do not have a high-lift leading edge device [37].
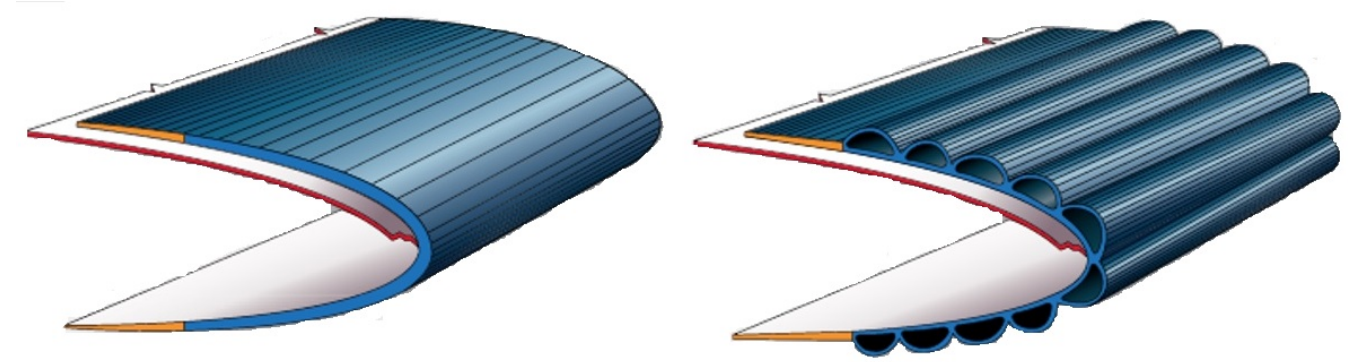

Figure 7: Pneumatic boot not in use (left) and inflated to shed ice (right) [38].

One of the drawbacks of using pneumatic de-icing boots is that the ice can freeze further back on the wing where there are no pneumatic boots to remove the ice. This was one of the factors that led to the crash of American Eagle Flight 4184 [31]. Since pneumatic de-icing boots are made of rubber, they must carefully be inspected for any holes and cracks prior to flight. 


\subsubsection{Bleed Air De-icing Systems}

Bleed air systems are used by large commercial aircraft to prevent the formation of ice on surfaces that produce lift. In this type of IPS, the hot air from the engine is redirected through small tubes to the inside of the engine inlets, wings, and tail to increase the surface temperature. As is the case with electro-thermal systems, the heat raises the temperature of the ice-skin interface and prevents ice from accumulating on the surface. The hot air is then released from the aircraft as it flows through tiny holes in the bottom surface of the wings.

Bleeding the air from the compressor stages of the engine reduces the overall efficiency of the engine and adds a significant amount of piping that must be maintained [37]. The amount of hot air required for de-icing is dependent on the temperature difference between the atmospheric air and the aircraft skin. At higher altitudes a larger flow rate of hot air is required due to the decreased atmospheric temperature, further reducing the engine efficiency. As the bypass ratio of large turbofan aircraft continues to increase, bleed air systems are being phased out in preference of other IPS [39]. Bleed air systems are also subject to the re-freezing issues that pneumatic boots experience since the systems are located at the leading edge of the flight surfaces.

\subsubsection{Electro-Thermal De-icing Systems}

An electro-thermal IPS uses resistive circuits underneath the outer surface that generate heat when a current is applied. The system can be used both for the prevention of ice accretion by running continuously or to delaminate any ice that has built up by running the system intermittently. The system functions by melting the ice directly attached to the wing, creating a thin layer of water between the ice buildup and the surface. This drastically reduces the shear force required 
to remove the ice sufficiently so that the aerodynamic forces can cause the ice to shed. For anti-icing purposes, the surface temperature is kept around $0{ }^{\circ} \mathrm{C}$ to prevent the accretion of ice [40]. These systems are commonly used in aircraft wings, propellers, rotor blades and wind turbine blades.

With the advancement of composite materials in the aerospace industry, electro-thermal de-icing systems are becoming more commonly used. Thermal wires can be embedded inside composite materials and heat can be generated by passing a current through the wires [41]. This technique would eliminate the re-freezing issues common to pneumatic boots and bleed air IPS. The use of carbon nanotubes is currently being explored as a potential conductive material for electro-thermal IPS [42]. The impact of electro-thermal de-icing systems on the structural integrity of the composite material has not been very well established.

\subsubsection{Electro-Mechanical De-icing Systems}

Electro-mechanical de-icing systems make use of mechanical force to knock off ice that has built up on a flight surface. Actuators are mounted on the inside of the leading edge of the wing. The actuator contains a capacitor that is charged during flight and when discharged, it releases a high current electrical pulse to the actuator causing it to deform at a fast rate which produces a force against the leading edge, dispelling any ice that has built up. This system requires less power than bleed air and electro-thermal IPS [43].

There are several variations of electro-mechanical de-icing systems. One variation uses the electro-mechanical system described above in combination with a heater. The heater keeps the leading edge of the the wing at a temperature above $0{ }^{\circ} \mathrm{C}$, while the actuator is used to break away ice that freezes to the surface aft of the heated portion of the wing. This hybrid system is referred to as a ThermoMechanical Expulsion De-icing System (TMEDS) [44]. These systems are designed 
to last the life of the aircraft whereas pneumatic boots need to be replaced every few months [43].

\subsubsection{Ultrasonic De-icing Systems}

Ultrasonic de-icing systems use piezoelectric actuators that are mounted on the inside surface of the skin. The actuators excite the structure at its natural frequency to break away ice buildup. When a voltage is applied to a piezoceramic, it causes the actuator to respond by producing a displacement. If the voltage is applied at a frequency, it will cause the actuator to produce a vibration in the structure. When excited at a natural frequency, the ice will break away if the shear force being generated is greater than the bond strength between the ice and the surface [45-47].

Ultrasonic de-icing systems are still under development and have yet to be tested in aircraft. These systems have the potential to have a lower power consumption than other systems in use and are not susceptible to ice re-freezing issues common to other IPS. More information on piezoelectric de-icing systems is provided in section 2.4 .2 .

\subsubsection{Weeping Wings}

A weeping wing is a de-icing system in which de-icing fluid is released during flight through holes on the leading edge of the wing. The fluid is pumped from a tank through micro-filters located on the inside of the wing. Once the fluid is released, it can break away ice that has built up. The systems was developed for use during World War II by the British and is still used today in piston-driven and small turboprop aircraft [43]. This system is not as effective at removing ice as other systems currently in service. 


\subsubsection{Passive Systems}

The previously discussed systems rely on the continuous use of chemicals, compressed air or electricity to enable effective anti-icing or de-icing. A passive method of interest is to use an icephobic coating to lower the bond strength of the ice to the aircraft surface [48], thus reducing the use of active systems. A passive approach alone would be unacceptable from a certification perspective as aircraft must have a method of removing accumulated ice during flight, however, the combination of an icephobic coating with one of the previously mentioned systems would result in a decreased amount of power required for de-icing as well as an overall reduction in weight.

\subsection{Surface Coatings and Anti-icing Applications}

Surface coatings can be used as a passive technology to prevent the accretion of ice on aircraft. In comparison to de-icing chemicals applied during pre/post-flight procedures, surface coatings do not need to be reapplied after each icing event. In addition, surface coatings do not have the negative environmental effects associated with the commercial use of de-icing fluid in the aviation industry.

There are two types of surface coatings that can be used to lessen the probability and effects of ice accretion.

\subsubsection{Hydrophobic Coatings}

The contact angle is a measure of how well a surface repels water. If a water droplet forms an obtuse angle with the surface, it is hydrophobic whereas the surface is hydrophilic if the reverse is true. An example of a hydrophobic substance is polytetrafluoroethylene (PTFE), also known as Teflon and it is used as a non-stick coating 
for cookware. Shown in Figure 8 is the contact angle of a surface coated with PTFE compared to an aluminum surface. Since hydrophobic surfaces repel water, it is difficult for water to accumulate and freeze on the surface. Hydrophobic surfaces also have the tendency to cause water to take longer to freeze [49]. By increasing the freezing delay time, the probability of the water droplet remaining on a surface and freezing decreases.

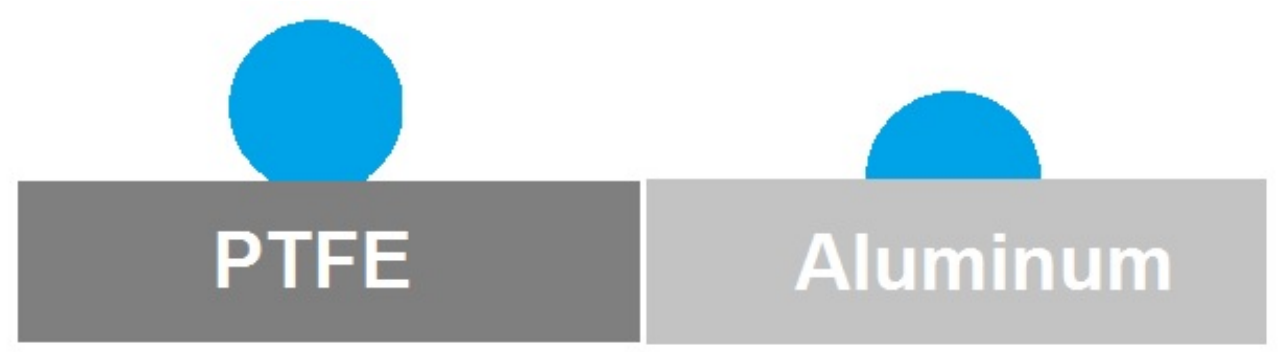

Figure 8: The contact angle of hydrophobic surface, PTFE (left) is much greater than a hydrophilic surface (right).

\subsubsection{Icephobic Coatings}

Several researchers define icephobic surfaces as a surface that lowers the ice adhesion strength while others define it as the ability of a surface to delay ice nucleation [50, 51]. For aerospace applications, the most important consideration is to reduce the ice adhesion strength, allowing for easier removal as any ice that builds up has a negative effect on aircraft performance. Icephobic surfaces also have hydrophobic properties, including a large receding contact angle and low surface roughness [52,53].

Icephobic coatings reduce the shear forces required to break the bonds of an accumulated layer of ice on the solid surface [54]. These coatings are specifically designed to repel ice and are usually silicone based. The structure of a typical 
polyorganosiloxane is shown in Figure 9 where the R molecules represent the functional organic groups comprised of methyl, phenyl or trifluoropropyl molecules.

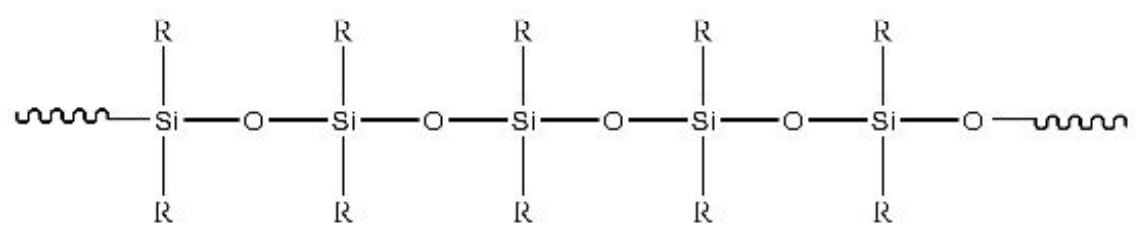

Figure 9: Chemical structure of a polyorganosiloxane [55].

Silicone molecules are highly elastic at low temperatures while being able to resist chemical breakdown at elevated temperatures. This combination of properties make them especially useful in harsh environments.

\subsubsection{NuSil Silicone R-2180}

$\mathrm{R}-2180$ is a silicone based coating produced by NuSil Technology that has the potential to reduce the adhesion of ice accumulation on aerodynamic surfaces and structures. This coating is formulated from high tear strength elastomers [18]. Silicone coatings are usually used as mold release agents, waterproof coatings and biomedical material due to their elastic properties and smooth surfaces [56]. Generally, silicones have a broad thermal operating temperature ranging from $-65{ }^{\circ} \mathrm{C}$ to $240{ }^{\circ} \mathrm{C}$. Silicone R-2180 does not prevent ice formation, however, it allows ice to break easily [18].

In a study conducted at the Cold Regions Research and Engineering Laboratory (CRREL) in Hanover, New Hampshire, silicone R-2180 was tested along with other commercially available icephobic materials for ice adhesion strength. All coatings were applied onto aluminum test pieces and allowed to freeze at $-10{ }^{\circ} \mathrm{C}$ for eight hours. The testing apparatus used was a Zero-Degree Cone Test shown 
in Figure 10. The results showed that silicone R-2180 had an ice adhesion strength of $37 \mathrm{kPa}+/-14 \mathrm{kPa}$ compared to Teflon with $238 \mathrm{kPa}$ [56].
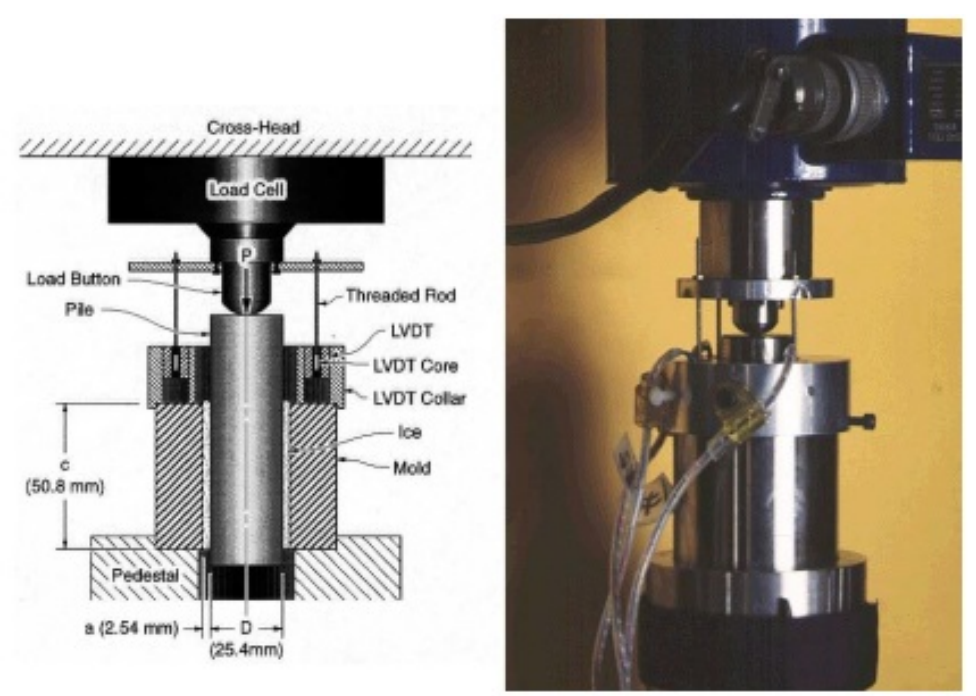

Figure 10: Zero Degree Cone Testing apparatus used for ice adhesion testing [57].

Another study was conducted by the US Army Corps of Engineers in evaluating all commercially advertised coatings, materials and paints known to have icephobic properties. All potential icephobic materials were applied onto highly durable paints previously applied since it was assumed that such icephobic coatings would not replace the existing paints but rather be applied over the paints. Silicone R-2180 was shown to be superior to all other coatings as can be seen in Figure 11. In addition to the ice adhesion testing conducted in the as-coated condition, silicone R-2180 was tested after exposure to extreme environmental conditions [56]. Results shown in Figure 12 suggest that silicone R-2180 performs better than Teflon, even after being exposed to a wide range of conditions. 


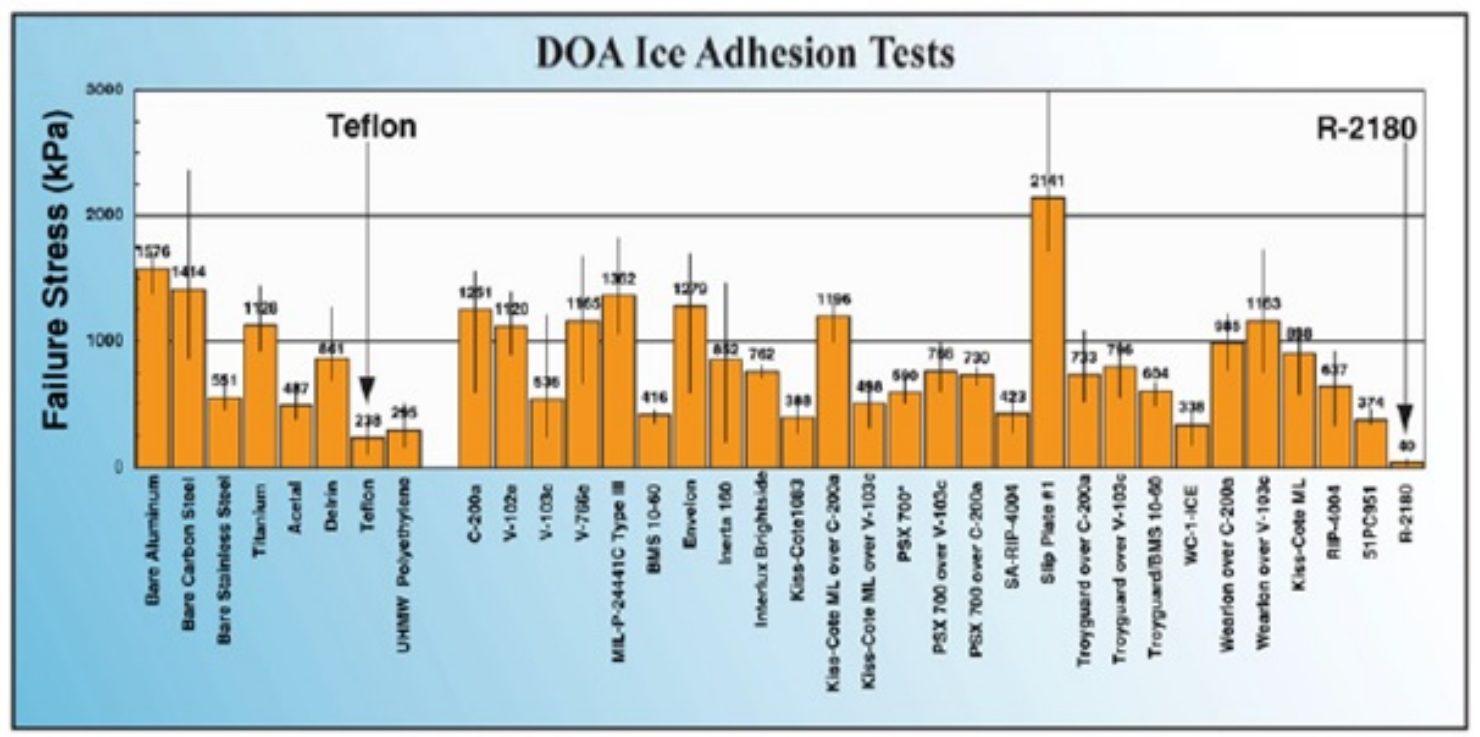

Figure 11: Ice adhesion of commercially available materials tested by the Department of the Army [18].

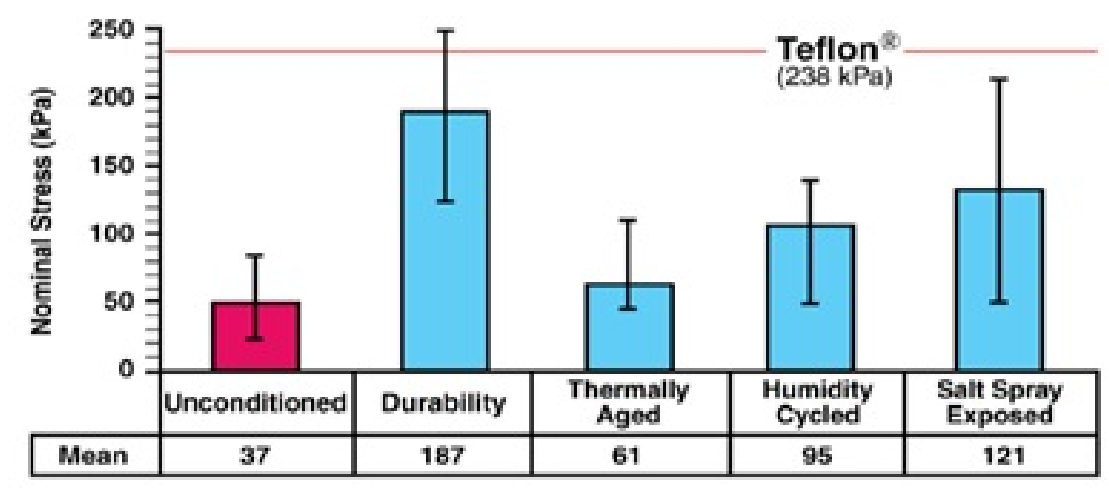

Figure 12: Silicone R-2180 tested after extreme environmental conditioning [18].

\subsubsection{NuSil Silicone R-1009}

NuSil Technology also manufactures a line of room temperature vulcanizing (RTV) cure cycle icephobic coatings. The ice adhesion strength of these coatings is shown in Figure 13. Silicone R-1009 lowers the ice adhesion strength approximately five times more than the industry standard R-2180 [58]. 


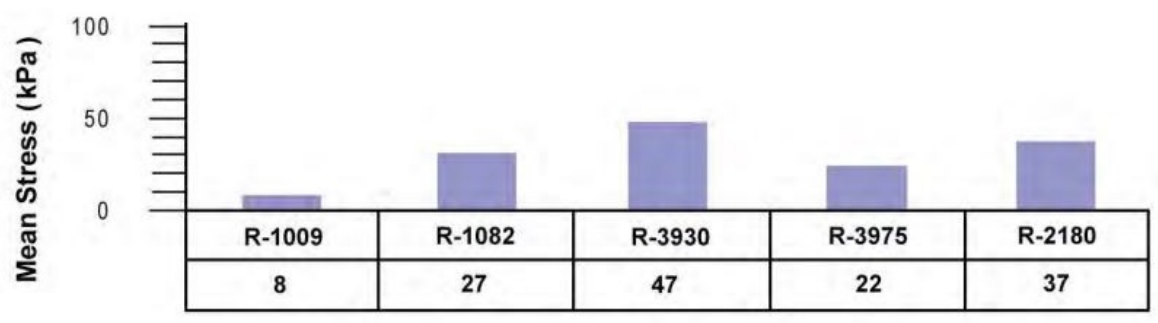

Figure 13: Shear stress of icephobic coatings manufactured by NuSil Technology [58].

Coatings requiring a RTV curing process provide a unique advantage when compared to those that cure at elevated temperatures. The coating can be applied to surfaces that are currently in service. This is critical when considering the applications in the aerospace industry. To apply a coating requiring an elevated temperature cure cycle, an aircraft would have to be disassembled to apply the coating and to perform the necessary cure cycle. RTV coatings can be applied to an entire aircraft without the need for disassembly.

\subsubsection{Coating Processes}

Each coating has a different application process. Several common processes are outlined below.

Dip coating is a common coating procedure due to its simplicity. It is completed by immersing the substrate into a liquid reservoir containing the coating and then retracting the substrate at a specified rate. Typically the length of time that the coating is immersed is specified by the operator and kept constant to allow for a consistent coating layer thickness. The coating is then left to dry or a curing cycle is required.

Brush coating is another simple coating technique that requires little equipment and is inexpensive. The desired amount of liquid coating is dispensed onto 
the substrate and the operator uses a brush to evenly disperse the coating. Brush coating allows for complex geometries to be coated but ensuring that the coating thickness is constant for a sample and consistent throughout a batch is difficult.

Spray coating is a method used to apply a material in particle form onto a surface. There are several different types of spray coating systems. In room temperature spraying, a spray gun is used to apply coating in a similar way as painting. In the plasma spray coating process, the powder being sprayed is heated above its melting point and propelled at high speeds onto the substrate where it cools and forms a coating layer [59].

\subsubsection{Parameters Affecting Ice Adhesion Strength}

There are various parameters that affect the bond strength of ice onto a surface. The main parameters are the contact angle, roughness of the surface and temperature. Additional parameters include the rate the shear force is applied and the droplet size, although they are not as substantial as the former ones.

\subsubsection{Contact Angle}

The contact angle is a way to quantify the wettability of a surface. It is a measure of the angle between the surface and a water droplet that is on the surface. Typically surfaces with contact angles greater than $90^{\circ}$ are classified as hydrophobic and when the contact angle is greater than $150^{\circ}$, the surface is superhydrophobic [60]. Hydrophobic molecules are polar by nature and can repel water.

It has been shown that the contact angle is an important parameter in determining the effectiveness of a hydrophobic surface. Meuler et al. showed that the higher the contact angle of a hydrophobic coating, the lower the adhesion strength [52]. Meuler also showed a linear relationship between the contact angle hysteresis and 
the ice adhesion strength of the surface.

\subsubsection{Surface Roughness}

As the roughness of a surface increases, so does the adhesion strength [13, 17, 61]. Hydrophobic surfaces show higher resistance to ice accretion than rough hydrophilic surfaces; however, hydrophilic surfaces with roughness values close to the minimum water droplet size show a higher icephobicity than rough superhydrophobic surfaces [49]. These results suggest that surface roughness should be treated as the key parameter when evaluating the potential feasibility of hydrophobic and icephobic coatings.

A low surface roughness has also been shown to increase the freezing delay time of a supercooled water droplet [49]. The freezing delay time is the length of time a supercooled water droplet takes to freeze on a surface. The larger the freezing delay time, the lower the probability of the droplet freezing on an aircraft as the aerodynamic forces can expel the droplet. Therefore using materials with a low surface roughness can be an effective way to achieve anti-icing.

\subsubsection{Temperature}

The adhesion strength of ice on a surface increases as the temperature decreases. Gouni showed that the ice adhesion strength of stainless steel increased linearly from $0.77 \mathrm{MPa}$ at $-10{ }^{\circ} \mathrm{C}$ to $1.42 \mathrm{MPa}$ at $-20^{\circ} \mathrm{C}$ [62]. For experimental work involving ice adhesion, it is important to maintain a constant temperature and have an accurate way to measure the temperature as any variation can cause a skew in experimental results. 


\subsection{Piezoceramic Materials and Applications}

Piezoelectric actuators are used to convert electrical signals into a displacement. When an electric field is applied, the ceramic will expand. If the voltage is pulsed, the actuator will expand and contract at the applied frequency. Actuators are often made from lead zirconate titanate (PZT) and can be used for a wide range of applications from controlling the timing of valves to adjusting the position of lenses [63]. PZT ceramic material is very brittle so new solutions are made of piezocomposite where the ceramic is enclosed into resin with the electrode. There are two main types of actuators; stack actuators and patch actuators as shown in Figure 14.

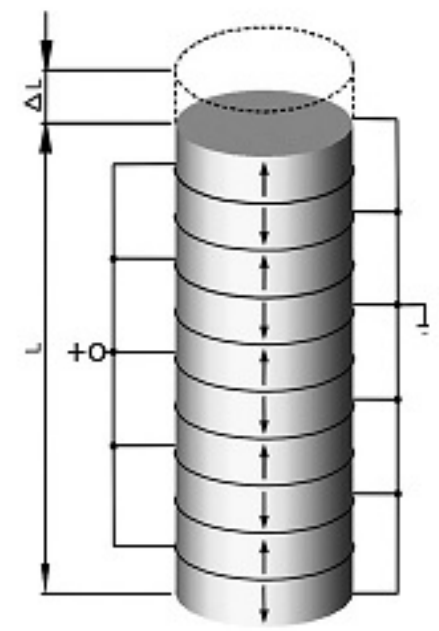

Stack Actuator

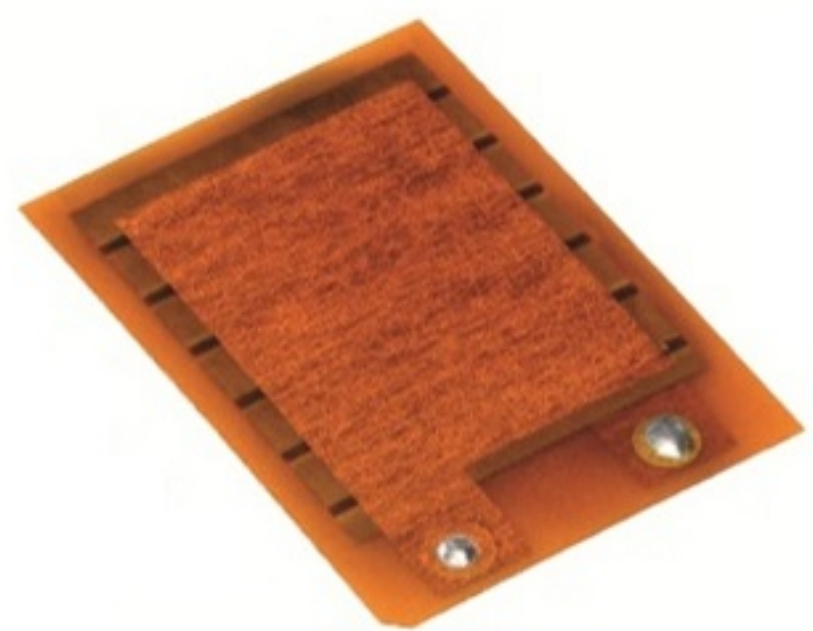

Patch Actuator

Figure 14: Piezoelectric stack actuator (left) and patch actuator (right).

Stack actuators are made by stacking different piezoelectric rings on top of each other and are used when a large force or small displacement is required. Patch (bender) actuators are comprised of two thin layers of piezoceramic material (or one layer of metal and one layer of ceramic) and can produce large displacements when compared with stack actuators [64]. 


\subsubsection{Piezoelectric Materials}

When a piezoelectric material is deformed, it generates an electric charge due to the piezoelectric effect. The opposite is also true as applying an electrical field will cause a piezoelectric material to deform.

PZT $\left(\mathrm{Pb}\left[\mathrm{Zr}_{\mathrm{x}} \mathrm{Ti}_{1-\mathrm{x}}\right] \mathrm{O}_{3}\right)$ is one of the most common piezoelectric ceramic materials. It is a metallic oxide powder that is formed at high temperatures. PZT is made by combining elemental lead and zirconium with the chemical compound titanate. Other piezoelectric materials exist including quartz, lithium tetraborate $\left(\mathrm{Li}_{2} \mathrm{~B}_{4} \mathrm{O}_{7}\right)$ and barium titanate $\left(\mathrm{BaTiO}_{3}\right)$.

\subsubsection{Use of PZT in Ultrasonic De-icing Systems}

There are two categories of applications for PZTs; when a high charge sensitivity is required or a large amount of power is necessary. Applications that require a high charge sensitivity use soft PZT ceramic powders and include ultrasonic non-destructive testing, precision component inspection for aerospace grade parts. Hard PZT ceramic powders are used to manufacture ceramics for applications including ultrasonic power transducers and sonar devices [63].

Ultrasonic de-icing systems are relatively new systems and experimental work is still in the research stage. Venna and Lin were the first to develop a finite element model for the delamination of ice from a plate [65]. It was found that the shear stress between the ice sheet and the plate resulting from the vibration was greater than the required shear force meaning that if a particular mode was excited, ice delamination could occur. The resonant modes computed by the model were verified experimentally by slowly increasing the frequency of the applied AC voltage between 0 and $1000 \mathrm{~Hz}$ and measuring the response of the plate. Delamination of the ice sheets did occur, however it was likely caused by thermal effects 
due to the length of time the voltage was applied. To ensure that temperature is not the cause of delamination, temperature monitoring is critical in obtaining true response information.

Palacios et al. used a similar technique to remove ice from rotor blades. Using a PZT actuator driven at $28.5 \mathrm{kHz}, 2 \mathrm{~mm}$ thick sheets of ice were instantaneously delaminated [11]. Palacios et al. also ensured that ultrasonic de-icing occurred due to generated shear forces rather than heating, by monitoring the temperature [66]. When delamination occurred; the temperature at the interface between the ice and plate was indeed below $0{ }^{\circ} \mathrm{C}$. The ice accumulation was simulated using an experiment where a cloud of supercooled water droplets are frozen onto the blade and subsequently how ultrasonic de-icing systems can be used to remove any ice that has built up [67,68].

Building on the work of Palacios et al., Budinger et al. were the first to develop a model for ice delamination using piezoelectric actuators [46, 48]. Contained in Figure 15 are the tensile and shear stresses for flexural and extensional modes as a function of the supplied frequency. It was also found that the ultrasonic frequency range should be greater than $20 \mathrm{kHz}$ when trying to de-ice using a flexural resonance mode and the shear stress de-icing mechanism. 


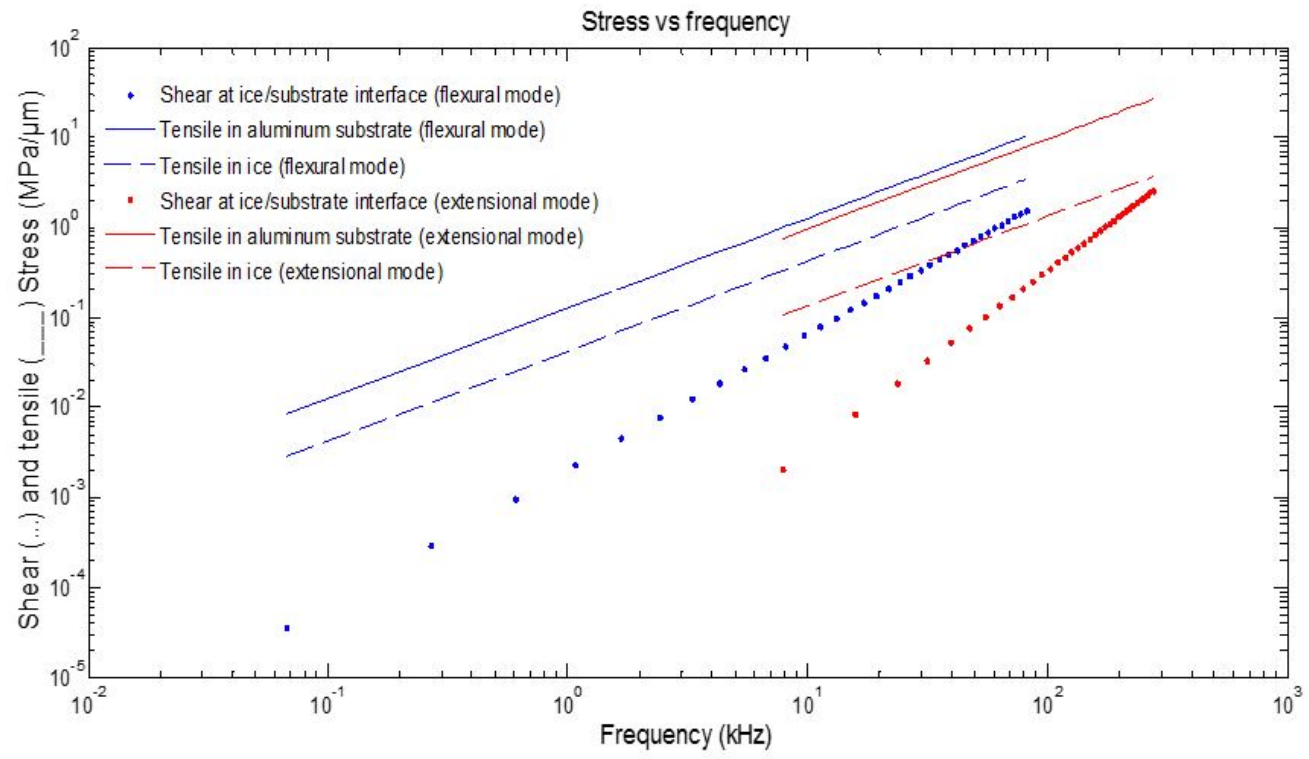

Figure 15: Tensile and shear stresses in the ice and aluminum substrate for flexural and extensional modes [46].

The model given in [48] also proposes the combination of an ultrasonic antiicing and de-icing system using piezoelectric actuators in conjunction with icephobic coatings. The ultrasonic de-icing system serves as an active approach to de-icing as it allows for the prevention and removal of ice. The icephobic coating is a passive solution that decreases the required shear stress to de-bond any ice that forms on aircraft surfaces. Due to the decrease in required shear stress provided by the coating, the power required by the PZT actuators decreases significantly, thus the overall size and weight of the system can be substantially reduced through an optimization process. 


\section{Chapter 3}

\section{Coating Procedures and Sample Preparation}

Using the literature as a guideline, a standardized procedure for preparation and cleaning of surfaces was used. In an as-received state, all samples and surfaces were considered as contaminated. If left in an open environment, freshly coated or cleaned surfaces can accumulate dust; adding to the potential variability in test results.

\subsection{Aluminum Substrate Preparation}

Aluminum 2024-T3 was selected as the substrate due to its use in the aerospace industry as a high damage tolerance alloy. Aluminum coupons were first cut to size using a hydraulic shear and later milled to the desired tolerance. They were then sandblasted to an even finish as it was found that the selected coatings adhere better to aluminum sandblasted surfaces than the base metal [69].

During the sandblasting process, a pressure of $550 \mathrm{kPa}$ was used while maintaining the nozzle at a $90^{\circ}$ angle to the sample at a distance of $10 \mathrm{~cm}$. Shown in Figure 16 is the sandblasting apparatus used to prepare the surface. Figure 17 shows the un-prepared and prepared surfaces. 


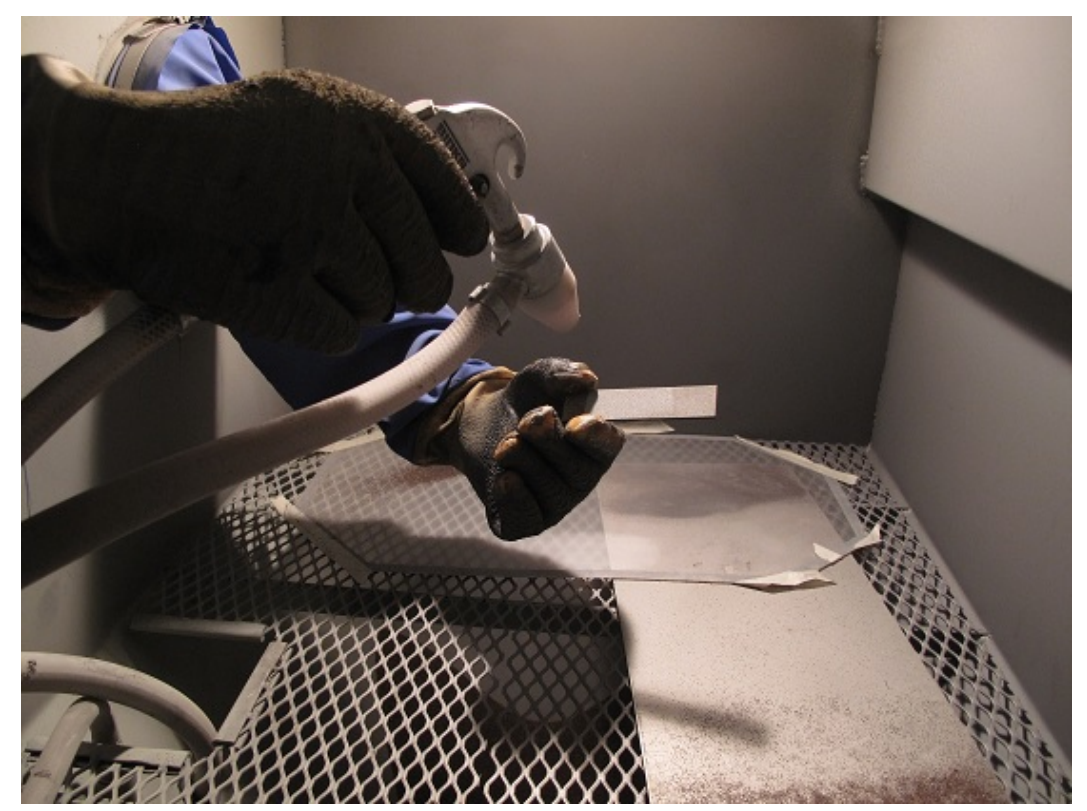

Figure 16: The sandblasting apparatus.

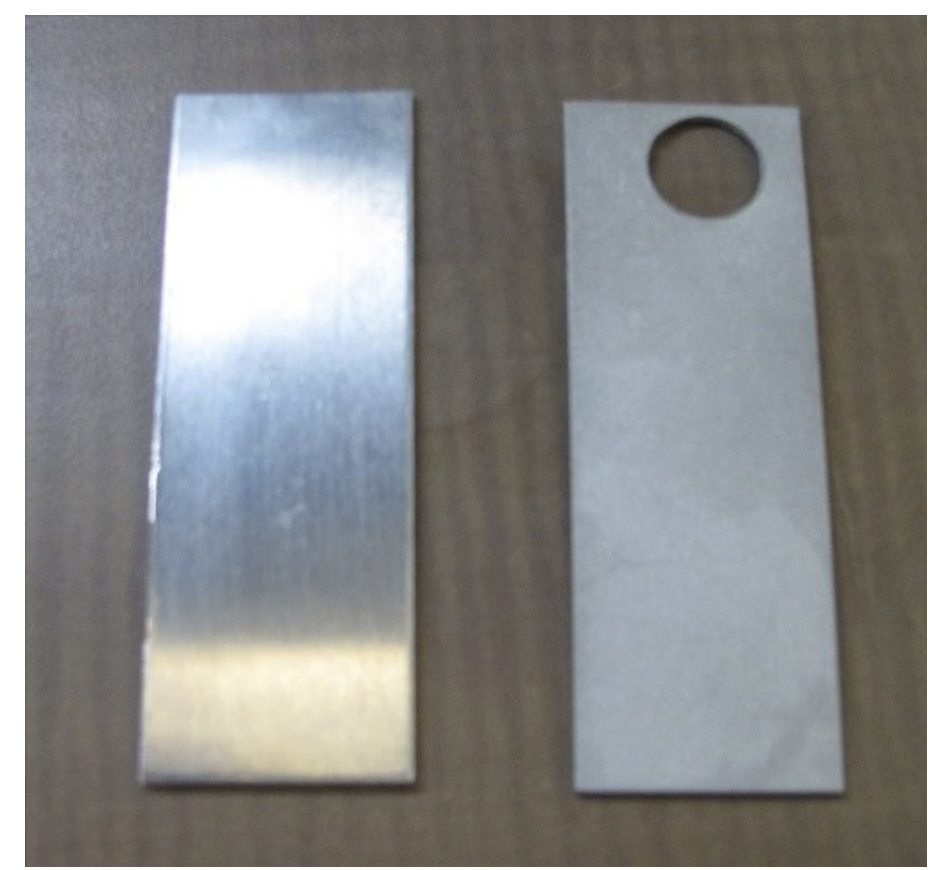

Figure 17: The aluminum surface prior to sandblasting (left) and after sandblasting (right). 
Prior to coating, all samples were cleaned using isopropyl alcohol followed by dry nitrogen gas to prevent any moisture from accumulating on the surface. The samples were then coated with the desired coatings described below.

\subsection{Icephobic Coating Selection}

Several icephobic coatings were selected to apply onto the substrate. These coatings were silicone R-2180 and silicone R-1009 which were both purchased from NuSil Technology located in California, USA. Silicone R-2180 can decrease the ice adhesion strength by a factor of ten in comparison with other icephobic coatings [55]. These results were verified by testing conducted at CRREL [18]. Silicone R-1009 is a newer coating also developed by NuSil and it has been shown to have an ice adhesion strength of $8 \mathrm{kPa}[58]$. In addition to the lower ice adhesion strength than silicone R-2180, silicone R-1009 can be cured at room temperature making it ideal for components that are already in service or have temperature restrictions.

In addition to these icephobic coatings, two hydrophobic coatings were selected to compare with the icephobic coatings. Ethylene tetrafluoroethylene (ETFE) is a non-stick polymer based coating used primarily for high temperature applications requiring corrosion resistance [70]. Advanced liquid glass (ALG) which is a non-toxic nano-coating used to protect a variety of surfaces from environmental degradation was also selected. Nanomaterials have been shown to be superhydrophobic (having contact angles above $150^{\circ}$ ) as they mimic a lotus leaf which has very low ice adhesion [71]. 


\subsection{Specific Coating Procedures}

Found below in Table 2 is a summary of the selected coatings, the application process, and cure cycle used.

Table 2: Applied coatings and properties

\begin{tabular}{|c|c|c|c|c|}
\hline Coating & Supplier & $\begin{array}{c}\text { Application } \\
\text { Method }\end{array}$ & $\begin{array}{c}\text { Curing } \\
\text { Method }\end{array}$ & $\begin{array}{c}\text { Cost } \\
\text { (CAD/Liter) }\end{array}$ \\
\hline Silicone R-2180 & NuSil Technology & Brush coating & Oven curing & $\$ 60.50$ \\
\hline Silicone R-1009 & NuSil Technology & Brush coating & RTV & $\$ 283.99$ \\
\hline ETFE & DuPont & Plasma sprayed & Oven baking & $\$ 278.00$ \\
\hline ALG & Liquid Glass Shield & Dip coating & Oven curing & $\$ 1857.26$ \\
\hline
\end{tabular}

Some coatings cured at room temperature in air while others required a higher temperature cure cycle. A Vulcan 3-550 bench-top furnace was used to cure coatings at elevated temperatures. The furnace is shown in Figure 18 . This furnace has a programmable interface allowing for the applicable cure cycle to be entered.

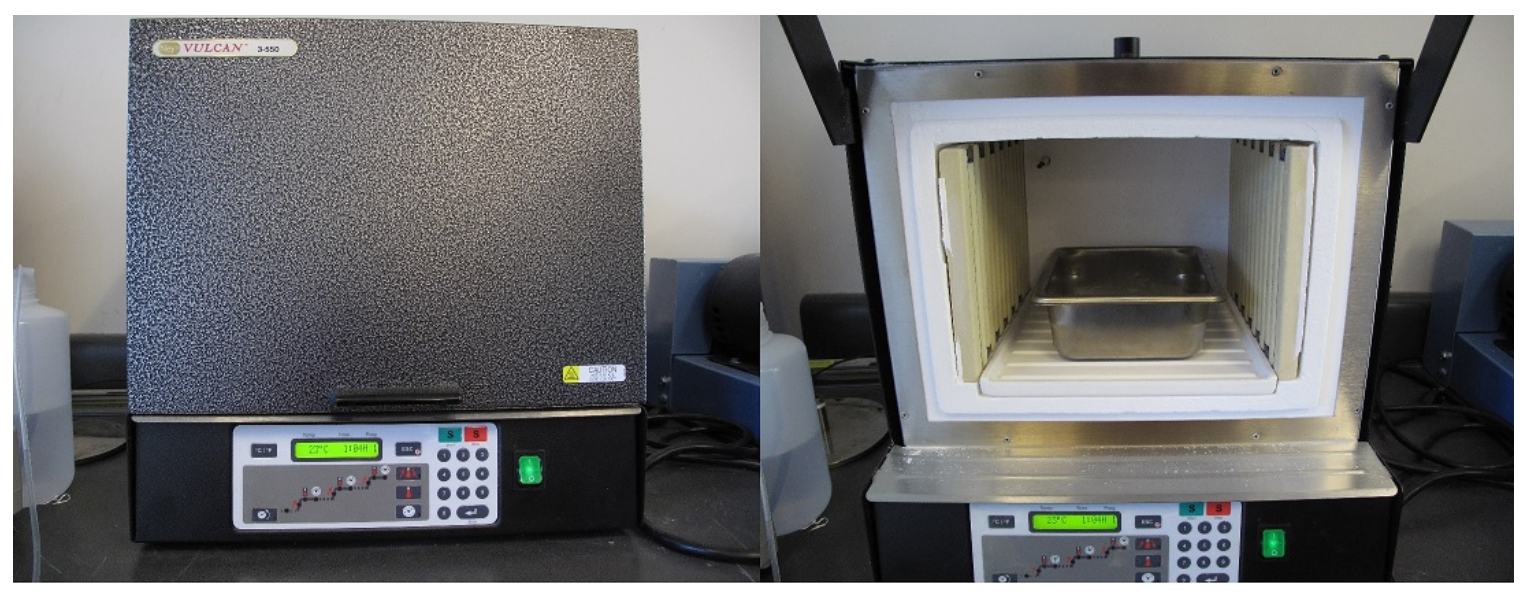

Figure 18: The Vulcan 3-550 furnace used for curing coatings following application.

Following the application of the coating, the specimens were put into a steel tray and placed in the furnace. The desired curing process was then carried out 
according to the manufacturer's specifications.

\subsubsection{Silicone R-2180}

Silicone R-2180 is a two part elastomer that was designed to have a low surface friction when in contact with ice [60]. Part A of the mixture contains the platinum catalyst required for curing inside of a silicone base and Part B is made up of crosslinker and inhibitor inside of the xylene base. The base contains silica as a reinforcing filler which enhances the van der Waals forces of the cured polymer and the hydrogen bonds formed between the hydroxyl groups and the surface of the silica particles. The two liquids in the as received state are shown in Figure 19 The two parts are mixed at a 1:1 ratio in a beaker prior to the application of the coating. The mixing took approximately five minutes in order to ensure that the mixing process was complete. The resulting mixture of silicone $\mathrm{R}-2180$ was viscous and it can be seen in Figure 20 .

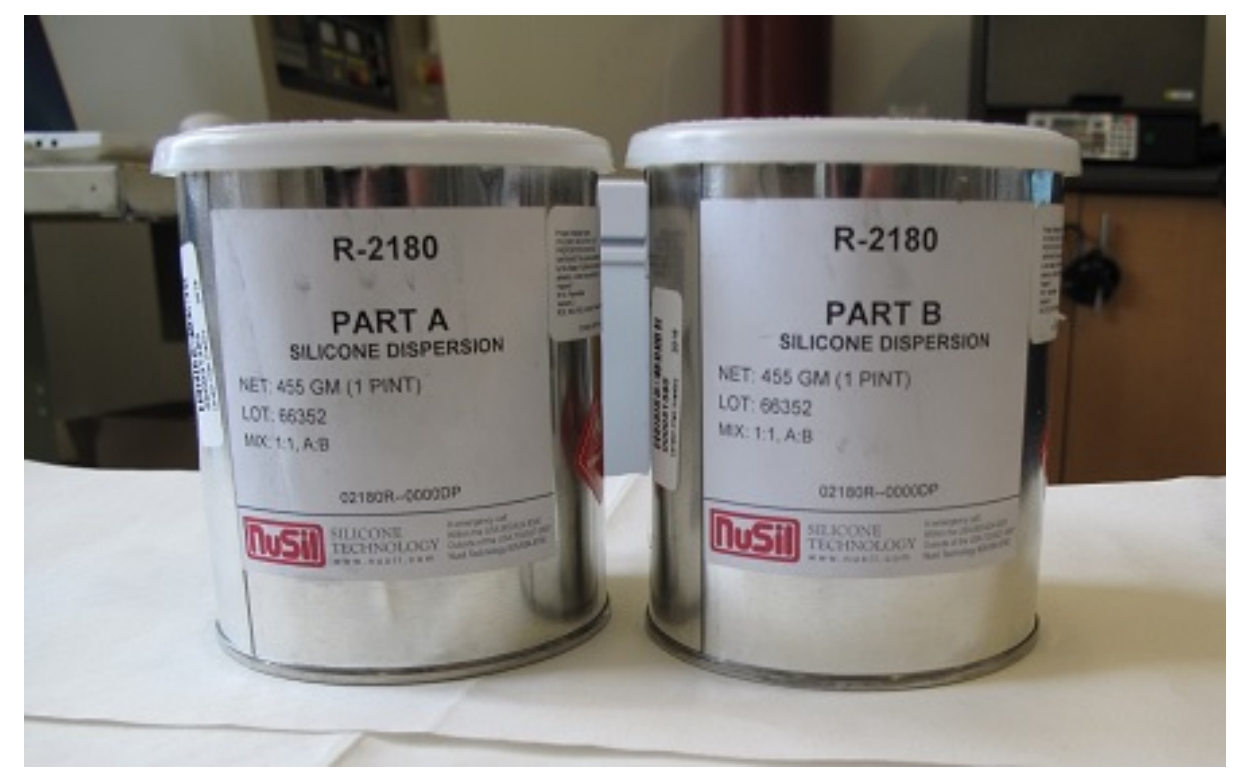

Figure 19: Silicone R-2180 Part A and Part B as received. 


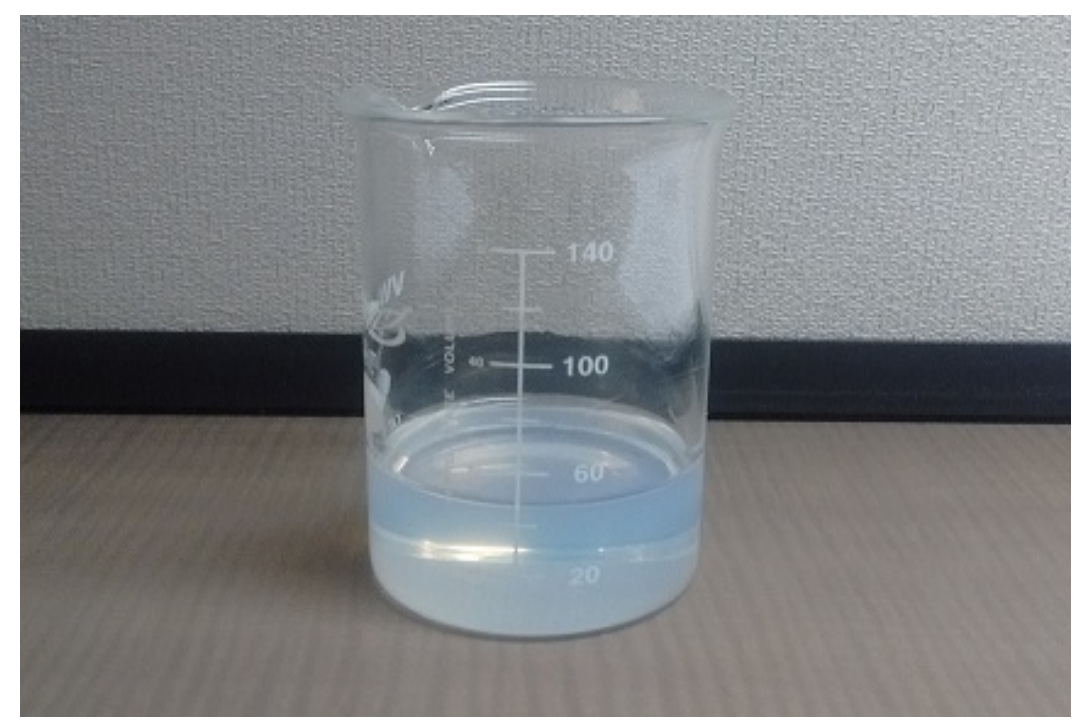

Figure 20: The silicone R-2180 mixture ready for application.

The coating was applied onto the aluminum and fiberglass substrates using a syringe. Approximately $0.7 \mathrm{~mL}$ was applied per square inch of substrate material. After application, the mixture was cured for 30 minutes at room temperature, followed by 45 minutes at $75{ }^{\circ} \mathrm{C}$ and finally 135 minutes at $150{ }^{\circ} \mathrm{C}$ [72]. After curing, the coating thickness was measured using a micrometer to be $0.010 "(250 \mu \mathrm{m})$. Differences in coating thickness did not influence the ice adhesion strength.

\subsubsection{Silicone R-1009}

Silicone R-1009 is a one-part silicone rubber dispersed in VM\&P Naphtha which is a petroleum solvent that evaporates during curing. Silicone R-1009 requires a RTV cure for 7 days in order to achieve its properties [73]. NuSil manufactures several other RTV icephobic coatings, however the R-1009 was selected as it has the lowest ice adhesion strength [58]. Shown in Figure 21 is the container received from NuSil and the coating placed into a beaker prior to application.

Similar to the silicone R-2180, the coating was applied to the substrate using 


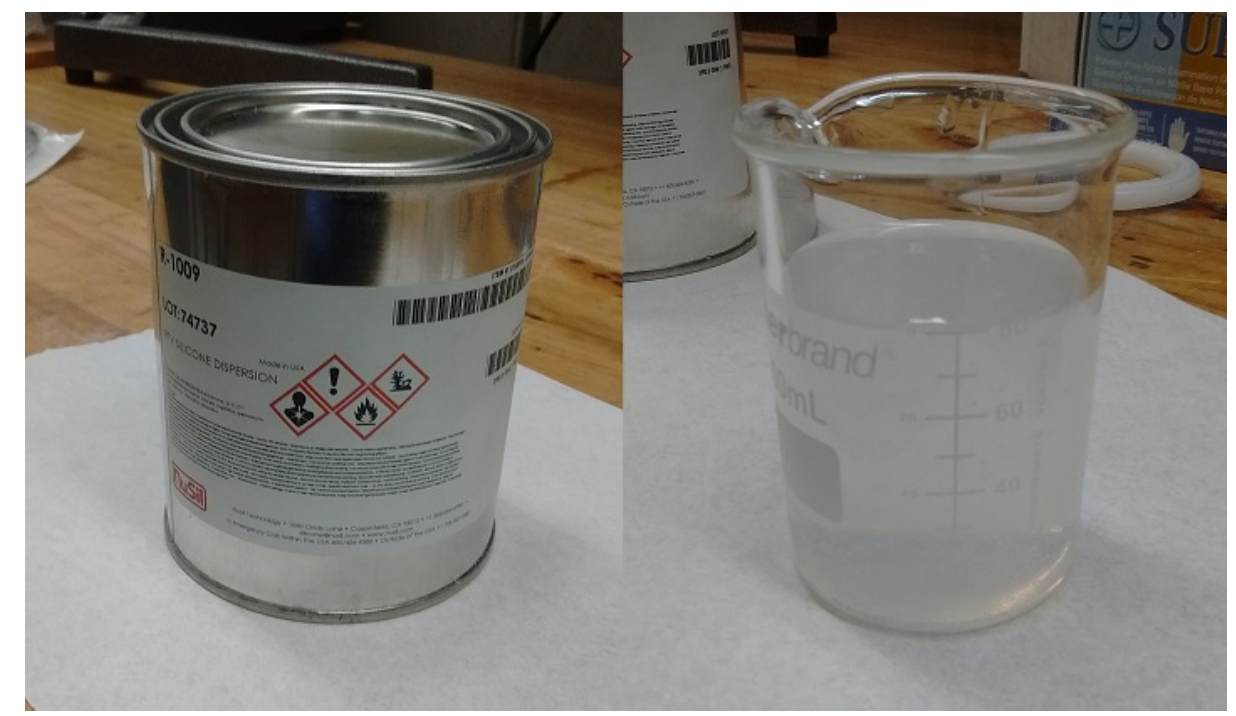

Figure 21: NuSil silicone R-1009 as received (left) and prior to application (right).

a syringe to control the quantity of coating applied. Approximately $1 \mathrm{~mL}$ was applied per square inch of material as the silicone R-1009 has a higher surface tension than the R-2180. The coating was left to cure in an isolated environment to prevent any dust particles from accumulating inside the coating while curing. The coating thickness was measured to be $0.015^{\prime \prime}(380 \mu \mathrm{m})$.

\subsubsection{ETFE}

ETFE is a thermoplastic based polymer fabricated by mixing ethylene $\left(\mathrm{CH}_{2} \mathrm{CH}_{2}\right)$ and tetrafluoroethylene $\left(C F_{2} C F_{2}\right)$ which is also referred to as Teflon ${ }^{\circledR}[74]$. The ETFE polymer was purchased from DuPont and it consisted of white powder particles with average particle size of $45 \mu \mathrm{m}$. Prior to the application of the coating, the ETFE powder was baked at $150{ }^{\circ} \mathrm{C}$ for 90 minutes to eliminate any humidity present in the polymer. 


\subsubsection{ETFE Application Process}

A plasma spraying system was used to apply the coating onto the aluminum substrates. Figure 22 shows the powder feeder and spraying equipment that was used. During spraying, a mixture of $20 \%$ nitrogen and $80 \%$ argon gas was used. The aluminum coupons were preheated for two minutes by the plasma stream before the coating was sprayed. Other spraying parameters for the ETFE coupons were $190 \mathrm{~A}$ arc current, 220 standard liters per minute (SLPM) Ar gas flow rate, 3/8" nozzle size and $100 \mathrm{~mm}$ distance between the nozzle and the coupons. After coating, all ETFE coupons were baked at $274{ }^{\circ} \mathrm{C}$ for 20 minutes as recommended by the supplier [74].

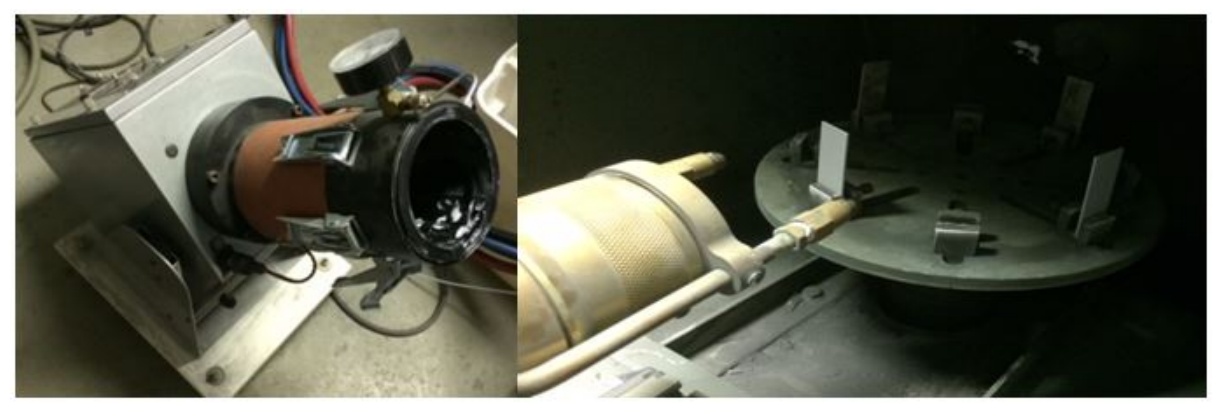

Figure 22: Plasma spray powder feeder (left) and the preheating and spraying chamber (right).

\subsubsection{Selection of Arc Current}

In order to increase the density and adhesion of the ETFE coating to aluminum substrate, the arc current was varied. The cross sections of the microstructure of ETFE coated sample under different arc currents were evaluated using a scanning electron microscope (SEM). Figure 23 shows the cross-section images of the four samples, with Zone 1 representing the sprayed coatings.

Since ETFE is applied using a spraying process, it has a relatively porous structure. As the arc current increases, the porosity decreases (Zone 1 in Figure 23). 
However, high current also resulted in lower spray efficiency, (i.e. less coating deposited onto the aluminum surface). To achieve a balance of density and thickness, an arc current of $190 \mathrm{~A}$ was used for spraying the ETFE powders.

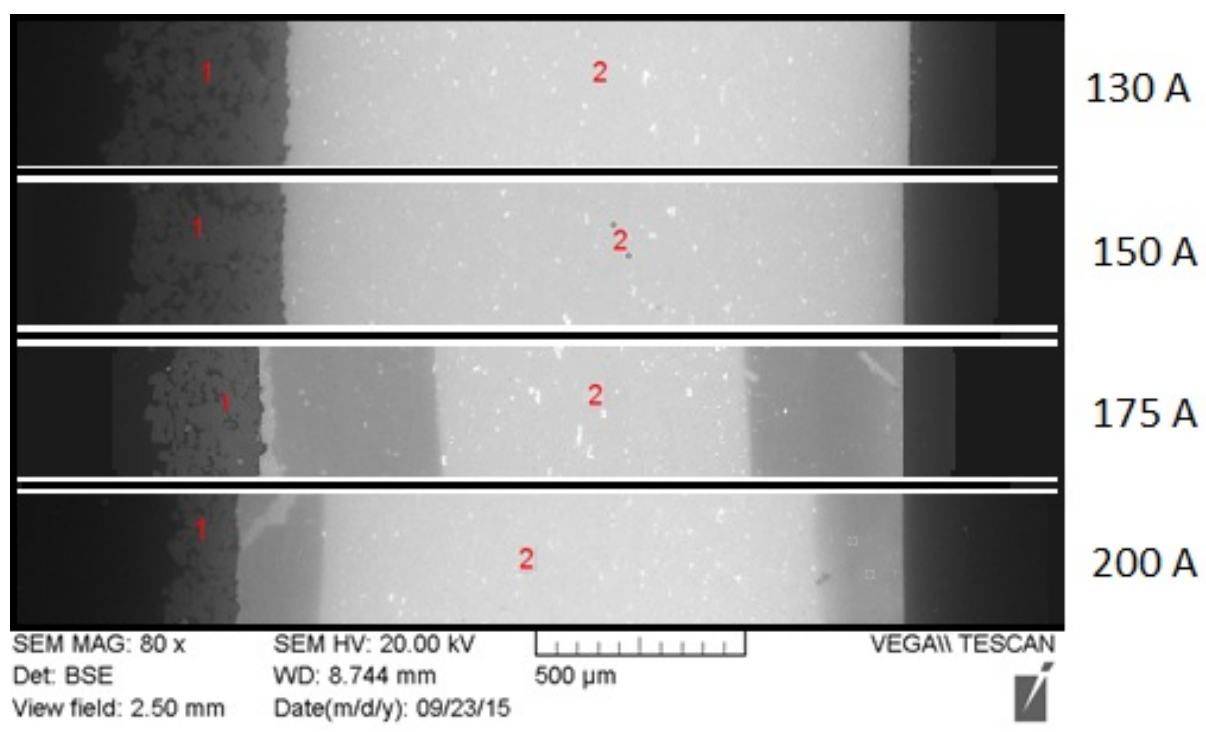

Figure 23: SEM micrograph showing ETFE coating microstructure.

The thickness of the coating is dependent on the length of time that the substrate is sprayed for. In general, samples were left in the chamber for four minutes. The resulting coating thickness was $0.021 "(530 \mu \mathrm{m})$. In comparison with the silicone R-2180 and R-1009 coated samples, the ETFE samples had a rougher surface finish. This is due to the porous nature of coatings that are applied with a spraying process compared to those applied evenly with a syringe.

\subsubsection{ALG}

Advanced liquid glass is a coating composed of silicone oxides which are used in the production of glass sheets. ALG is transparent and can be used for applications requiring anti-bacterial, anti-abrasion and protection from corrosion. Liquid glass is commonly used to protect medical equipment and automobiles [75]. It 
was purchased from Liquid Glass Shield in London, United Kingdom. The coating is comprised of an active agent siloxane $\left(\mathrm{R}_{2} \mathrm{SiO}\right)$, antimicrobial agent ethanol $\left(\mathrm{C}_{2} \mathrm{H}_{5} \mathrm{OH}\right)$, and uses butanone $\left(\mathrm{CH}_{3} \mathrm{C}(\mathrm{O}) \mathrm{CH}_{2} \mathrm{CH}_{3}\right)$ as a solvent. This coating can be seen in Figure 24

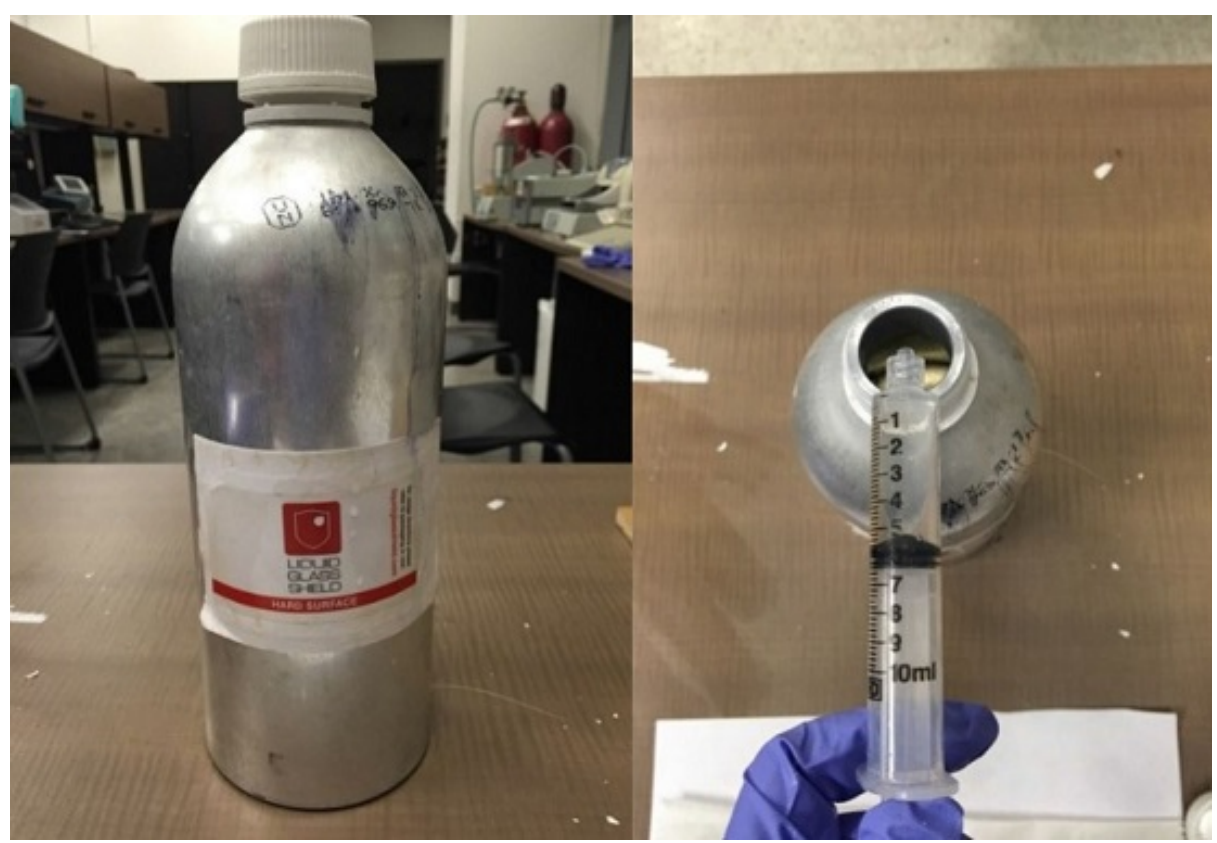

Figure 24: The bottle of ALG (left) and the liquid being removed in a syringe (right).

To apply the ALG coating onto the aluminum substrate, the coupon is dipped in a beaker containing the ALG liquid for 10 seconds. After removing the coupon from the beaker, the sample is cured at $250{ }^{\circ} \mathrm{C}$ for 1 hour. After the curing was completed, the coating thickness was measured at $0.0015^{\prime \prime}(38 \mu \mathrm{m})$. Compared to the other coatings, the ALG coating thickness is small. Since ALG is a ceramic containing coating, it is difficult to bond subsequent layers of the coating on top of each other. 


\subsubsection{Coating Surface Observations}

All the coated surfaces described previously can be seen in Figure 25. The untreated aluminum surface is shown in Figure 25(a), followed by the sandblasted aluminum in Figure 25(b). The ALG coating shown in Figure 25(c) has a matte colour while the ETFE is white. Both silicone R-2180 and R-1009 are translucent when applied onto the surface. ETFE has the roughest surface of all the coatings. The silicone based coatings have a high viscosity and flow to fill in any voids on the surface. This results in a smoother, continuous surface.

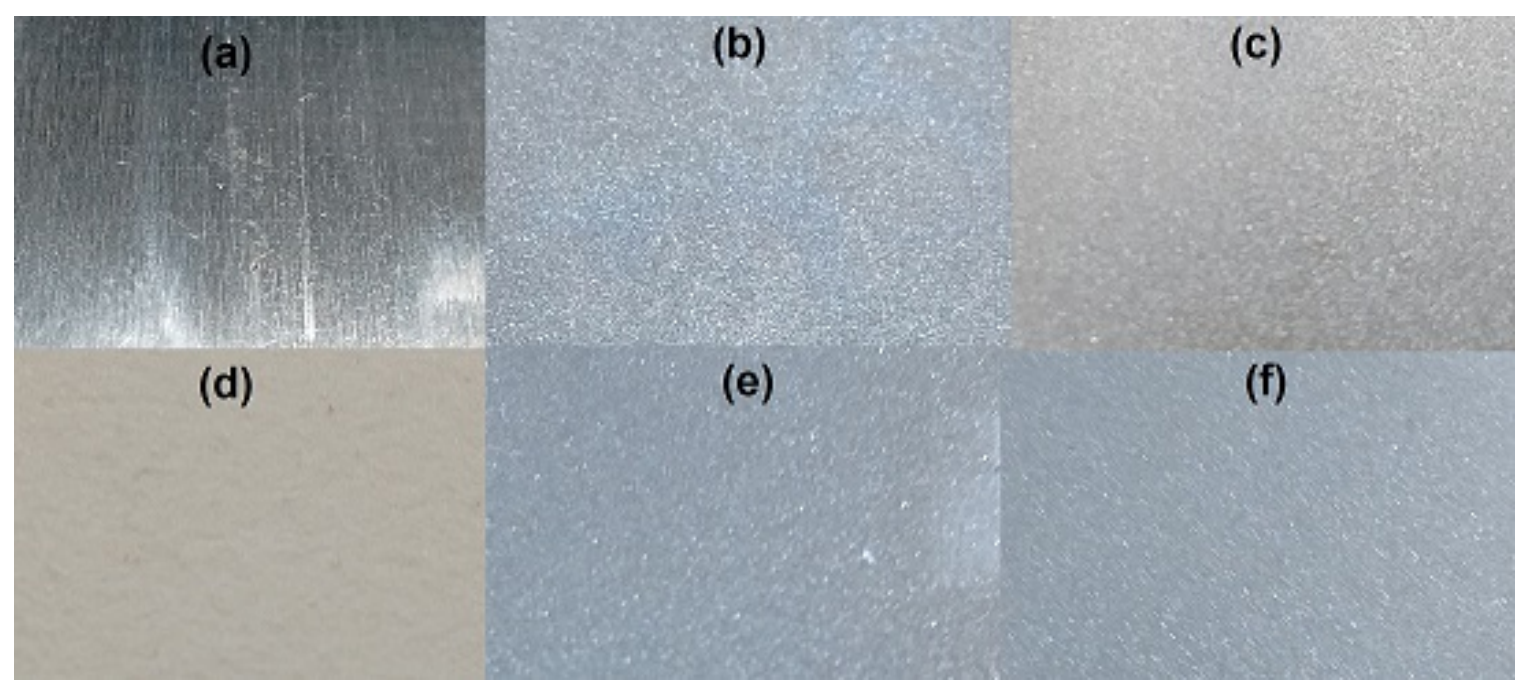

Figure 25: All the surfaces used: (a) aluminum, (b) sandblasted aluminum, (c) ALG, (d) ETFE, (e) silicone R-2180, and (f) silicone R-1009.

\subsection{Sample Storage}

After a sample was coated, it was stored in a sealed plastic bag to prevent the accumulation of dust on the surface. As an additional precaution, the prepared part of the surface was covered using a tissue. Samples were cleaned with isopropanol prior to testing to ensure that there would be no dust or other impurities on the surface. 
Following each test, the sample was collected and cleaned as if it were to be tested again. The sample was then stored in a microscope slide box in case a reproduction of a specific test was required.

\subsection{Bonding the Piezoelectric Actuators}

The piezoelectric actuator needed to be bonded to the samples in order to have an efficient transfer of mechanical force. The layout of the location of the actuators with respect to the plate is shown in Figure 26. The process from which the piezo was received to being ready for testing is described below.

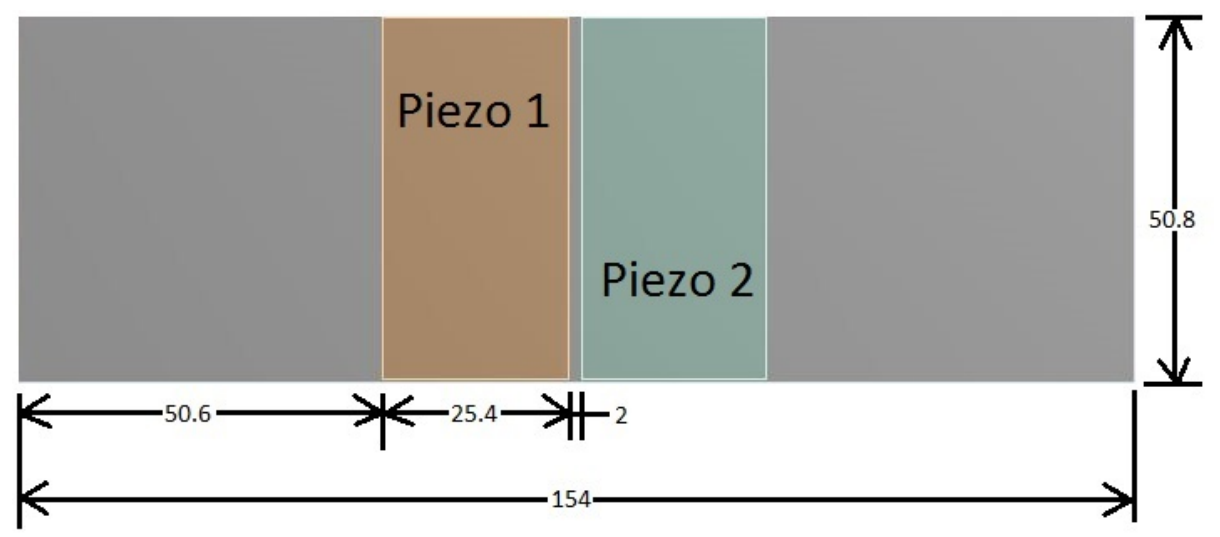

Figure 26: The actuators were placed in the centre of the plate with a $2 \mathrm{~mm}$ gap between them (units provided in $\mathrm{mm}$ ).

The actuators were supplied by PI Ceramic in Lederhose, Germany and had a size of $50 \mathrm{~mm} \times 25 \mathrm{~mm} \times 0.5 \mathrm{~mm}$. In the as received state, they were ready for mounting. A piece of tape measuring $10 \mathrm{~mm} \times 10 \mathrm{~mm}$ was applied in the centre of the actuator. Following this step, a non-conductive spray was applied to the top surface of the piezoceramic. It was then left to dry for one hour. The tape was then removed as it served as a temporary means for the spray to not contact the centre of the piezoceramic. 


\subsubsection{Bonding the Actuator to the Substrate}

Once the actuator was prepared, the next step was to bond it onto the substrate. First the measurements shown in Figure 26, were transferred to the substrate. Tape was then placed at the edges shown in Figure 27 to ensure that the adhesive would not extend past the location of the piezoceramic. The electrically conductive adhesive (supplied by Polytec) created an electrical connection between the bottom surface of the piezoceramic and the substrate.

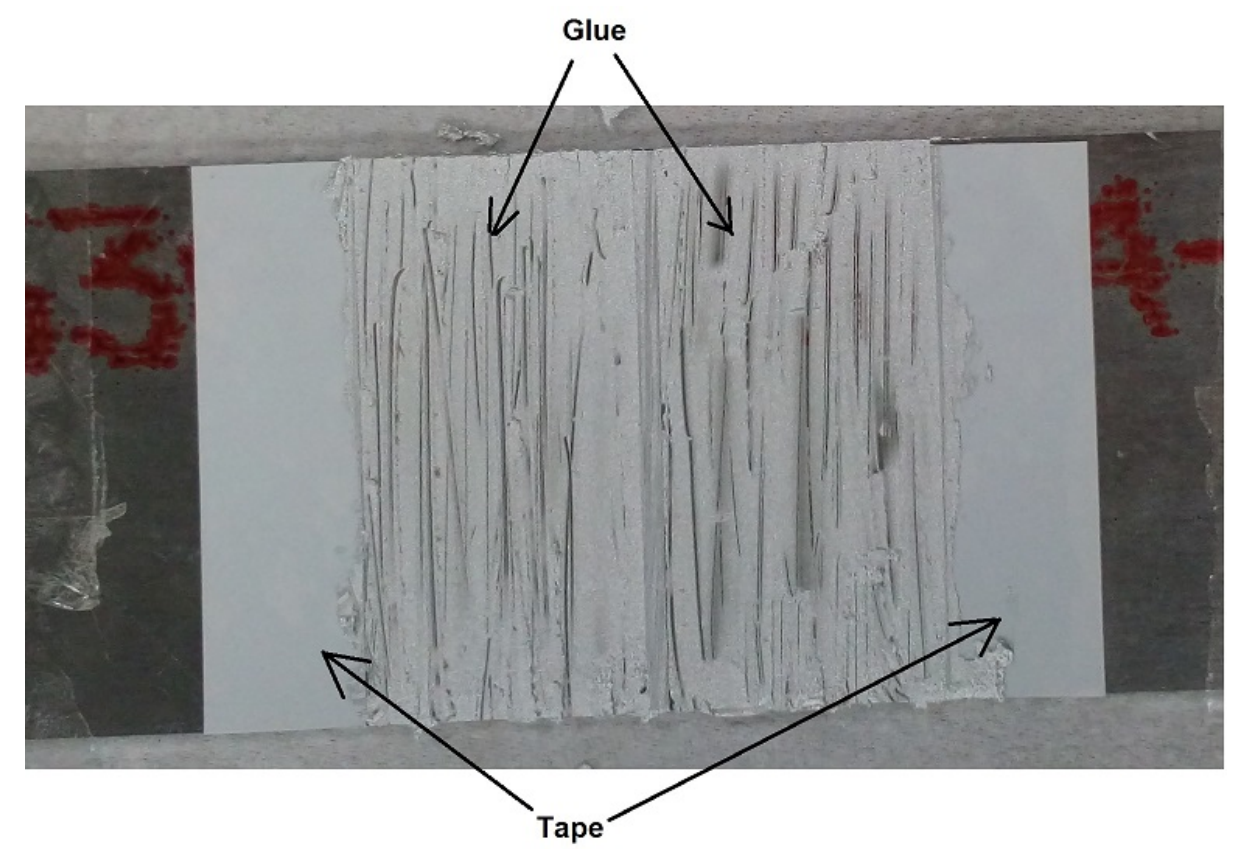

Figure 27: Tape was placed on the surface to prevent the glue from spreading past the intended area.

Weights were used to hold each piezoceramic in the desired position as shown in Figure 28. The sample was then left to dry over night and inspected once drying was completed. 


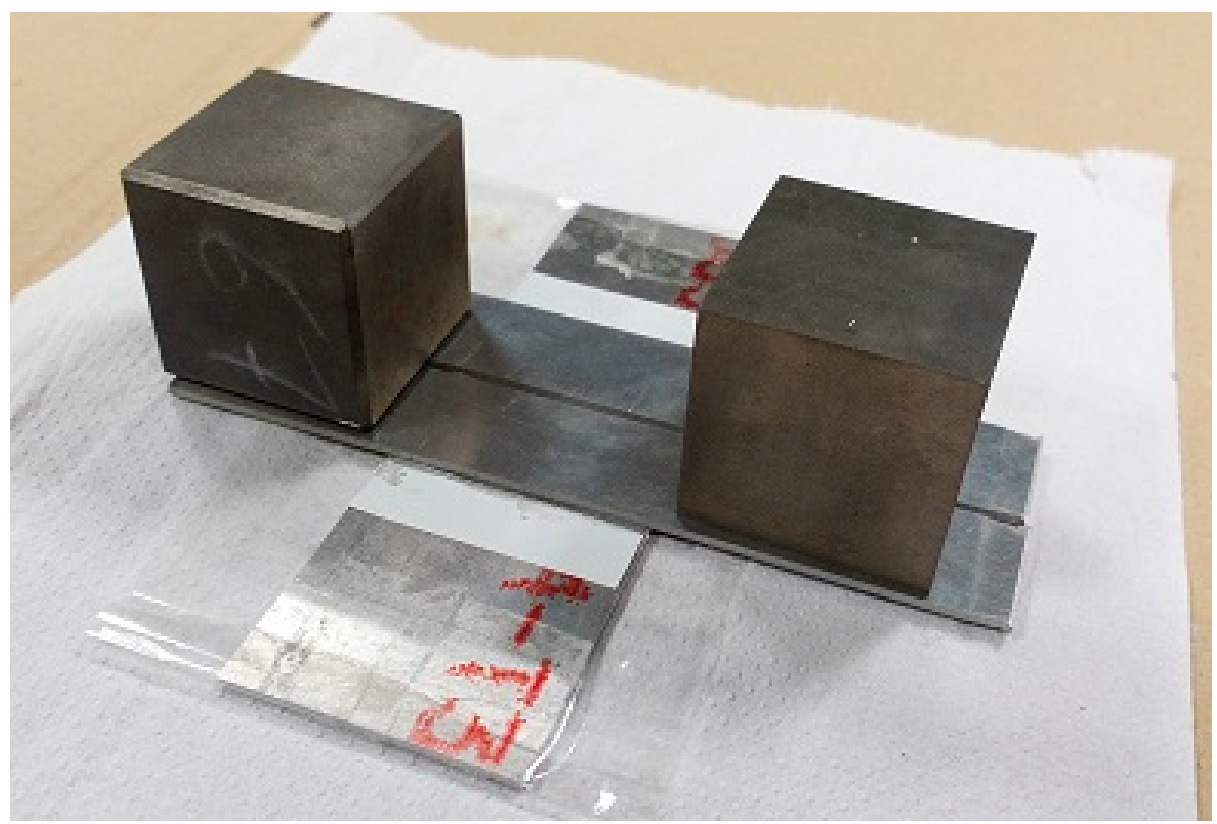

Figure 28: Weights used to keep the piezoceramic in place.

\subsubsection{Verifying Electrical Conductivity}

After the glue had hardened, the electrical connectivity was checked by verifying that there was no short-circuit between the electrodes of the ceramic. If there was a short, the contact point between the piezoceramic and ground would be removed by chipping away at the glue. A short circuit would produce a faulty response during the experiment, so it was critical that if present, it was removed.

After the circuit was determined to function as intended, wires were soldered onto the conductive part of the piezoceramic. These wires allow for a circuit to be created with the power supply so that a voltage can be passed into one piezoceramic while the second would serve as a sensor. To protect the electrical contacts, an insulating spray was applied to the back of the sample. This would ensure that no new electrical connections would form. The uncoated side of the sample is shown in Figure 29. 


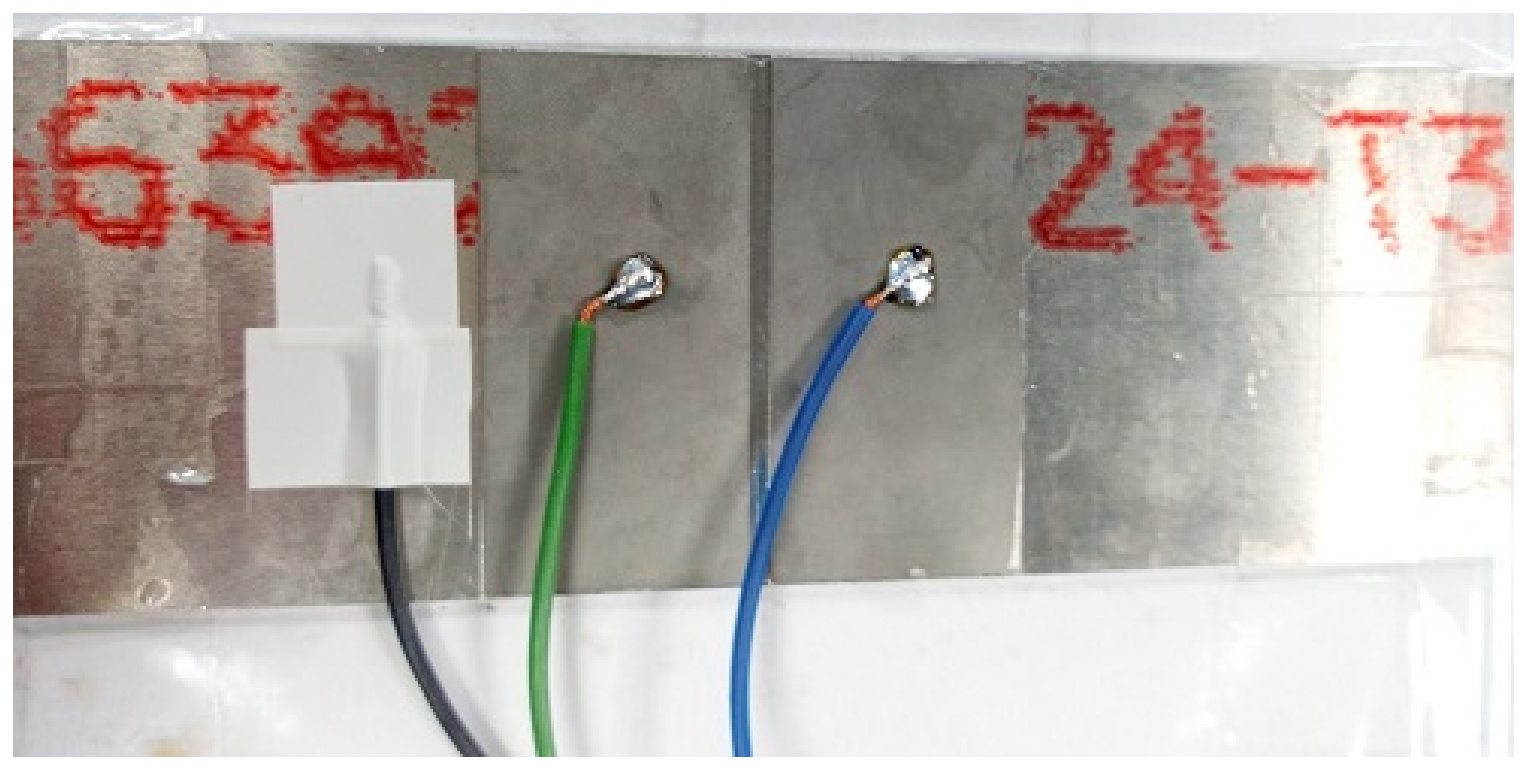

Figure 29: Aluminum sample with two piezoceramics mounted that is ready for testing.

Careful preparation of the samples is critical in order for the experimental results to match the model described in Chapter 4 


\section{Chapter 4}

\section{Numerical Modelling of Ice Delamination}

De-icing can occur by either internal ice fracture (cohesive) or delamination at the ice-substrate interface (adhesive). We will focus here on delamination as the coatings will have a major effect on this mechanism.

Numerical modelling was used to compute the resonance frequencies of the various vibrational modes and the power required to delaminate a sheet of ice from the surface. The resonance frequencies were then validated experimentally using a test setup described in Section 5.5. Delamination was attempted for resonance modes requiring voltages below $100 \mathrm{~V}$, (the limit of the power supply and half of the depolarization limit for a $0.5 \mathrm{~mm}$ thick ceramic patch) and a stress below $24 \mathrm{MPa}$, (maximum permissible stress in the ceramic to avoid failure) [46].

\subsection{The Numerical Model}

The numerical model was created using ANSYS 17.2 software. It consists of a plate with two piezoceramic patches mounted on the back surface with a space of $2 \mathrm{~mm}$ between the patches. In the model, one patch is used as an actuator while the other is used as a sensor to measure the response voltage. On the front surface of the plate is a sheet of ice. An ice thickness of $2 \mathrm{~mm}$ was selected based on 
customer requirements. The dimensions of the model are listed in Table 3 . In the model, the results of interest are the resonance frequency, deformation, stress in the piezoceramic, voltage, current and power required for delamination.

Table 3: Dimensions of the numerical model

\begin{tabular}{|l|c|c|c|}
\hline Dimension & Plate & Piezoceramic & Ice \\
\hline Length $(\mathrm{mm})$ & 154 & 25.4 & 154 \\
\hline Width $(\mathrm{mm})$ & 50.8 & 50 & 50.8 \\
\hline Thickness $(\mathrm{mm})$ & 1.6 & 0.5 & 2.0 \\
\hline
\end{tabular}

The model is empirically based and uses several variables that were obtained from experimental work. A quality factor of 100 was chosen based on a preliminary experiment and its measurement procedure is described in Section 5.5.6. From literature, the adhesion strength between ice and aluminum is approximately $1 \mathrm{MPa}$.

\subsubsection{Material Properties}

Aluminum 2024-T3 was used as the substrate and the piezoceramic was composed of soft PZT (PIC 151). Listed in Table 4 are the material properties of both these materials and the properties of the ice used in the model.

Table 4: Material properties of the numerical model

\begin{tabular}{|l|c|c|c|}
\hline Material & Density $\mathbf{( k g / \mathbf { m } ^ { 3 } )}$ & Young's Modulus (GPa) & Poisson's Ratio \\
\hline Aluminum & 2770 & 71.0 & 0.33 \\
\hline Ice & 920 & 9.33 & 0.30 \\
\hline PZT & 7800 & ${ }^{*}$ & $*$ \\
\hline
\end{tabular}

*Elasticity matrix and electromechanical coupling matrix are used to model PZT materials. 
PZT is transversely isotropic as it has the same properties in the $x-y$ plane and different properties in the z-direction. The coefficients of the elasticity matrix are shown below. These properties for the piezoceramic were obtained from the manufacturer, PI Ceramic [76].

$$
\left[\begin{array}{c}
\sigma_{x x} \\
\sigma_{y y} \\
\sigma_{z z} \\
\sigma_{y z} \\
\sigma_{z x} \\
\sigma_{x y}
\end{array}\right]=\left[\begin{array}{ccccccc}
107.6 & 63.12 & 63.85 & 0 & 0 & 0 \\
63.12 & 107.6 & 63.85 & 0 & 0 & 0 \\
63.85 & 63.85 & 100.4 & 0 & 0 & 0 \\
0 & 0 & 0 & 19.62 & 0 & 0 \\
0 & 0 & 0 & 0 & 19.62 & 0 \\
0 & 0 & 0 & 0 & 0 & 22.4
\end{array}\right] \times 10^{9} \times\left[\begin{array}{c}
\epsilon_{x x} \\
\epsilon_{y y} \\
\epsilon_{z z} \\
\epsilon_{y z} \\
\epsilon_{z x} \\
\epsilon_{x y}
\end{array}\right]
$$

\subsubsection{Boundary Conditions}

In the model, both ends of the plate were given a free boundary condition. This allows the plate to freely vibrate at the supplied frequency, matching the physics of the experiment explained in Section 5.5 .

\subsubsection{Element Selection}

The model uses 3D solid rectangular prism elements. Due to the substrate, ice and piezoceramics being rectangular, rectangular elements are suitable. Triangular elements can also be used however, they will produce larger errors. The resonance frequencies can be validated with a frequency sweep described in Section 5.5.3 and the displacements can be measured with a vibrometer as discussed in Section 5.5.4. 


\subsubsection{Initial Mesh}

The initial mesh is comprised of square elements measuring $3 \mathrm{~mm}$ by $3 \mathrm{~mm}$ with a thickness of $0.8 \mathrm{~mm}$ in the aluminum substrate and $1 \mathrm{~mm}$ thick in the ice sheet. Stresses and deformations in both the ice and the substrate are not of concern as there is no risk of plastic deformation in the substrate due to the low stresses.

Stresses in the piezoceramic are higher than in the plate and the tensile strength of the patch is $24 \mathrm{MPa}$; a limiting factor. Elements in the piezoceramic measure $2 \mathrm{~mm}$ by $2 \mathrm{~mm}$ with a thickness of $0.25 \mathrm{~mm}$. The initial mesh used is shown in Figure 30(a) and the elements in the x-z plane are shown in Figure 30(b).

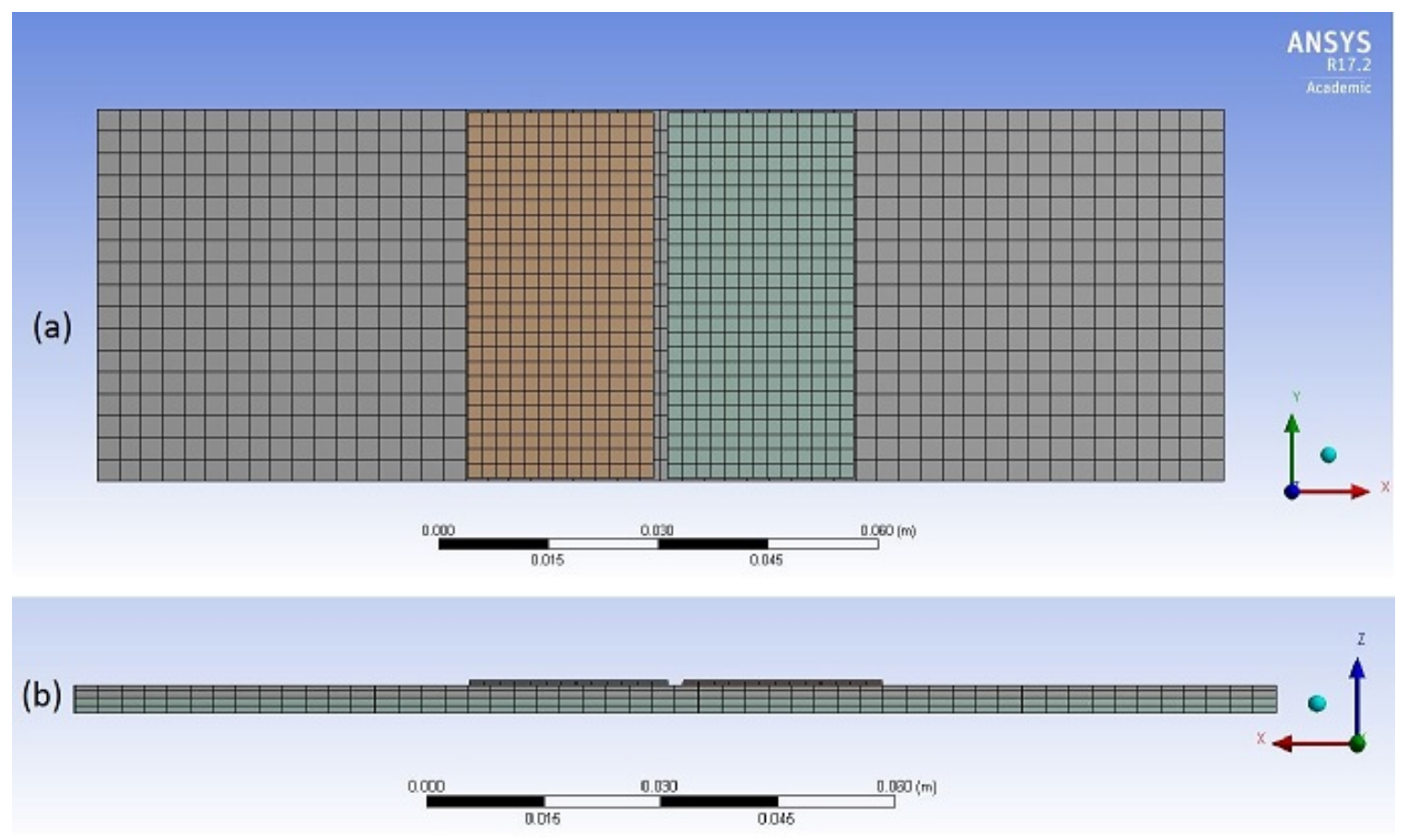

Figure 30: Initial mesh used in the (a) $x-y$ plane and (b) $x-z$ plane. 


\subsection{Mesh Convergence Study}

Using a finer mesh results in a more accurate solution, but increases the computational time. With a mesh convergence study, a satisfactory tradeoff can be established between the accuracy and time.

\subsubsection{Approach}

Using the initial mesh, the solution was found and treated as a baseline for the mesh convergence. Each meshing parameter was then varied individually to determine its effect on the solution. Convergence was considered when the results were within $2 \%$ of the previous (coarser) set of results.

The first mesh parameter to be adjusted was the number of divisions within each piezoceramic (increasing the aspect ratio). Figure 31 shows how increasing the number of elements in the piezoceramic causes the stress to converge to the solution. The modes selected for Figure 31 are either flexural modes or are potential de-icing modes as described in Section 4.4 . Using the $2 \%$ convergence criteria, using at least 1200 elements in the piezoceramic is sufficient for convergence. The stress takes the longest to converge as the resonant frequency, deformation, voltage and current all converge at much faster rates.

The mesh size of elements within the plate and the ice were then adjusted by decreasing the aspect ratio. Shown in Figure 32 is how the value of the von Mises stress within the piezoceramic converges with an increasing number of elements in the ice sheet and plate. Using the $2 \%$ convergence criteria, 3500 elements in the each of the plate and the ice are sufficient for convergence. 


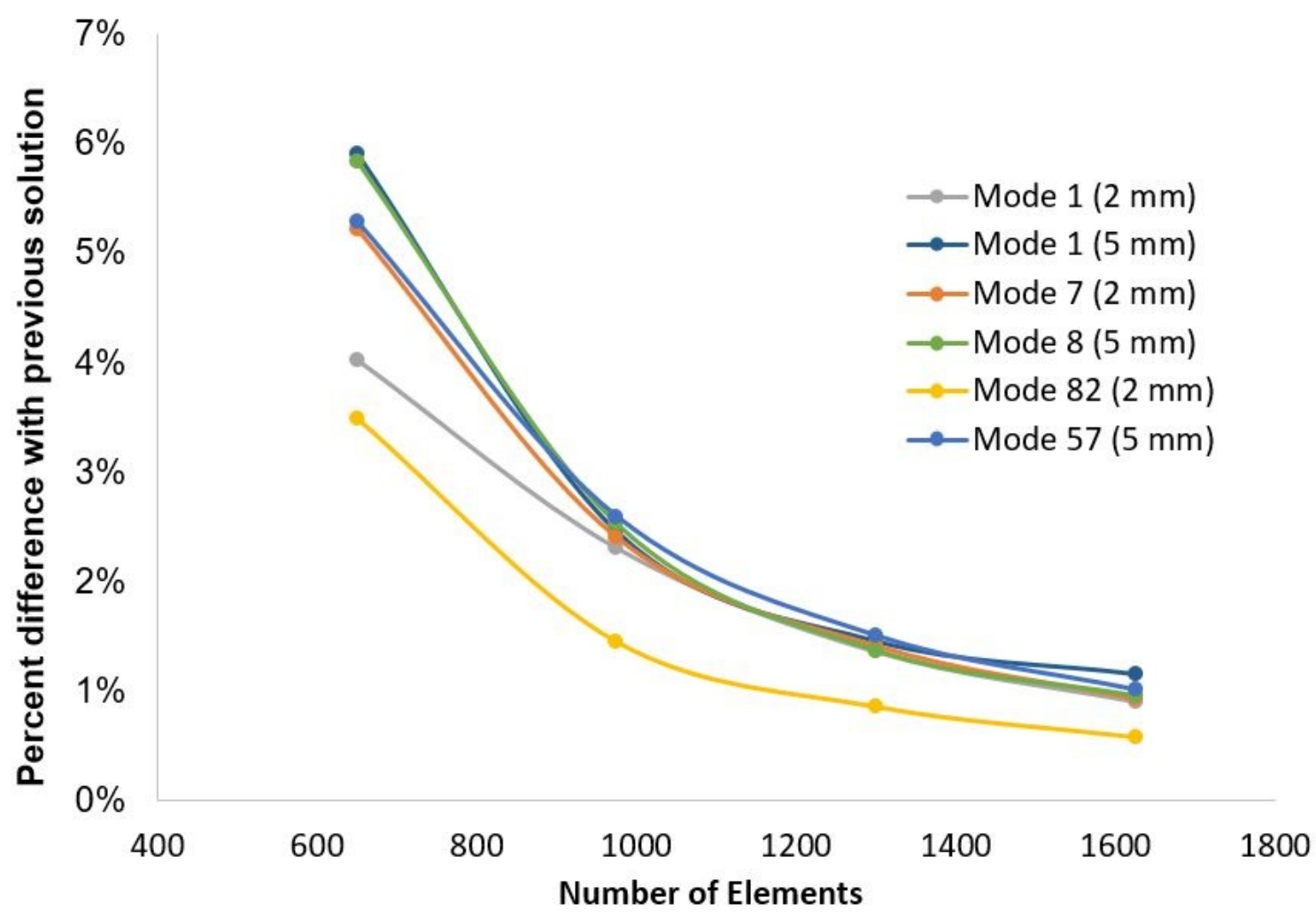

Figure 31: Convergence of the solution varying the element size in the piezoceramic.

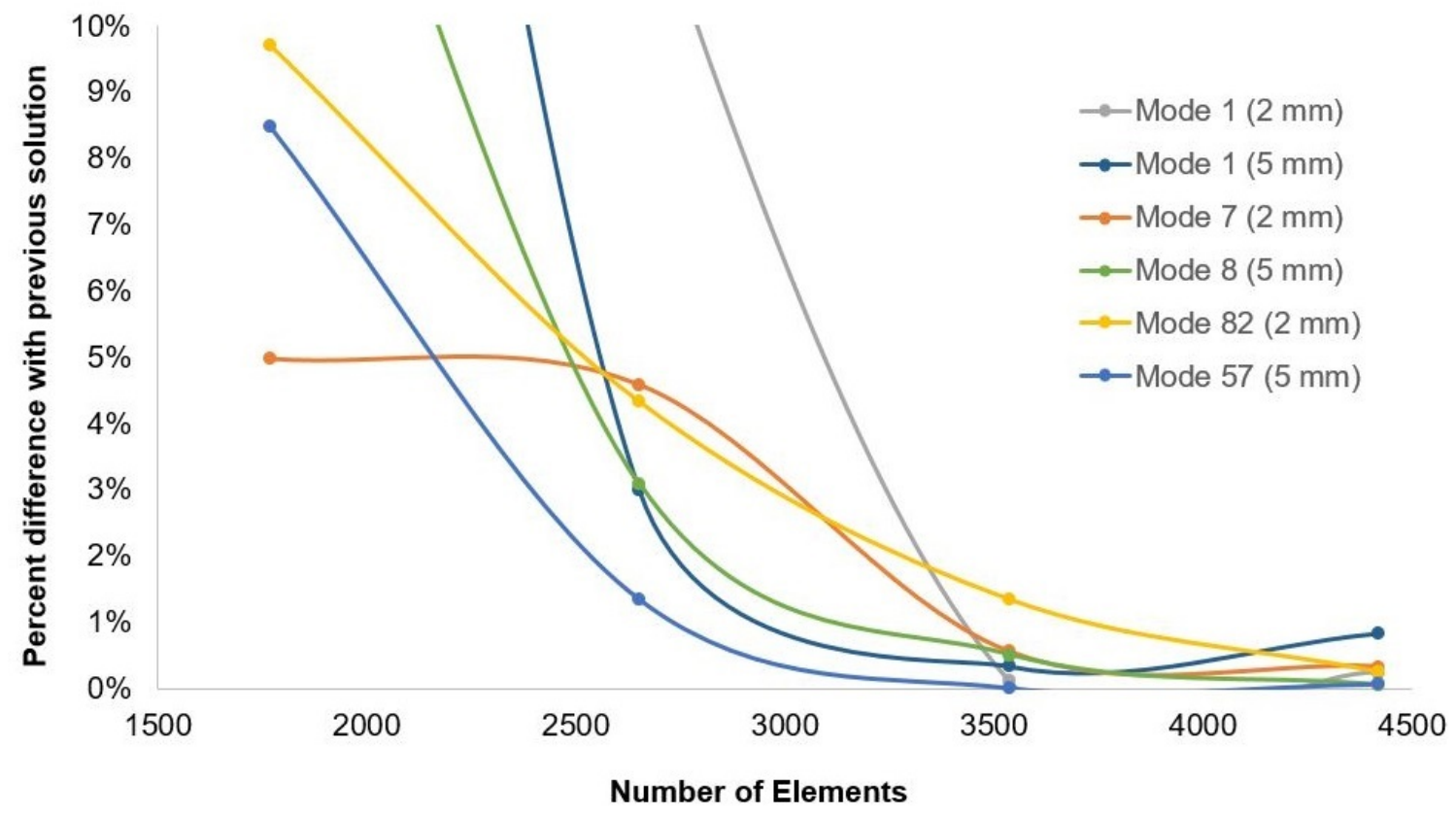

Figure 32: Convergence of the solution varying the element size in the substrate. 


\subsubsection{Selected Mesh}

The selected mesh uses square elements with a size of $1.69 \mathrm{~mm}^{2}$ and a thickness of $0.125 \mathrm{~mm}$ in the piezoceramic and an element size of $4 \mathrm{~mm}^{2}$ with a thickness of $0.4 \mathrm{~mm}$ in the plate. This mesh was used for the simulations conducted in this study.

\subsection{Variables Affecting Delamination}

There are several input parameters used within the model that can impact the resonance frequency and required power for delamination. These parameters are the mechanical quality factor, the thickness of the ice sheet, the ice adhesion strength on the surface, the size of the plate and its material properties.

\subsubsection{Quality Factor}

The quality factor is a parameter that describes the damping of an oscillator by comparing its bandwidth to its centre frequency. The higher the quality factor, the lower the amount of damping. Figure 33 shows the bandwidth of an oscillator with respect to the damping. The quality factor is calculated using Equation (1):

$$
Q_{m}=\frac{f_{c}}{f_{u}-f_{l}}
$$

Where $Q_{m}$ represents the quality factor, $f_{c}$ denotes the resonance frequency and $f_{u}$ and $f_{l}$ represent the maximum and minimum frequencies used in computation of the bandwidth. For low damping, the quality factor can then be related to the damping coefficient using Equation 2 


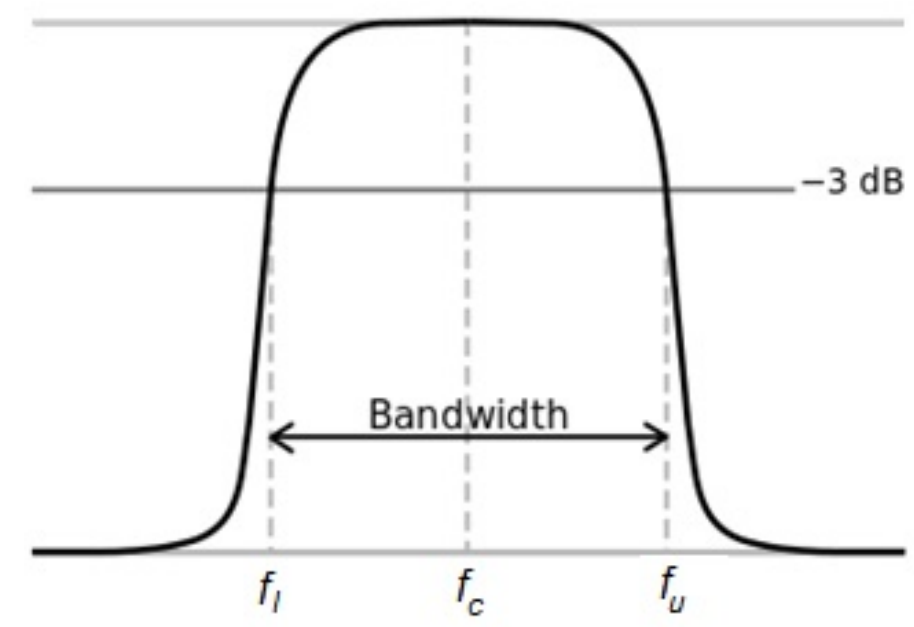

Figure 33: Frequencies used in the calculation of quality factor.

$$
Q_{m}=\frac{1}{2 \zeta}
$$

From the numerical model, increasing the quality factor decreases the voltage required for delamination while not having an impact on the stress in the piezoceramic. Table 5 contains the important characteristics of the fifth flexural mode (the 4790 and $8771 \mathrm{~Hz}$ frequencies) and a higher frequency mode involving both bending and torsion. These two modes are shown in Figure 34 . These results showed how the ice thickness and quality factor can influence both the stress in the piezoceramic and the voltage required for delamination. All results presented in Table 5 are for $50 \%$ ice delamination and an assumed ice adhesion strength of $1 \mathrm{MPa}$.

From Table 5 , increasing the quality factor leads to a linear decrease in the voltage and power required for delamination. Increasing the quality factor also has no effect on the stress generated in the piezoceramic. Using this approach, a design space can be created which selects an optimal frequency range in terms of quality factor and attempts delamination at various resonance frequencies. Within this 
Table 5: Comparing the affects of quality factor

\begin{tabular}{|c|c|c|c|c|c|}
\hline $\begin{array}{c}\text { Ice } \\
\text { Thickness } \\
(\mathbf{m m})\end{array}$ & $\begin{array}{c}\text { Quality } \\
\text { Factor }\end{array}$ & $\begin{array}{c}\text { Resonance } \\
\text { Frequency } \\
\mathbf{( H z )}\end{array}$ & $\begin{array}{c}\text { Stress in } \\
\text { Piezoceramic } \\
\mathbf{( M P a )}\end{array}$ & $\begin{array}{c}\text { Voltage } \\
\text { Required for } \\
\text { Delamination (V) }\end{array}$ & $\begin{array}{c}\text { Power } \\
\text { Required for } \\
\text { Delamination (W) }\end{array}$ \\
\hline 2.0 & 100 & 4790 & 44.68 & 80.90 & 12.09 \\
\hline 2.0 & 110 & 4790 & 44.68 & 73.55 & 10.99 \\
\hline 2.0 & 200 & 4790 & 44.68 & 40.45 & 6.047 \\
\hline 2.0 & 100 & 37250 & 13.50 & 173.9 & 12.49 \\
\hline 2.0 & 110 & 37250 & 13.50 & 158.1 & 11.35 \\
\hline 2.0 & 200 & 37250 & 13.50 & 86.97 & 6.245 \\
\hline 5.0 & 100 & 8771 & 28.34 & 121.7 & 24.63 \\
\hline 5.0 & 110 & 8771 & 28.34 & 110.7 & 22.39 \\
\hline 5.0 & 200 & 8771 & 28.34 & 60.86 & 12.31 \\
\hline
\end{tabular}

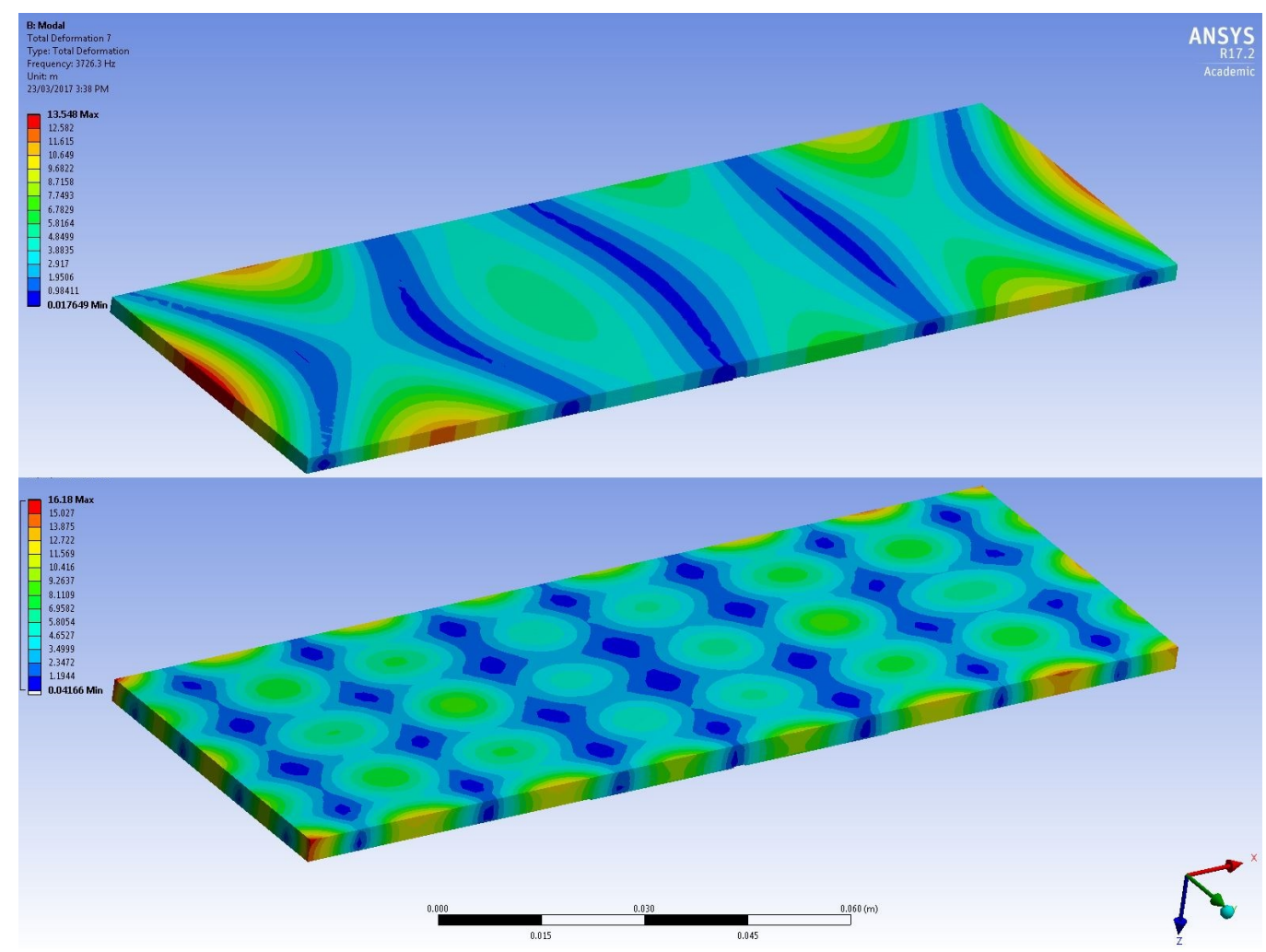

Figure 34: The flexural mode with 5 nodes (top) and a higher order combination mode (bottom). 
range, the stresses will not cause the piezoceramic to crack.

\subsubsection{Ice Thickness}

The natural frequency of an object is based on its mass and stiffness. As the thickness of the ice sheet atop a plate increases, so do the total mass and stiffness. The mass increases as a function of the volume while the stiffness increases by the cube of the ice thickness. The change in several natural frequencies due to varying the ice thickness is shown in Figure 35. The blue line tracks the resonance frequency of the flexural mode with five nodes while the red line shows the change in frequency for the torsional mode with two nodes and the green shows the shear mode with two nodes. The shape of the resonance modes used in this comparison are shown in Figure 36 ,

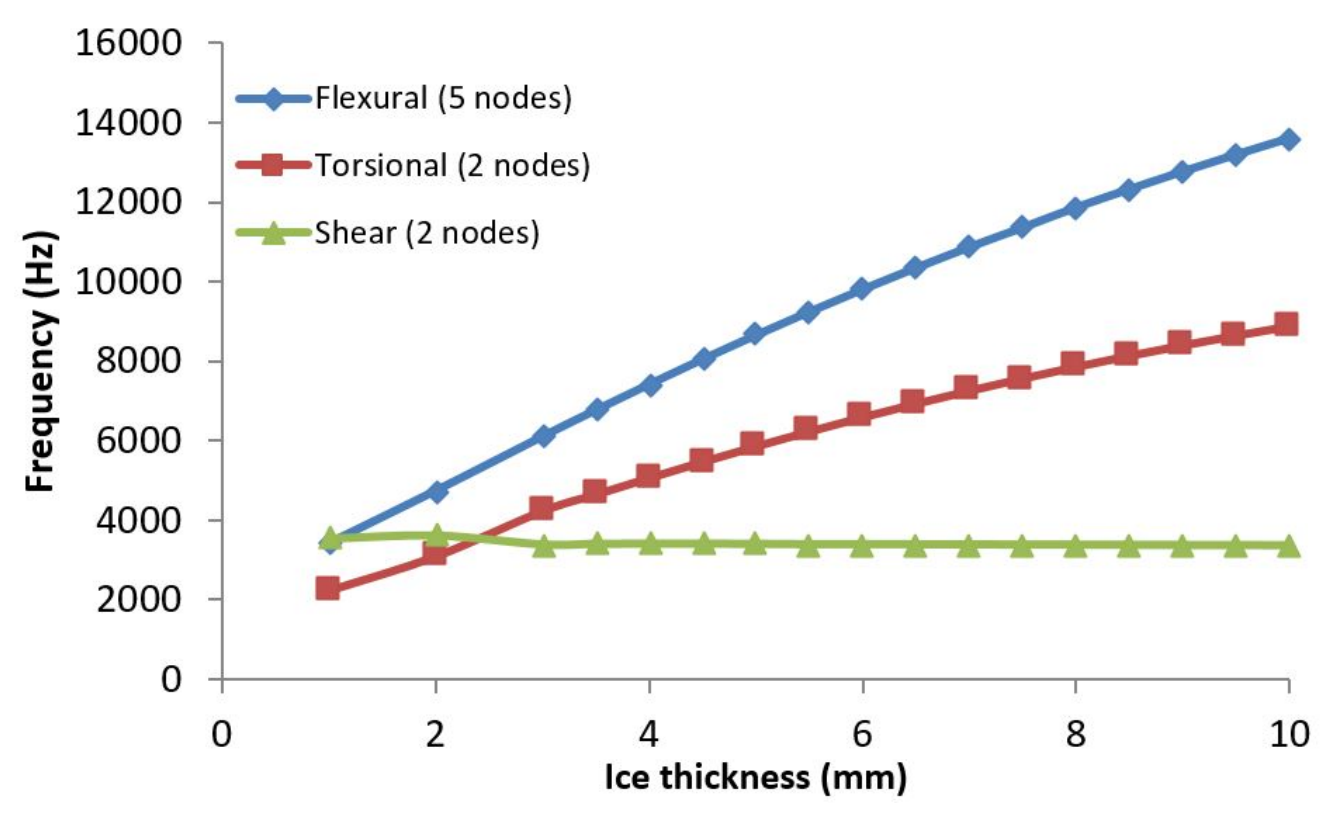

Figure 35: Shift in resonance frequency with ice thickness.

From Figure 35, the frequencies are observed to exhibit a fairly linear trend 


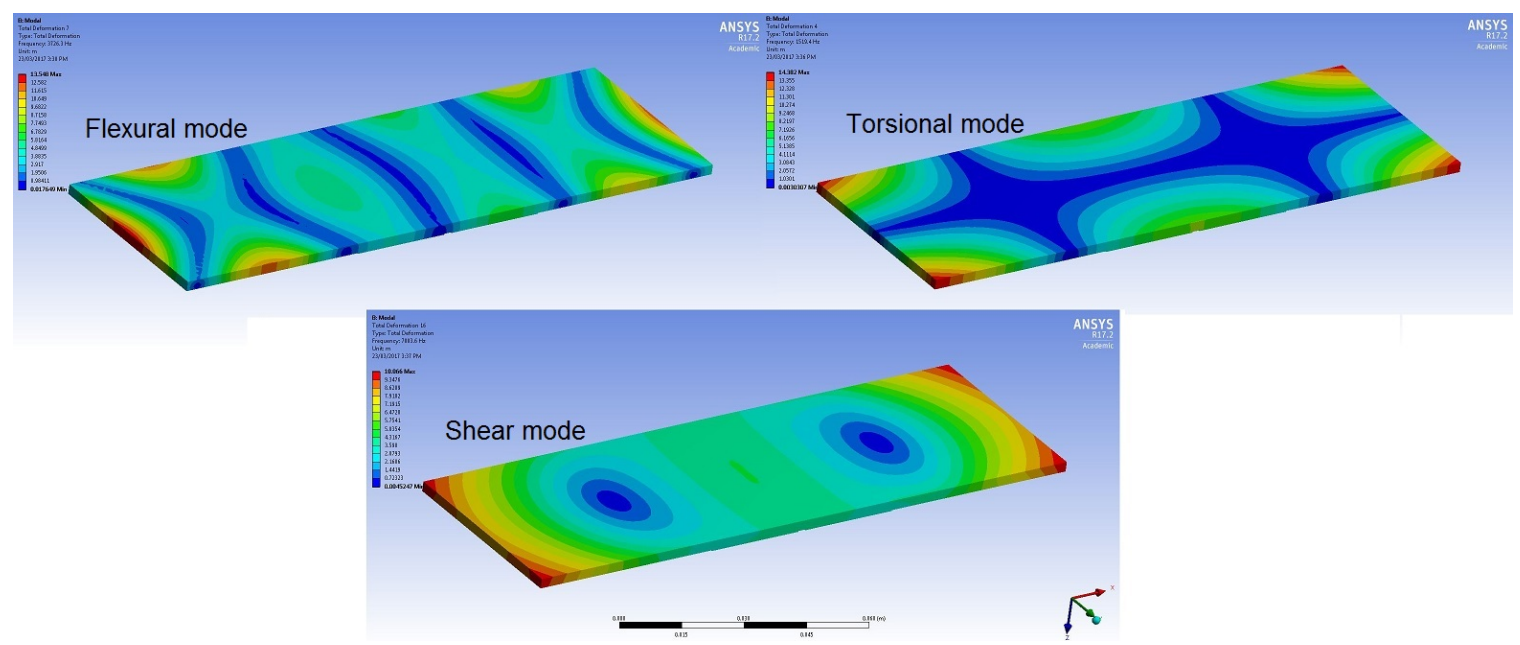

Figure 36: Resonance mode shapes for the flexural (top left), torsional (top right) and shear (bottom) modes used in Figure 35.

meaning that the resonance frequency of a certain vibrational mode can be predicted with good accuracy for a specific ice thickness. Another trend is the magnitude increase for higher vibrational modes. The second flexural mode (not shown on the graph) and the fifth flexural mode are not shifted by the same magnitude of frequency. This confirms that the number of nodes acts as a scaling factor as given by Equation (3) [48]:

$$
\omega=\pi^{2}\left(\frac{n}{a}\right)^{2} \sqrt{\frac{E I}{\rho_{i c e} h_{i c e}+\rho_{A l} h_{A l}}}
$$

with the stiffness and position of the neutral line being calculated by:

$$
\begin{gathered}
E I=\frac{E_{A l}}{3}\left(h_{n}^{3}+\left(h_{A l}-h_{n}\right)^{3}\right)+\frac{E_{i c e}}{3}\left(\left(h_{n}-h_{i c e}\right)^{3}-h_{n}^{3}\right) \\
h_{n}=0.5 \frac{E_{A l} h_{A l}{ }^{2}-E_{i c e} h_{i c e}^{2}}{E_{A l} h_{A l}+E_{i c e} h_{i c e}}
\end{gathered}
$$

The ice thickness not only affects the resonant frequency of the various modes, 
but it also has an effect on the stress carried by the piezoceramic and voltage required for delamination. As the ice thickness increases, the voltage required for delamination also increases and so does the required power. However, increasing the ice thickness decreases the amount of stress in the piezoceramic. A balance is required for achieving a minimum voltage and a stress that is not going to cause the piezoceramic to break. Table 6 compares the power requirements for an ice thickness of $2 \mathrm{~mm}, 5 \mathrm{~mm}$ and the optimal ice thickness [46] to deice $50 \%$ of the plate based on the fifth flexural mode. A standard quality factor of 100 and assumed ice adhesion strength of $1 \mathrm{MPa}$ were used for this comparison.

Table 6: Comparing the affects of ice thickness

\begin{tabular}{|c|c|c|c|c|}
\hline $\begin{array}{c}\text { Ice } \\
\text { (Thickness) } \\
(\mathbf{m m})\end{array}$ & $\begin{array}{c}\text { Resonance } \\
\text { Frequency (Hz) } \\
\mathbf{( H z )}\end{array}$ & $\begin{array}{c}\text { Stress in } \\
\text { Piezoceramic } \\
\mathbf{( M P a )}\end{array}$ & $\begin{array}{c}\text { Voltage } \\
\text { Required for } \\
\text { Delamination (V) }\end{array}$ & $\begin{array}{c}\text { Power } \\
\text { Required for } \\
\text { Delamination (W) }\end{array}$ \\
\hline 2.0 & 4790 & 44.68 & 80.90 & 12.09 \\
\hline 4.41 & 8004 & 30.18 & 114.0 & 21.97 \\
\hline 5.0 & 8771 & 28.34 & 121.7 & 24.63 \\
\hline
\end{tabular}

The thickness of ice that maximizes the out-of-plane shear stress at the icealuminum interface can be calculated for a substrate using its thickness and Young's modulus as per Equation (6) [46]:

$$
h_{i c e}=h_{A l} \sqrt{\frac{E_{A l}}{E_{i c e}}}
$$

Thus for aluminum, the optimal ice thickness is $4.41 \mathrm{~mm}$ for a $1.6 \mathrm{~mm}$ thick aluminum plate. From Table 6, the thinner the sheet of ice, the less voltage and power is required for de-icing. As the power supply is limited to $100 \mathrm{~V}$ in the present lab setup, de-icing of $2 \mathrm{~mm}$ thick ice was experimented. However, this mode with an ice thickness of $2 \mathrm{~mm}$ is undesirable as the stress in the piezoceramic 
is above the $20 \mathrm{MPa}$ design criteria.

\subsubsection{Ice Adhesion Strength}

The force required to separate an ice sheet from the plate also has a significant role in determining the power required to cause delamination. The properties of the surface can be modified by adding an icephobic coating which would lower the ice adhesion strength. The adhesion reduction factor (ARF) is used to compare the shear strength of a coated surface to the bare aluminum surface as shown in Equation 7

$$
A R F=\frac{\tau_{A l}}{\tau_{s}}
$$

In an analytical model developed by Budinger et al. [46], it was shown that the power decreases as the square of the ARF. Coatings with higher ARF are preferred as they have a significant effect on decreasing the power required for delamination. Validating the analytical model with the numerical result showed that both the voltage and current decrease linearly with the ice adhesion strength. Presented in Table 7 are the power required for delaminating ice under the fifth flexural mode (as shown in Figure 34) for $2 \mathrm{~mm}$ and $5 \mathrm{~mm}$ ice sheets with different ice adhesion strengths.

As shown in Table 7, a decrease in the ice adhesion strength by a factor of two causes a decrease in the required power by a factor of four since both the voltage and current decrease by a factor of two. Due to the squared relationship between power and ice adhesion strength, using an icephobic coating on the surface of the aircraft can result in a significant decrease in the amount of power required to remove the accumulated ice. 
Table 7: Comparing the affects of ice adhesion strength

\begin{tabular}{|c|c|c|c|c|c|}
\hline $\begin{array}{c}\text { Ice } \\
\text { Thickness } \\
(\mathbf{m m})\end{array}$ & $\begin{array}{c}\text { Ice Adhesion } \\
\text { Strength } \\
\mathbf{( k P a )}\end{array}$ & $\begin{array}{c}\text { Resonance } \\
\text { Frequency } \\
\mathbf{( H z )}\end{array}$ & $\begin{array}{c}\text { Stress in } \\
\text { Piezoceramic } \\
\mathbf{( M P a )}\end{array}$ & $\begin{array}{c}\text { Voltage } \\
\text { Required for } \\
\text { Delamination (V) }\end{array}$ & $\begin{array}{c}\text { Power } \\
\text { Required for } \\
\text { Delamination (W) }\end{array}$ \\
\hline 2.0 & 1000 & 4790 & 44.68 & 80.90 & 12.09 \\
\hline 2.0 & 500 & 4790 & 22.34 & 40.45 & 3.023 \\
\hline 2.0 & 100 & 4790 & 4.468 & 8.090 & 0.1209 \\
\hline 5.0 & 1000 & 8771 & 28.34 & 121.7 & 24.63 \\
\hline 5.0 & 500 & 8771 & 14.17 & 60.86 & 6.156 \\
\hline 5.0 & 100 & 8771 & 2.834 & 12.17 & 0.2463 \\
\hline
\end{tabular}

\subsubsection{Aspect Ratio}

The aspect ratio (AR) is defined as the length to width ratio of the specimen. Four different ARs were studied and the dimensions of each plate and the piezoceramic patch glued on the back of the plate are listed below in Table 8

Table 8: Size of the plates modelled

\begin{tabular}{|c|c|c|c|}
\hline Plate & AR & Plate Dimensions (mm) & Piezoceramic Dimensions (mm) \\
\hline 1 & $6: 1$ & $154 \times 25.4 \times 1.6$ & $25.4 \times 25.0 \times 0.5$ \\
\hline 2 & $3: 1$ & $154 \times 50.8 \times 1.6$ & $25.4 \times 50.0 \times 0.5$ \\
\hline 3 & $2: 1$ & $154 \times 76.2 \times 1.6$ & $25.4 \times 75.0 \times 0.5$ \\
\hline 4 & $1: 1$ & $154 \times 152.5 \times 1.6$ & $25.4 \times 150.0 \times 0.5$ \\
\hline
\end{tabular}

By changing the AR of the plate, there is a minimal change in the resonant frequency of flexural modes. This is due to the ratio of stiffness to mass remaining constant. For the same resonance mode at the same ice thickness, the tensile stress within the piezoceramic and the voltage remain approximately the same while the current and power increases linearly with delamination area. This means that 
the same power density is required to de-ice a larger plate using the same resonance mode. The stress, voltage and power are listed in Table 9 for the four AR ratio plates. Two different flexural resonance modes ( 2 and 5 nodes) as shown in Figure 37 are considered. An ice thickness of $2 \mathrm{~mm}$, quality factor of 100 and ice adhesion strength of $1 \mathrm{MPa}$ are used in the comparison.

Table 9: Comparing the affects of plate and actuator size

\begin{tabular}{|c|c|c|c|c|}
\hline $\begin{array}{c}\text { Aspect } \\
\text { Ratio }\end{array}$ & $\begin{array}{c}\text { Resonance } \\
\text { Frequency } \\
\mathbf{( H z )}\end{array}$ & $\begin{array}{c}\text { Stress in } \\
\text { Piezoceramic } \\
\mathbf{( M P a )}\end{array}$ & $\begin{array}{c}\text { Voltage } \\
\text { Required for } \\
\text { Delamination (V) }\end{array}$ & $\begin{array}{c}\text { Power } \\
\text { Required for } \\
\text { Delamination (W) }\end{array}$ \\
\hline $6: 1$ & 574 & 102.1 & 197.4 & 3.659 \\
\hline $3: 1$ & 576 & 107.5 & 202.4 & 7.863 \\
\hline $2: 1$ & 576 & 108.3 & 204.8 & 12.12 \\
\hline $1: 1$ & 658 & 110.5 & 3619 & 24.63 \\
\hline $6: 1$ & 4790 & 37.03 & 98.37 & 5.658 \\
\hline $3: 1$ & 4790 & 44.68 & 80.90 & 12.09 \\
\hline $2: 1$ & 5073 & 49.16 & 79.74 & 15.26 \\
\hline $1: 1$ & 4948 & 53.24 & 88.78 & 35.61 \\
\hline
\end{tabular}

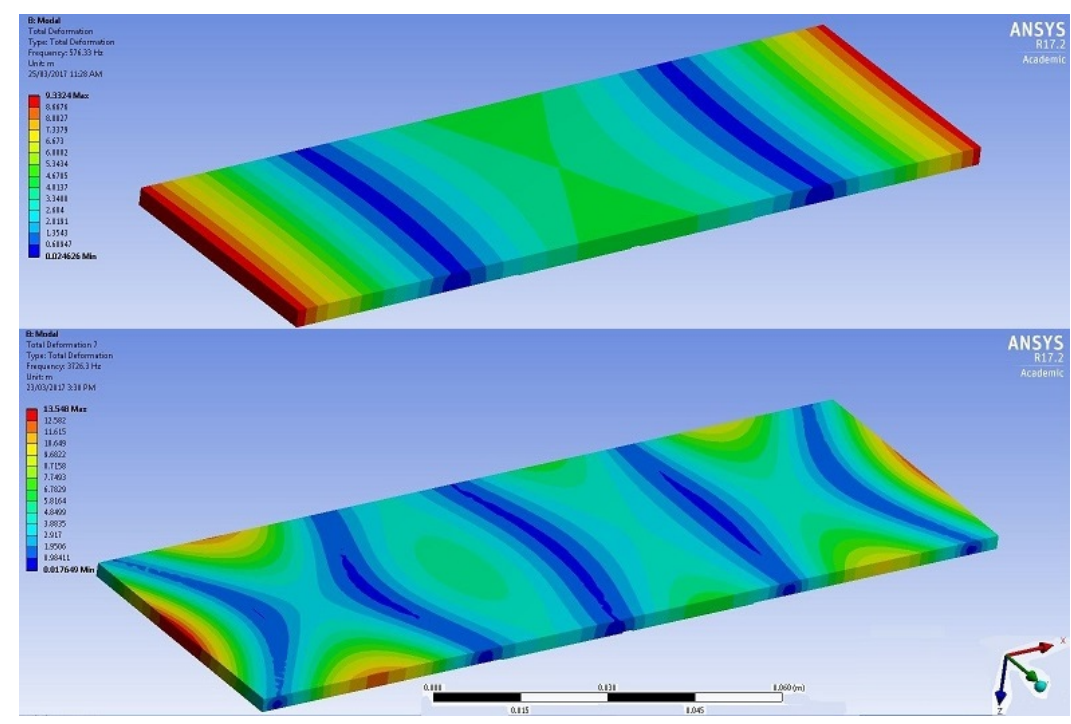

Figure 37: Resonance mode shapes for the two node and five node flexural mode. 


\subsection{Test Points}

The majority of modes in which de-icing is possible exhibit a deformation pattern as shown in Figure 38. From the numerical model, these modes require voltages below $100 \mathrm{~V}$ to delaminate $50 \%$ of the ice sheet. In this pattern, the nodes (areas of minimal displacement) are represented by the blue colour and the displacement is the highest in areas where the colour is red. The pattern shows a two component lattice structure where an anti-node (area of relatively high displacement) is surrounded by four nodes.

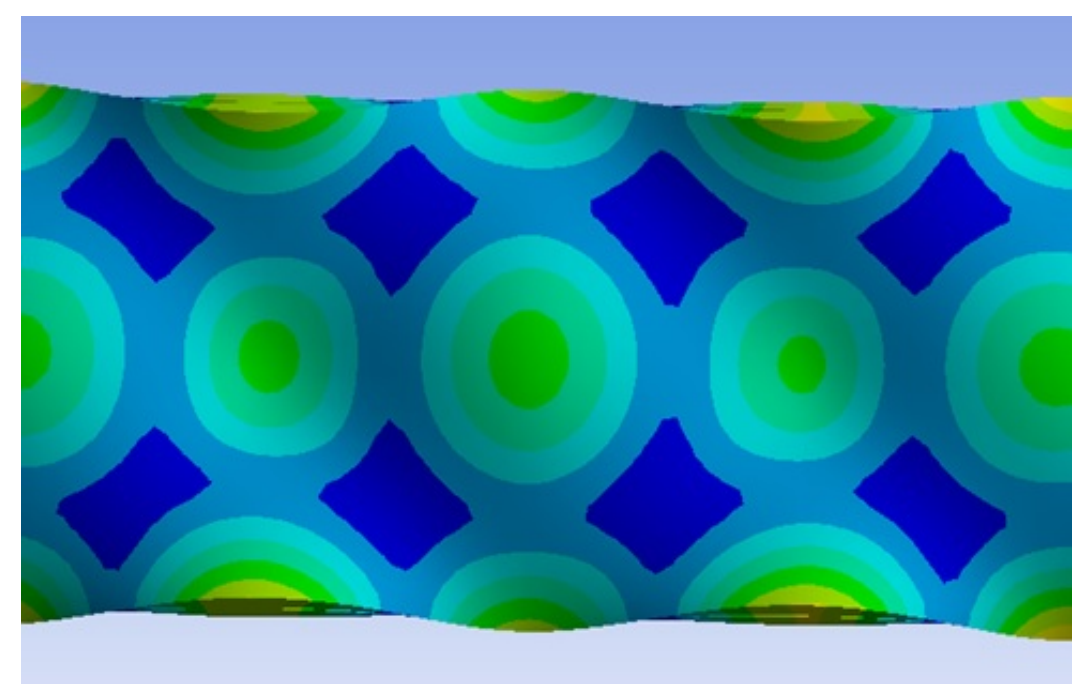

Figure 38: Typical deformation pattern observed for modes requiring low voltages for delamination.

From the numerical model, a set of data points can be compiled and tested to verify that ice delamination is possible. Only the 3:1 AR plate was tested experimentally. Two different ice thicknesses were used to validate the numerical model in which a thinner ice sheet requires less voltage to delaminate. A bare aluminum plate and a plate coated with silicone R-1009 were tested to confirm that the icephobic coating requires less power to be used in the delamination process.

Presented in Table 10 is a list of possible resonance modes that the numerical 
model predicts delamination will occur. These modes are shown visually in Figure 39 for an ice thickness of $2 \mathrm{~mm}$ and Figure 40 for a $5 \mathrm{~mm}$ thick sheet of ice.

Table 10: Resonance modes predicted by the numerical model where delamination may occur

\begin{tabular}{|c|c|c|c|c|c|}
\hline $\begin{array}{c}\text { Ice } \\
\text { Thickness } \\
(\mathbf{m m})\end{array}$ & $\begin{array}{c}\text { Mode } \\
\text { Number }\end{array}$ & $\begin{array}{c}\text { Resonance } \\
\text { Frequency } \\
\mathbf{( H z )}\end{array}$ & $\begin{array}{c}\text { Stress in } \\
\text { Piezoceramic } \\
\mathbf{( M P a )}\end{array}$ & $\begin{array}{c}\text { Voltage } \\
\text { Required for } \\
\text { Delamination (V) }\end{array}$ & $\begin{array}{c}\text { Power } \\
\text { Required for } \\
\text { Delamination (W) }\end{array}$ \\
\hline 2.0 & 49 & 28009 & 15.99 & 201.7 & 12.40 \\
\hline 2.0 & 55 & 31530 & 17.74 & 138.4 & 12.42 \\
\hline 2.0 & 66 & 37250 & 13.50 & 173.9 & 12.49 \\
\hline 2.0 & 80 & 43341 & 17.52 & 245.0 & 11.91 \\
\hline 2.0 & 88 & 45866 & 15.34 & 331.6 & 13.11 \\
\hline 2.0 & 90 & 47496 & 11.15 & 381.3 & 12.65 \\
\hline 5.0 & 55 & 40242 & 13.09 & 92.70 & 41.27 \\
\hline 5.0 & 57 & 41325 & 21.51 & 70.45 & 39.54 \\
\hline 5.0 & 58 & 41621 & 18.60 & 127.8 & 32.12 \\
\hline
\end{tabular}

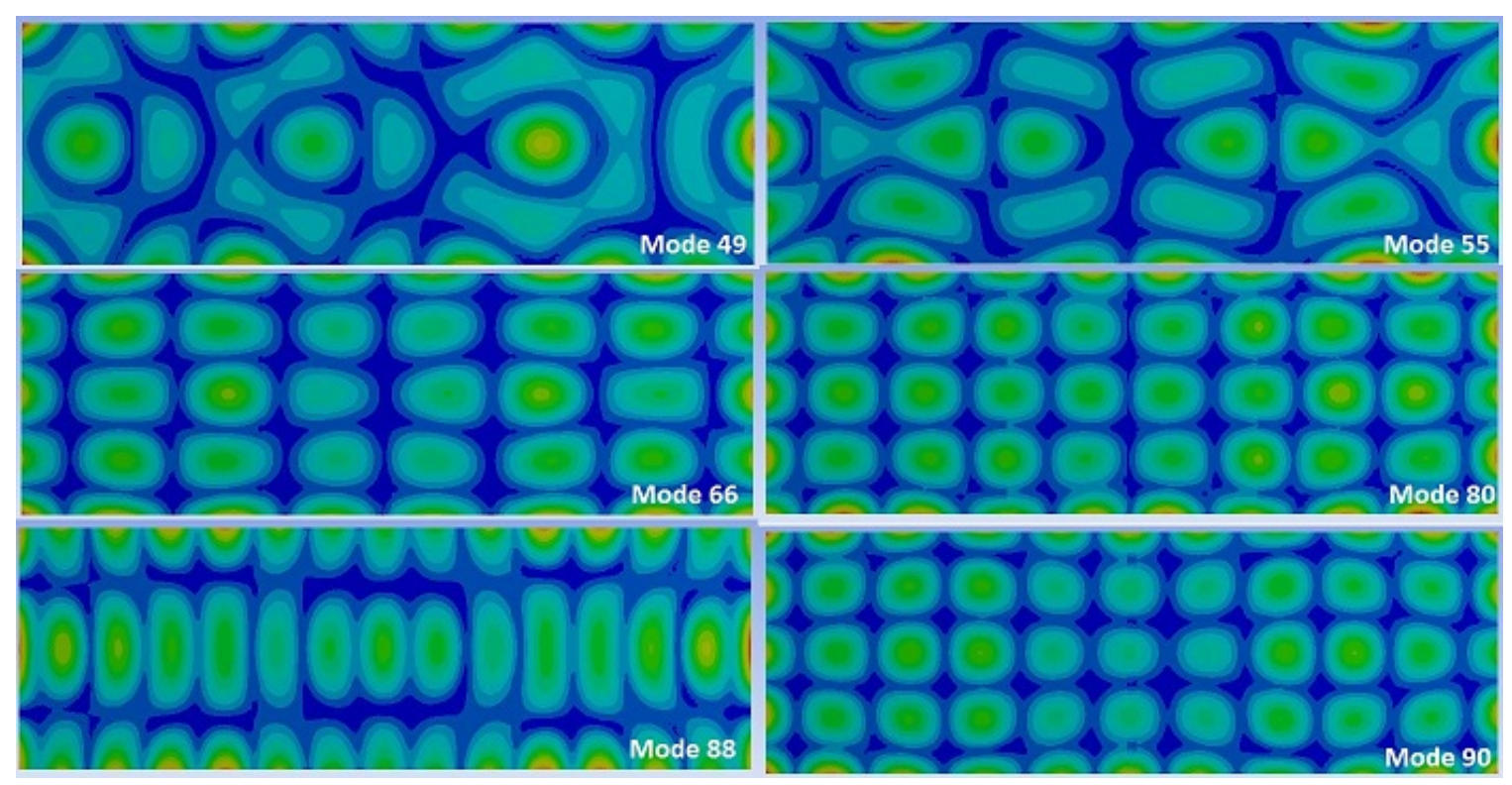

Figure 39: Possible resonance modes that will cause delamination of a $2 \mathrm{~mm}$ thick ice sheet. 


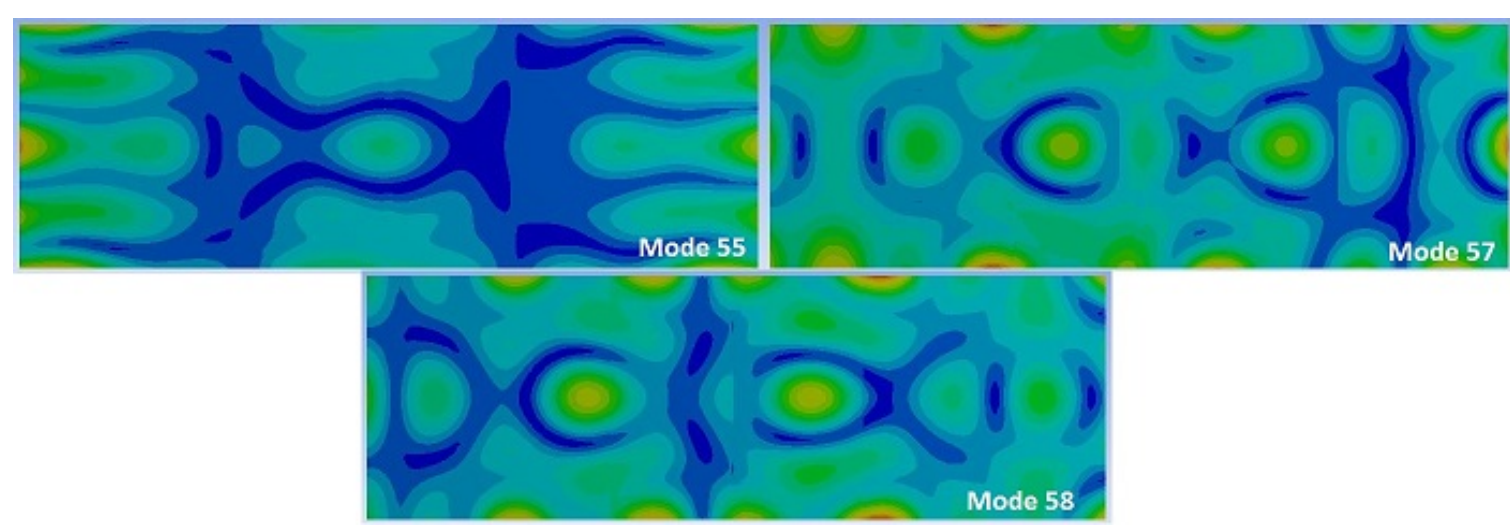

Figure 40: Possible resonance modes that will cause delamination of a $5 \mathrm{~mm}$ thick ice sheet.

Most of the resonance modes investigated occur in the $40 \mathrm{kHz}$ range. At these frequencies, there exists more nodes and anti-nodes that delaminate the ice in various areas of the plate. The continuity of the bond between the ice and substrate decreases as the number of nodes and anti-nodes increases. To validate this model a future experiment shall be created to see if delamination is possible at these resonance frequencies. 


\section{Chapter 5}

\section{Experimental Results and Discussion}

To determine the most appropriate coating for the hybrid de-icing system, experiments were conducted to determine the ice adhesion strength of the selected coatings to verify the results from previous researchers. Additionally, testing was done to determine the wear loss and assess the durability of a coating in service to justify its selection.

To validate the results from the numerical model presented in Chapter 4 , the ice adhesion strength of the coating is required as an input. Experimental work can then be carried out to determine the resonance frequency, applied voltage and power required to cause ice sheets to delaminate.

\subsection{Wear Testing of Polymer Coatings}

A pin-on-disk wear test was carried out to evaluate a coating's resistance to wear. The test was performed under the dry sliding condition, according to ASTM: 99 05 (2010), using a wear tester (model No: NEO-TRIBO MPW110 by NEOPLUS) shown in Figure 41. This apparatus uses a rotating pin pressed under a normal force of $2.45 \mathrm{~N}$ against a static coating sample. The pin used was a Teflon ball having a radius of $2.5 \mathrm{~mm}$. During the test, the specimen was placed horizontally with 


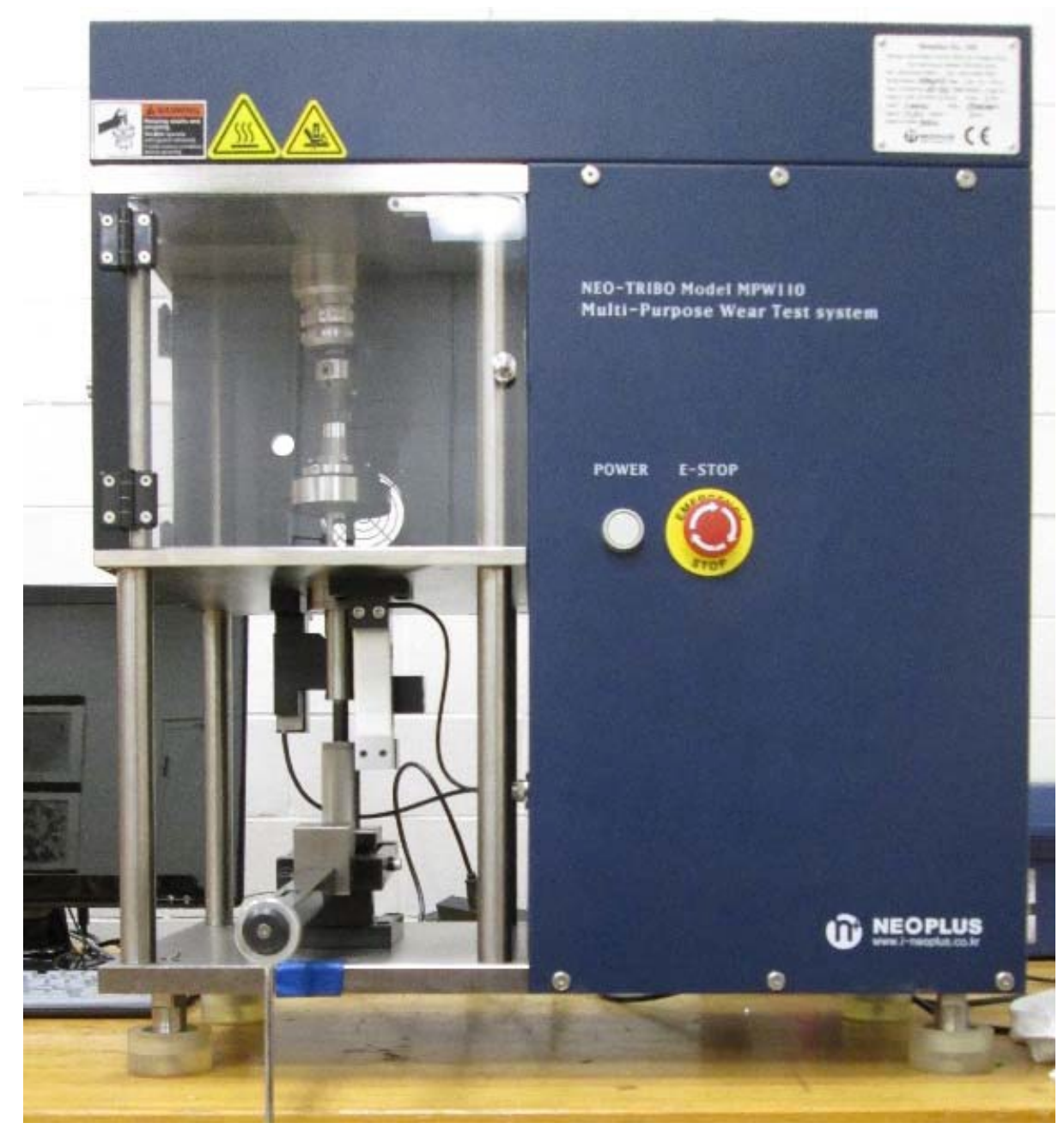

Figure 41: Wear testing apparatus used for determining wear loss.

its centre at a distance of $5 \mathrm{~mm}$ away from the vertical axis of the pin shaft. The pin (ball) was spinning at a constant speed of 50 RPM. As the result of friction, a $10 \mathrm{~mm}$ diameter circular wear track was generated on the specimen surface. Wear loss of the coating material was measured from the change in vertical position of the ball. A new Teflon ball was used for each test to remove the effect of Teflon ball wearing and to eliminate cross contamination between samples. After the wear testing, an SEM was used to assess the damage to the coatings.

The amount of wear was dependent on the type of coating and the duration of 
the test. Each coating was tested for durations of 1, 2, 4 and 8 minutes. A graph showing the wear loss, in terms of wear depth tracked by the vertical location of the pin of the four coatings plotted against the number of cycles can be found in Figure 42 . The silicone R-2180 has the highest wear rate of all the tested coatings, approximately two times that of R-1009. ALG had the highest resistance to wear.

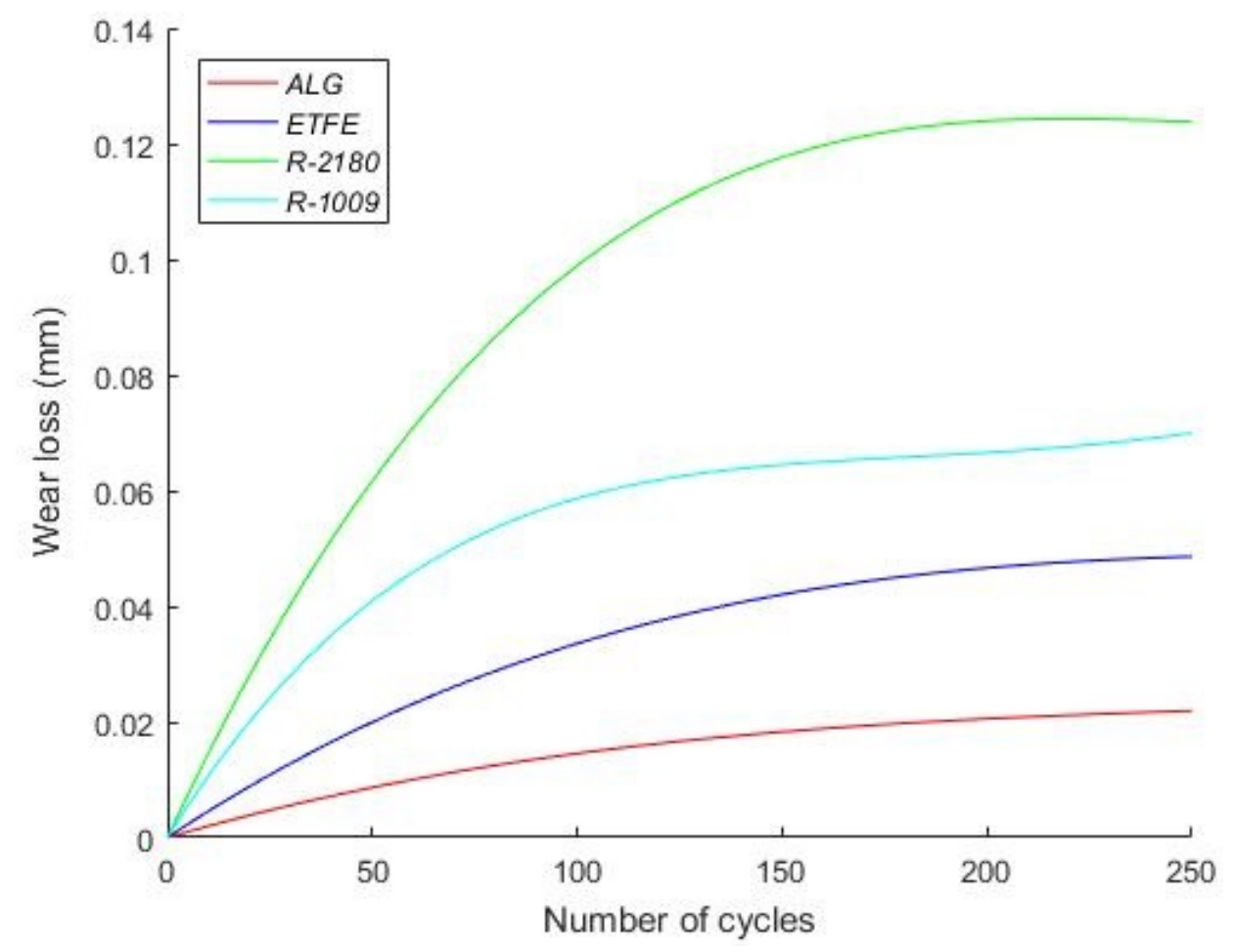

Figure 42: Wear loss for the ALG (red), ETFE (blue), silicone R-2180 (green) and silicone R-1009 (cyan) samples.

As the test duration increased, the wear rate of each coating decreased. This can be expected as the longer the test lasts, the Teflon ball comes into contact with more coating surface area and a larger force is required to displace the coating. ALG coating, being a primarily $\mathrm{SiO}_{2}$ based, was the most resistive to wear. The silicone R-2180 is an elastomer-based coating and is fairly soft so the ball could easily displace the coating along the wear track. There was also a net mass increase 
in each sample due to the deposition of Teflon flakes from the pin onto the sample. As the surface of the pin was in contact with the coating, flakes wore off from the tip and were left along the wear track. Figure 43 shows the flakes that were deposited into R-2180 coating that was tested for 4 minutes. This further confirms the importance of using a new ball for each test.

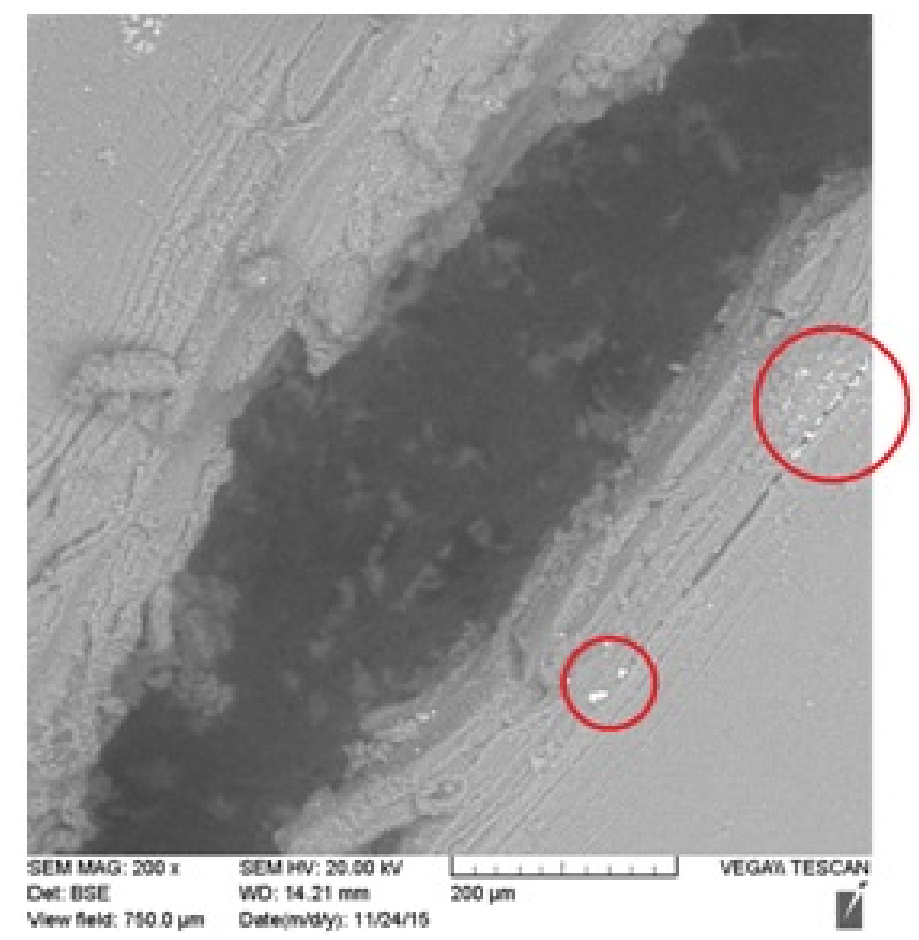

Figure 43: Teflon flakes were deposited into the wear track.

Figure 44 shows the wear track profile for the tested coatings. The top images show the full wear track under 20 times magnification and the lower images display the width of the track under 100 times magnification. The R-2180 coated sample suffered the most degradation after the 8 minute of wear test. As can be seen from Figure 44, the coating completely deteriorated and the base metal was exposed based on the contrast of the SEM images (where heavier elements such as metals give high brightness under secondary electron image mode). An attempt to measure the profile of the track was unsuccessful due to the tip of the profilometer 


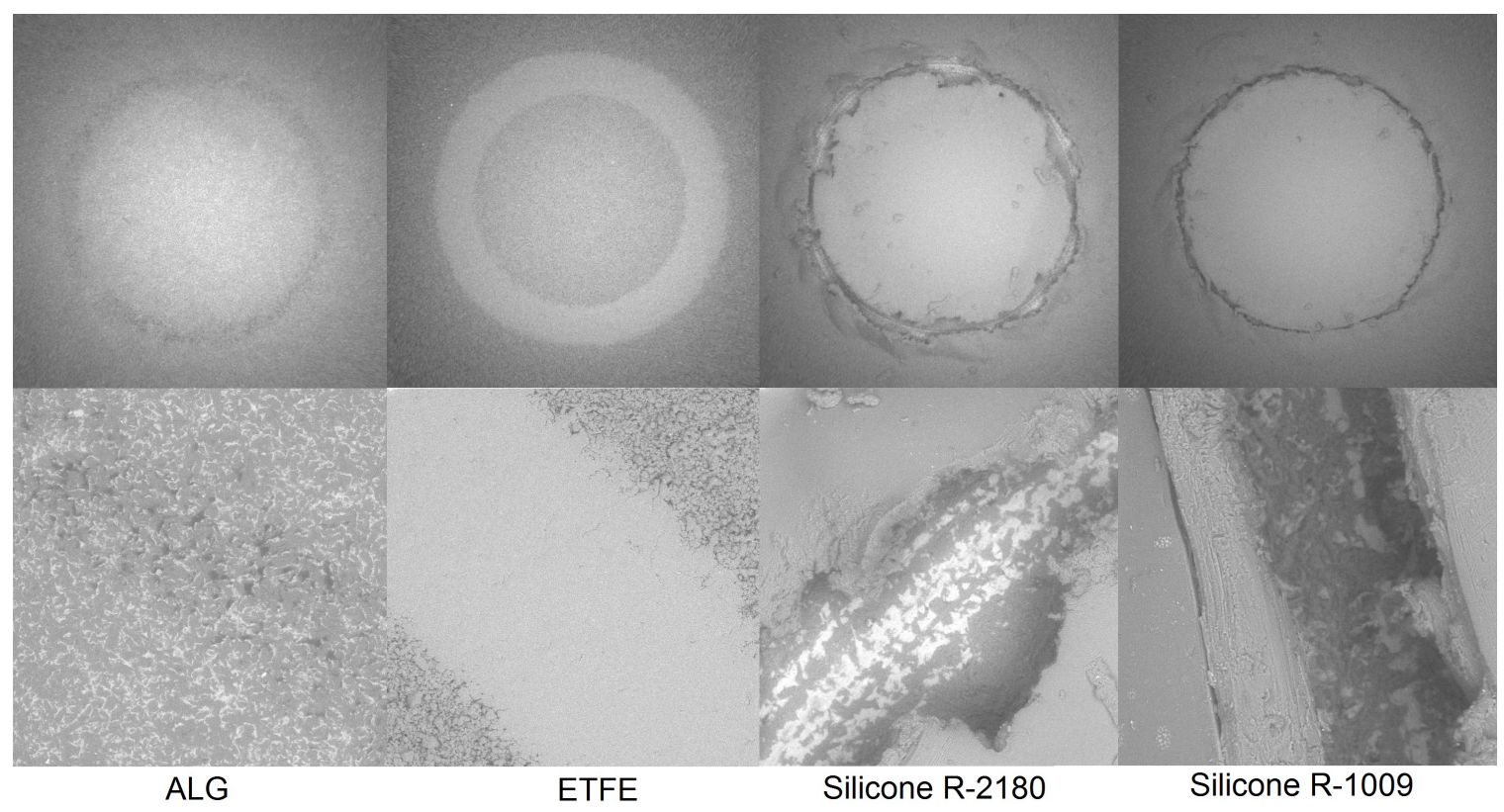

Figure 44: Wear tests for ALG (left), ETFE (second from left), silicone R-2180 (third from left) and silicone R-1009 (right).

indenting into the coating.

Unlike the silicone R-2180, the ALG coating is very resistant to wear. Figure 44 shows the wear track of an ALG sample after 8 minutes of wear test under the SEM and there is little indication that wear was present on the sample. To the human eye, the wear track was not detectable. The SEM analysis revealed that there was indeed a wear track however the width of the track was about $0.5 \mathrm{~mm}$. A further investigation was conducted using a profilometer to record the profile of the track. No usable results were obtained as the noise in the equipment was too high in relation to the generated signal. This means that the depth of the track cannot be precisely measured as the surface roughness falls into the same scale as that of wear tracks.

Figure 44 also showed that the ETFE coating remained in place (not being displaced to the sides); however, the coating became denser under the applied load. Due the porous nature of the ETFE coating, it is possible to increase the coating 
density after spraying using a peening process. This may in turn increase the hydrophobic and icephobic properties of ETFE coating.

Further analysis was carried out to determine the volumetric wear loss of the ETFE coatings. Using a profilometer, the profile of the wear track was measured. The profile for the sample wear tested for 2 minutes can be seen as the red line in Figure 45. Also shown in Figure 45 is the outline of the Teflon pin tip (black) that was used for the test. Both the surface profile of the wear track and the outline of the ball correspond to a circular shape, showing that the profile can be approximated by the depth of the ball during the test.

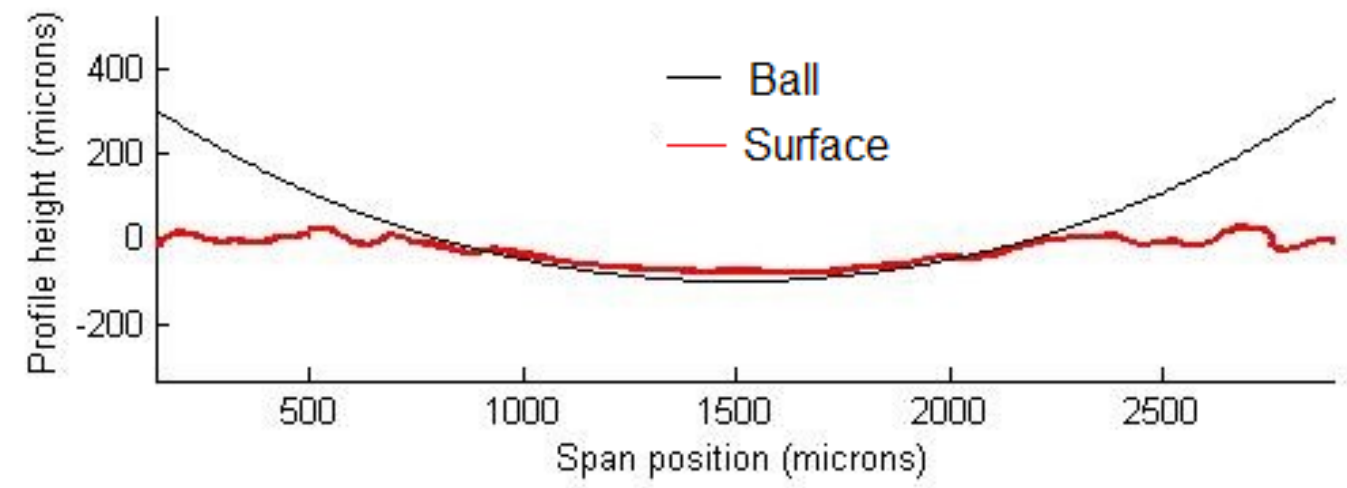

Figure 45: Wear track profile for the ETFE sample that was wear tested for 2 minutes.

The volumetric wear loss was plotted against the number of cycles in order to verify the trends obtained from the tribometer. The plot can be found in Figure 46 . The measured volumes for the samples that underwent the 1,2, 4 and 8 minute wear tests are indicated on the graph with red circle. The trend follows that of a square root function, similar to the wear loss curves. Due to the resemblance in the two sets of data, either volumetric wear loss measured using a profilometer or the wear loss under load measurement can be used to assess the extent of wear. 


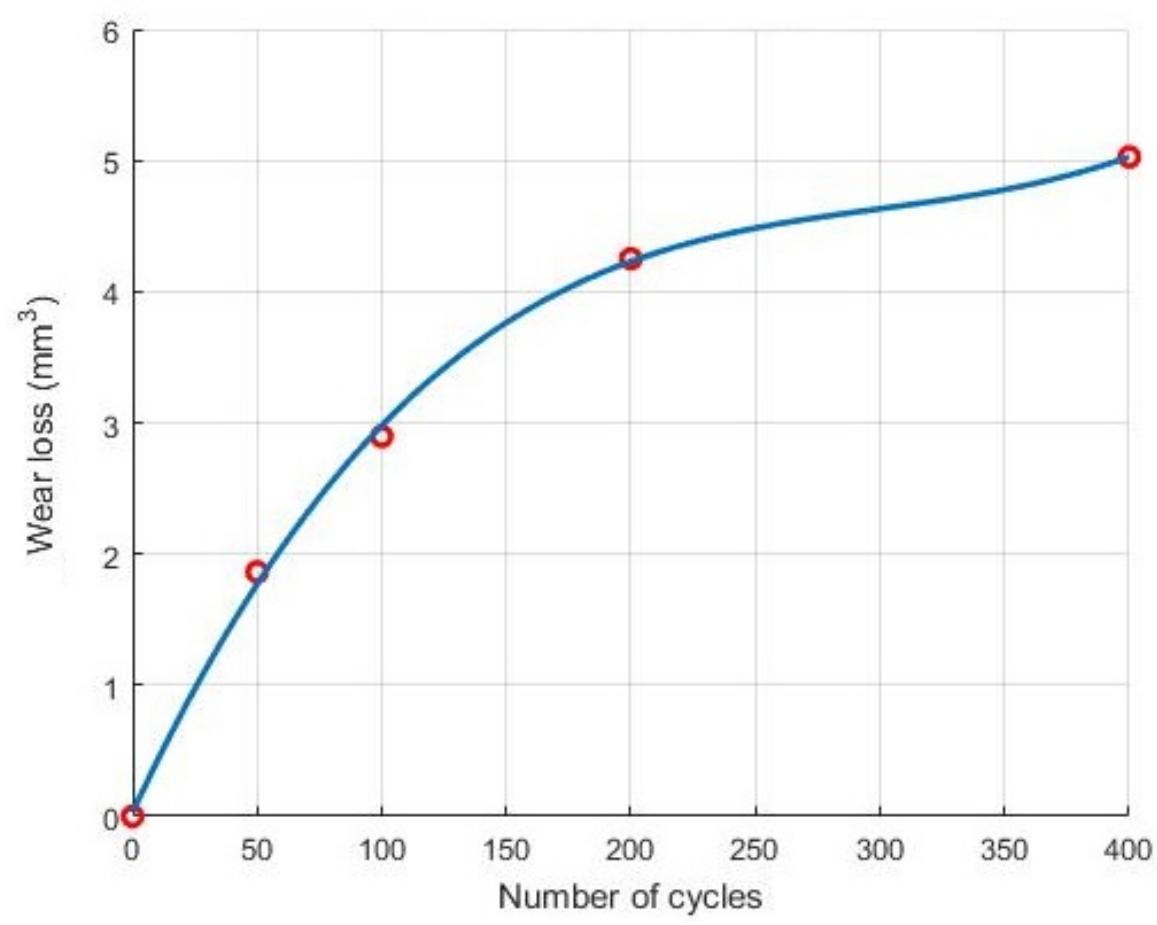

Figure 46: Volumetric wear loss for the ETFE samples.

\subsection{Single Shear Ice Adhesion Test}

A single shear ice adhesion test was used to determine the adhesion strength of ice to various coated and uncoated surfaces. The test involved the creation of a lap joint using two plates with a layer of ice in-between. Using a Material Testing System (MTS), the force required to break the lap joint was measured. From the measured force, the shear stress at which the bond between the ice and the surface can be found.

\subsubsection{Test Setup}

A freezing jig was manufactured to hold the coupons in place during the freezing process. The jig was designed such that the gap clearance between the top and 
bottom coupons remains constant at $0.039^{\prime \prime}(1 \mathrm{~mm})$. The jig shown in Figure 47 measures $15^{\prime \prime}$ long by 5 " wide and $0.5^{\prime \prime}$ thick and uses slots milled to a depth of 0.02 " to keep the coupons aligned and can hold six test specimens at once (a total of 12 coupons) using the toggle clamps. The samples measured 3" by 1 " and the joint had 1 sq. in. of overlap between the two samples. A layer of parafilm was placed on top of the jig to prevent the coupons from sticking to the surface of the jig during the freezing process. Using a $1 \mathrm{~mL}$ syringe, $0.6 \mathrm{~mL}$ of deionized water was then injected into the hole in the lap shear joint and the jig was placed in a freezer for 24 hours. This was done to ensure a complete transition of water to ice between the two coated surfaces. After 24 hours, each specimen was removed and inspected to ensure complete formation of ice between the two surfaces.

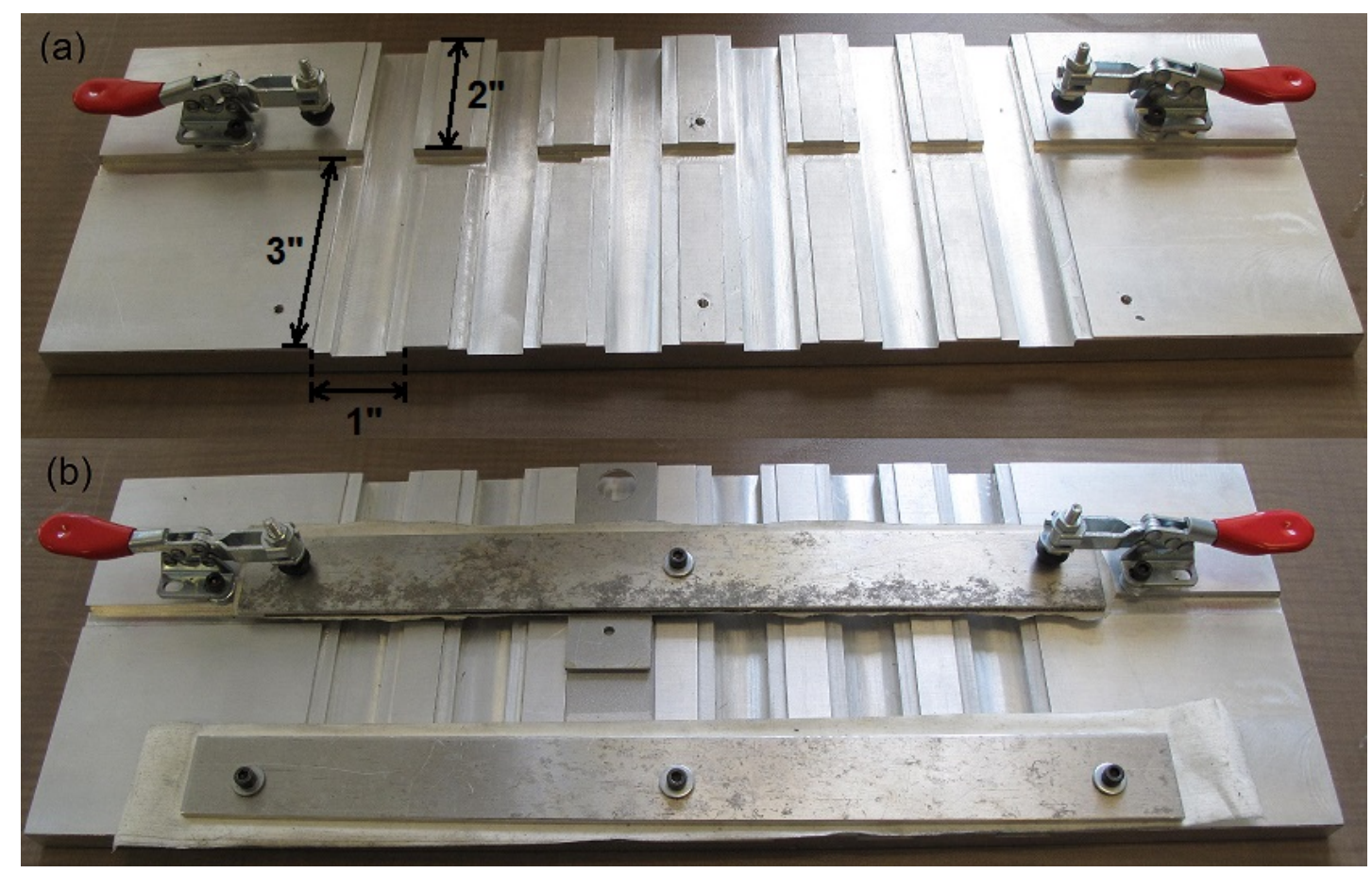

Figure 47: (a) As fabricated jig used to align lap shear samples during freezing and (b) jig with one lap shear sample.

Ice adhesion testing was carried out using a $100 \mathrm{kN}$ MTS to measure the load required to break the lap joint. The frozen specimen was placed inside an insulated 
chamber and gripped by the MTS. The chamber was instrumented with a thermocouple and a constant temperature of $-20^{\circ} \mathrm{C}$ was maintained for the duration of the test. The test setup is shown in Figure 48(a) while the inside of the chamber is shown in Figure 48(b). An axial displacement rate of $1 \mathrm{~mm} / \mathrm{min}$ was used to pull the joint apart. The maximum load was then recorded for each sample.

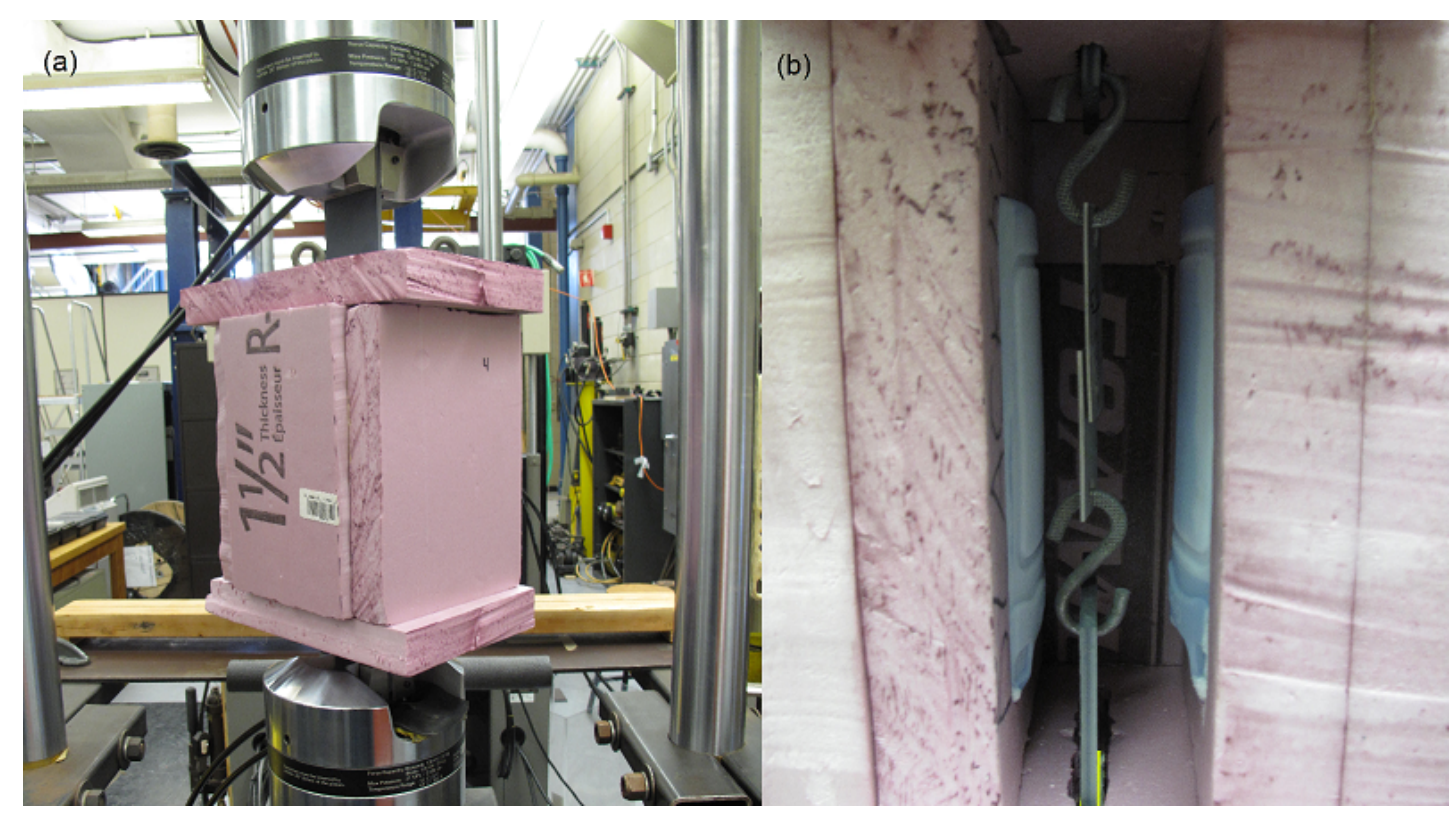

Figure 48: a) Insulated chamber shown in the MTS and (b) cross-section of the insulated chamber with a loaded sample.

\subsubsection{Adhesion Strength Results}

All samples exhibited adhesive failure and the results are presented in Table 11 The sandblasted aluminum samples were used as a baseline reference and required approximately $447 \mathrm{kPa}$ to shear the ice formation on $25 \mathrm{~mm}$ by $25 \mathrm{~mm}$ surface area. This indicates that the sandblasted coupons exhibited a stronger adhesion to ice than the other coatings tested in this study.

A total of six samples were tested for each type of coating. A large variation was observed in the results obtained from this study. However these variations in 
Table 11: Ice Adhesion Strength for Icephobic Surfaces using a Controlled Displacement

\begin{tabular}{|l|c|c|}
\hline Surface & Adhesion Strength (kPa) & ARF \\
\hline Sandblasted Al & $447 \pm 71$ & 1.00 \\
\hline ETFE & $357 \pm 72$ & 1.25 \\
\hline ALG & $151 \pm 69$ & 2.39 \\
\hline Silicone R-2180 & $187 \pm 26$ & 2.96 \\
\hline Silicone R-1009 & $23.8 \pm 9$ & 18.8 \\
\hline
\end{tabular}

adhesion strength for each coating group are similar and also comparable to those from previous tests conducted by other researchers. The ice adhesion strength of aluminum has been measured as low as $242 \mathrm{kPa}$ and sandblasted aluminum has been measured at $610 \mathrm{kPa}$ [16, 17]. In a similar experiment carried out using a lap joint shear test conducted by Dixon et al., the ice adhesion strength of the bare aluminum 2024 sample was $399.7 \mathrm{kPa}$ which closely resembles the $447 \mathrm{kPa}$ obtained in this work [77]. Although the results of this study do not closely match previous work, the ARF instead acts as a ranking tool for the tested coatings [18]. The silicone R-1009 had the highest ARF of 18.8, followed by ALG with 2.96, R-2180 (2.39) and ETFE (1.25). With its high ARF in comparison to the other coatings, the potential exists for silicone R-1009 to be used as a passive approach to ice accretion on aircraft structures. ALG and silicone R-2180 coatings can also be used, however, they will not be as effective.

There are several variables that could not be controlled during the testing and lead to variations in the results. Any deviation in terms of actual ice temperature would have an impact on the required shear force. Another variable is the clamping pressure used during freezing. While the position of the clamps was constant for freezing each sample, the pressure exerted on each sample could be different 
due to the effects of the surface tension exerted by the water. Since each surface is different in its surface tension, hydrophobic effects can vary significantly and cause a difference in the adhesion of ice to the sample.

All MTS testing was done at a constant temperature of $-20^{\circ} \mathrm{C}$. Using a constant force test, the temperature dependence of the ice adhesion strength can be investigated in a future study.

\subsection{Ice Adhesion Testing Using a Vertical-Axis Rotor}

The aim of this experiment is to measure the shear force required to cause ice delamination on different surfaces by varying the temperature. A frozen water droplet is placed on an icephobic surface and a constant rotational velocity is supplied by a DC motor. During the test, the temperature inside the freezer rises allowing for a shear force measurement to be taken as a function of the temperature. Based on the lap shear test results shown in Table 11, it was determined that three coatings will be further tested; silicone R-2180, R-1009 and ALG.

\subsubsection{Test Setup}

Shown in Figure 49 is the Vertical Axis Spin Testing Apparatus (VASTA). A brushless DC motor is used to spin a propeller at a desired speed, creating a centrifugal force that will cause a frozen water droplet to eject from the surface when the force exceeds the product of the ice adhesion strength and contact area. The motor is powered by a $12 \mathrm{~V}$ DC power supply connected to an electronic speed controller (ESC) that converts the DC power to three-phase power and controls the speed of motor using the input from the operator. 


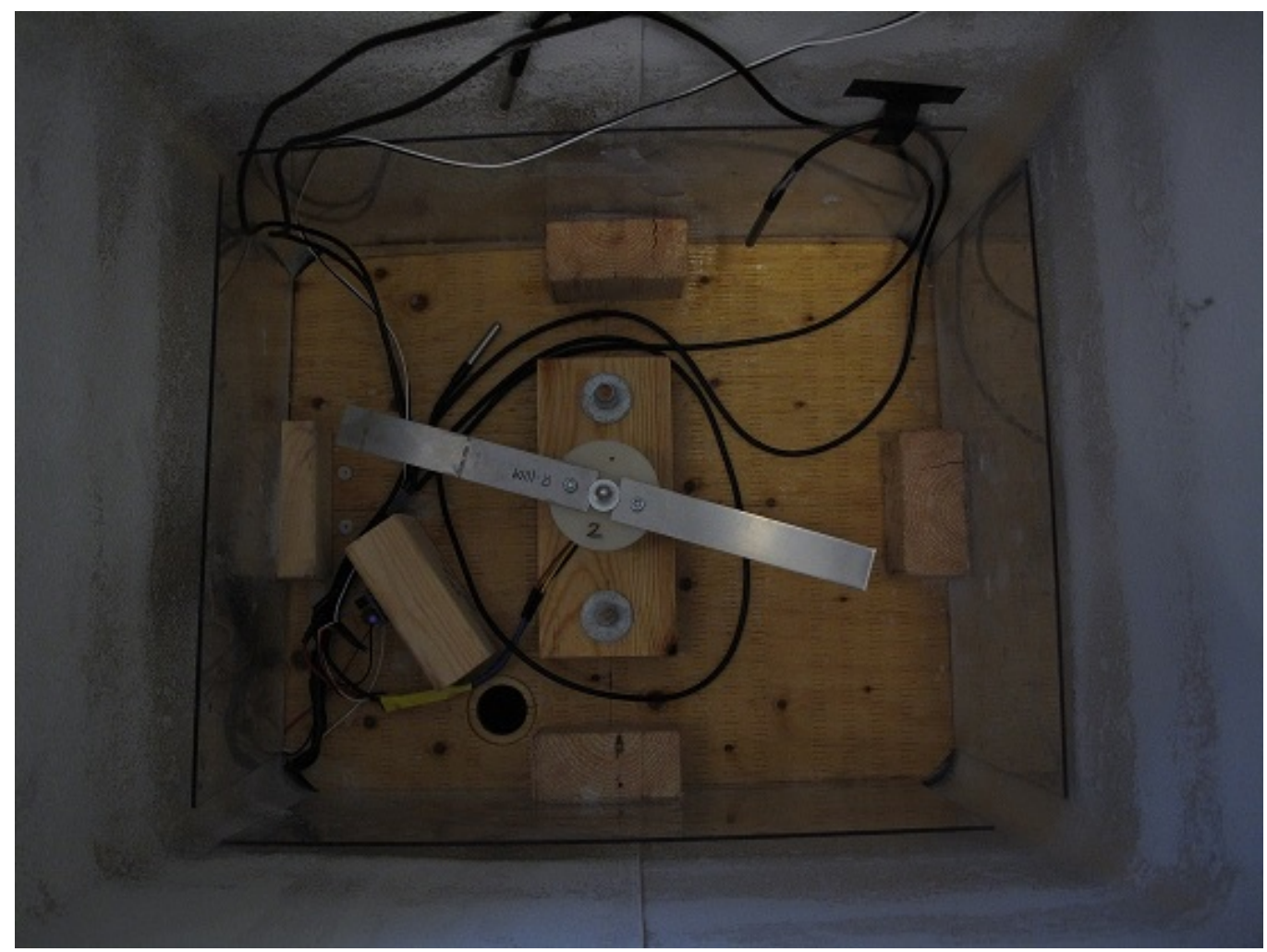

Figure 49: The Vertical Axis Spin Testing Apparatus.

\subsubsection{Measurement of Parameters}

There are several parameters required to compute the shear stress for a water droplet to be ejected from the surface. The shear stress can be calculated using Equation 8,

$$
\tau_{s}=\frac{m_{d} r_{d} \Omega^{2}}{A_{d}}
$$

where $\tau_{s}$ is the ice adhesion strength of the surface being tested, $m_{d}$ is the mass of the water droplet, $r_{d}$ is the distance between the droplet and the centre of rotation, $\Omega$ is the rotational speed and $A_{d}$ is the droplet contact area. The mass of the droplet is measured using a scale accurate to $\pm 0.1 \mathrm{mg}$ and the distance of the droplet to the centre of rotation is measured using a caliper. The angular velocity 
is measured using an infrared sensor and was verified using digital stroboscope. Finally, the contact area between the water droplet and the coated surface was calculated using an open source image processing software called Image] [78]. ImageJ can calculate the area of an object by defining a pixel scale within the image and translating that to a length scale using a reference within the image. The area of a polygon can then be calculated using defined points by the user. Figure 50 shows the calculation of the droplet area for a $0.05 \mathrm{~mL}$ droplet on an aluminum surface.

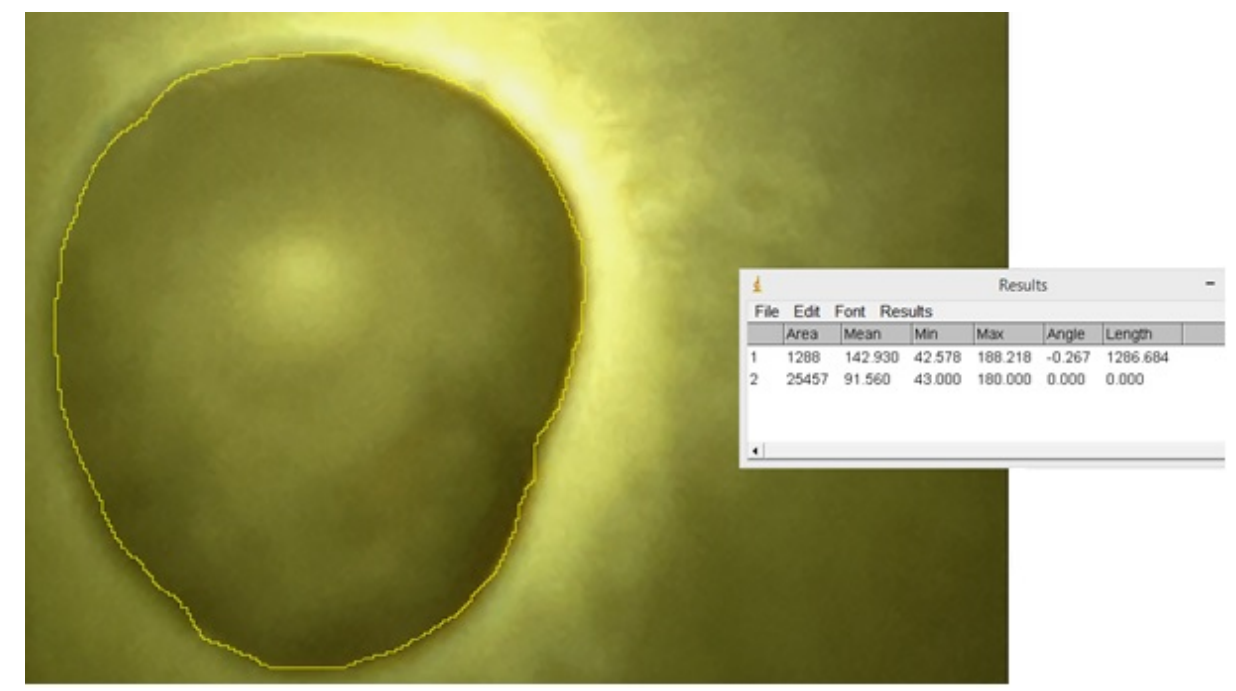

Figure 50: A spline is drawn around the droplet in order to determine its area.

Tarquini et al. showed that there is a relationship between the ice adhesion strength and the environment temperature [68]. Therefore, three temperature sensors were placed inside the freezer to monitor the rise in temperature during the test. One temperature probe is at the base of the platform, the second is positioned approximately $3 \mathrm{~cm}$ above the path of the rotor and the third was placed near the top of the freezer. The second temperature probe was used to estimate the surface temperature of the sample. Using Equation 8, a relationship between the calculated shear stress and the temperature can be established for different icephobic surfaces. 


\subsubsection{Accounting for Mass Loss}

Allowing time for the droplets to freeze introduces variations in mass loss due to evaporation and sublimation. It was observed over a two week period that water droplets of several sizes would decrease in both mass and contact area when left in a freezer. The contact area is a function of both the type of surface and dispensed volume which caused different mass loss rates for different droplet sizes. Since different coatings have different water contact angles, hence a different droplet shape, a calibration curve was created for each surface tested in this study to account for the mass lost due to sublimation.

Shown in Figure 51 is the average mass loss relative to the amount of dispensed water on each type of surface. A constant freezing time of 24 hours was used to determine the average amount of mass lost for each surface. The trend showed that regardless of surface type, larger droplets would lose more total mass than smaller droplets. This is due to the amount of surface area for the droplet. Having a larger surface area can be correlated to a faster sublimation rate. This can also be used to explain why coated surfaces, which have higher contact angles and smaller contact areas lose mass at a slower rate than the bare aluminum surface.

When normalized to the original mass of the droplet, larger droplets lose a smaller percentage of their original mass than smaller droplets. Again this correlates to the surface area increase as a function of the droplet size. Surface area increases at a slower rate than the dispensed volume showing that the smaller the droplet, the faster it will decrease in size.

In order to account for the mass loss due to sublimation, Equation 8 can be multiplied by a mass loss function taking into account the type of surface and dispensed volume of water. 


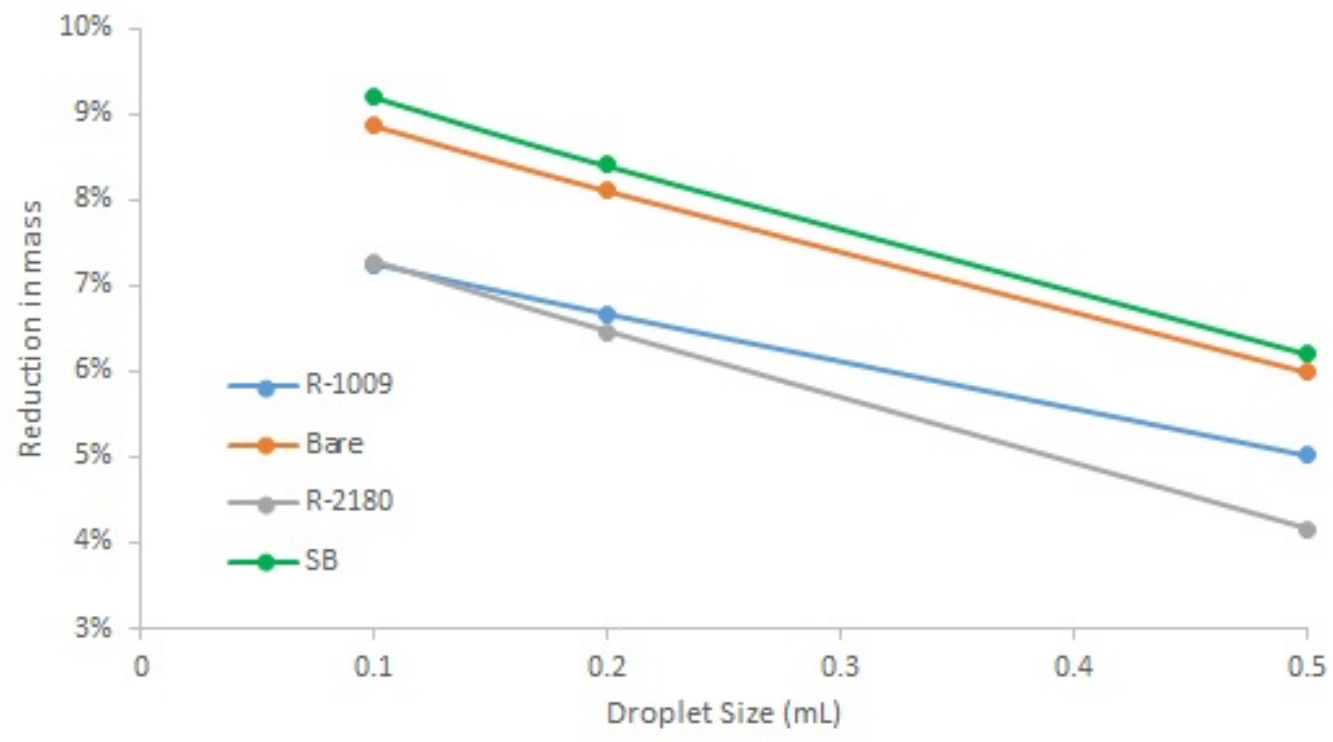

Figure 51: Relative mass loss due to sublimation as a function of droplet size (with $\mathrm{SB}$ representing the sandblasted surface).

\subsubsection{Ice Adhesion as a Function of Temperature}

Shear stresses were calculated for bare and sandblasted aluminum surfaces in addition to the R-2180 and R-1009 icephobic coatings. Presented in Figure 52 is the shear stresses required to remove frozen droplets (i.e., the adhesion strength between ice and substrate) as a function of temperature obtained using the Vertical Axis Spin Testing Apparatus. Contained in Table 12 is the average ice adhesion strength at $-2{ }^{\circ} \mathrm{C}$ and $-15{ }^{\circ} \mathrm{C}$ for each surface.

There are several observations that can be made from Table 12. First is the temperature range in which the droplet is ejected. Ice droplets on both the bare and sandblasted aluminum surfaces can only be ejected at temperatures just below 0 ${ }^{\circ} \mathrm{C}$ as there is a limiting factor in the amount of shear stress (determined primarily by rotational speed) that the motor can produce. Droplets on coated surfaces can be ejected at temperatures below $-20^{\circ} \mathrm{C}$. 


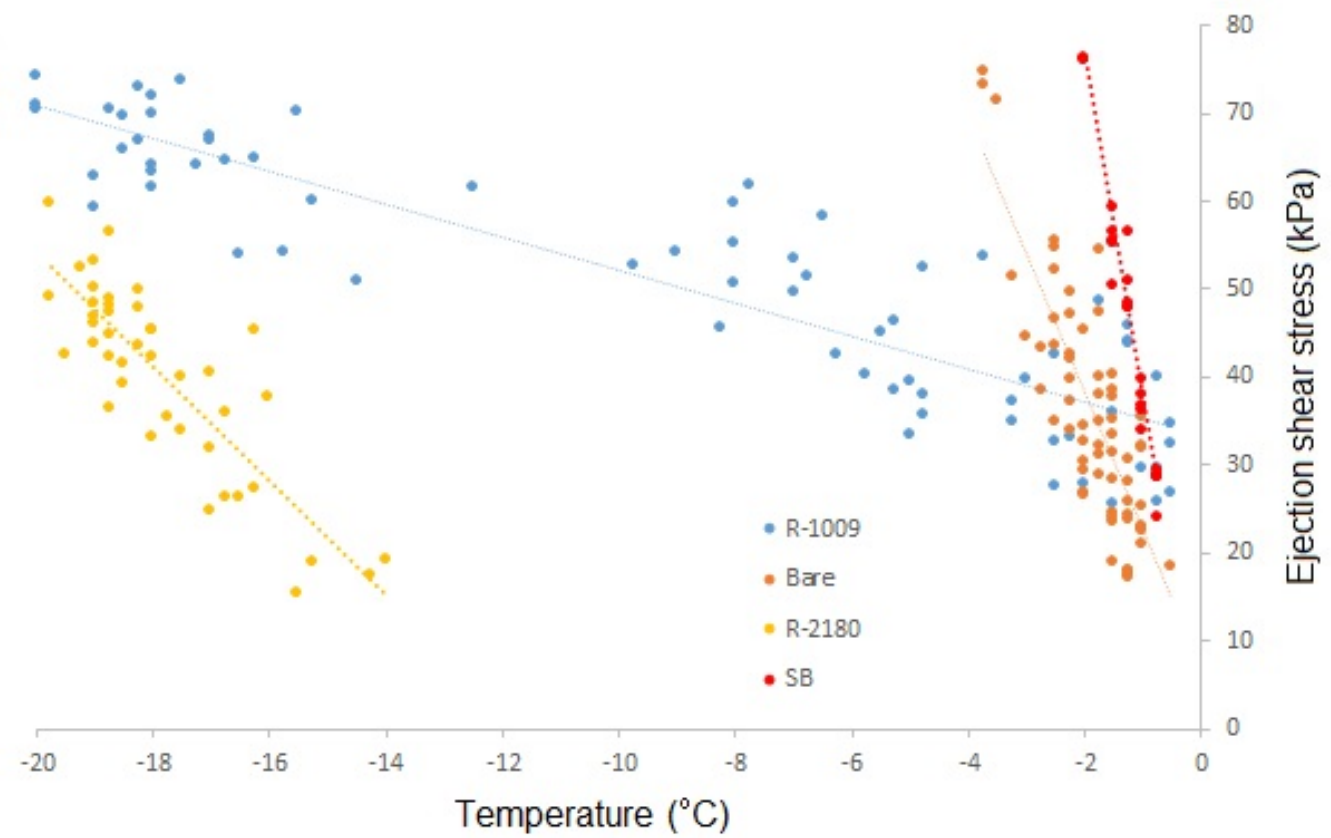

Figure 52: Shear stress required to eject a droplet as a function of temperature and surface.

Table 12: Ejection shear stresses for different surfaces and temperatures

\begin{tabular}{|l|c|c|c|}
\hline Surface & $\begin{array}{c}\text { Ejection } \\
\text { Temperature }\left({ }^{\circ} \mathbf{C}\right)\end{array}$ & $\begin{array}{c}\text { Average Shear } \\
\text { Stress (kPa) }\end{array}$ & $\Delta \tau /{ }^{\circ} \mathbf{C ~ ( k P a ) ~}$ \\
\hline Bare Al & -2 & 38.1 & -15.5 \\
\hline Sandblasted Al & -15 & 76.1 & -38.3 \\
\hline Silicone R-1009 & -15 & $*$ & -1.9 \\
\hline \multirow{2}{*}{ Silicone R-2180 } & -2 & 37.2 & -6.5 \\
& -15 & +1.5 & \\
\hline
\end{tabular}

*Shear stress values at $-15^{\circ} \mathrm{C}$ were not obtainable for bare and sandblasted aluminum as the motor could not produce the required shear stress to cause delamination.

tDelamination for silicone R-2180 always occurred below $-2{ }^{\circ} \mathrm{C}$, regardless of shear stress. 
The second key point is the shear stress magnitude in the ejection temperature range. Ice frozen on both silicone R-1009 and silicone R-2180 require less shear stress in order to be ejected at $-15{ }^{\circ} \mathrm{C}$ than bare or sandblasted aluminum at $-3{ }^{\circ} \mathrm{C}$. For aircraft applications, the temperature range in which icing is experienced is between $0{ }^{\circ} \mathrm{C}$ and $-20{ }^{\circ} \mathrm{C}$ so an icephobic surface needs to lower the ice adhesion strength between these temperatures.

The slope of the shear stress and temperature plot in Figure 52 is also important in defining if a coating will be effective in practice. Icephobic surfaces will have a shallower slope in comparison to an uncoated surface. The silicone R-2180 has a slope that is approximately 2.5 times lower than the bare surface while the silicone $\mathrm{R}-1009$ slope is a approximately a factor of eight lower than the bare aluminum surface. A linear trend line was used to approximate the slopes of each surface as the coefficient of determination was above 0.65 for each surface. Gorni also observed a linear relationship between ice adhesion strength and temperature [62]. The equation of the linear relationship for each surface is listed in Table 13 as well as the $r^{2}$ coefficient, where $T$ is the freezer temperature $\left({ }^{\circ} \mathrm{C}\right)$.

Table 13: Equations of linear trend lines fitted for each surface

\begin{tabular}{|l|c|c|}
\hline Surface & Shear stress equation $\mathbf{( k P a )}$ & $r^{2}$ value \\
\hline Bare $\mathrm{Al}$ & $\tau_{s}(T)=-15.6(T)+6.91$ & 0.68 \\
\hline Sandblasted $\mathrm{Al}$ & $\tau_{s}(T)=-38.3(T)-0.57$ & 0.92 \\
\hline Silicone R-1009 & $\tau_{\mathcal{s}}(T)=-1.87(T)+33.4$ & 0.81 \\
\hline Silicone R-2180 & $\tau_{s}(T)=-6.47(T)-75.3$ & 0.72 \\
\hline
\end{tabular}

The large differences between slopes for coated and uncoated surfaces raises the question of the reference temperature to be used in ice adhesion testing. A 
variety of temperatures between $-10{ }^{\circ} \mathrm{C}$ and $-20{ }^{\circ} \mathrm{C}$ have been used by other researchers [18, 57,58]. A company may be able to publish results at a temperature where the ARF is maximized. By comparing the shear stress functions of coated and uncoated surfaces, an ARF function can be calculated as per Equation 9 .

$$
A R F(T)=\frac{\tau_{A l}(T)}{\tau_{s}(T)}
$$

With the ARF function, the ARF of any coated surface can be related to a reference surface at any temperature. Listed in Table 14 is the ARF function for the silicone R-1009 and R-2180 coatings related to both the bare aluminum and sandblasted surfaces. The ARF at $-20^{\circ} \mathrm{C}$ is also listed.

Table 14: Equations for the ARF function for each surface

\begin{tabular}{|l|c|c|c|}
\hline Surface & $\begin{array}{c}\text { Reference } \\
\text { Surface }\end{array}$ & ARF Function & $\begin{array}{c}\text { ARF at } \\
\mathbf{- 2 0}{ }^{\circ} \mathbf{C}\end{array}$ \\
\hline Silicone R-1009 & Bare Al & $\begin{array}{c}A R F(T)=-0.0045 T^{2} \\
-0.2893 T+0.5783\end{array}$ & 4.48 \\
\hline Silicone R-1009 & Sandblasted Al & $\begin{array}{c}A R F(T)=-0.0115 T^{2} \\
-0.7334 T+0.9166\end{array}$ & 10.8 \\
\hline Silicone R-2180 & Bare Al & $\begin{array}{c}A R F(T)=0.0007 T^{4}+0.07 T^{3} \\
+2.5758 T^{2}+42.069 T+263.25\end{array}$ & 5.87 \\
\hline Silicone R-2180 & Sandblasted Al & $\begin{array}{c}A R F(T)=0.0017 T^{4}+0.1661 T^{3} \\
+6.1131 T^{2}+99.842 T+624.99\end{array}$ & 14.2 \\
\hline
\end{tabular}

Since the slope of the sandblasted aluminum surface is higher than the bare aluminum surface, the ARF is higher when selecting it as the reference surface. A consistent reference surface should be used when performing ice adhesion testing at different facilities. This consistent surface will establish the testing baseline and should provide similar results, regardless of the experimental setup. 
An icephobic coating should maximize the value of the ARF function in the desired de-icing temperature range. This in turn will cause ice to delaminate at a shear stress below that of the original surface at the same temperature. If a hybrid system involving both icephobic coating and heating is used in practice, less heating will be required to remove the ice.

\subsubsection{Comparison to the Single Shear Ice Adhesion Test}

These results obtained using VASTA compare reasonably well with the results obtained from the single shear ice adhesion test. The icephobic coatings showed that they can reduce the ice adhesion strength of a bare aluminum surface. Listed in Table 15 is the adhesion strength for sandblasted Al, silicone R-2180 and silicone R-1009 at $-20{ }^{\circ} \mathrm{C}$ obtained using each test as well as the ARF.

Table 15: Comparison of the two ice adhesion tests

\begin{tabular}{|l|cc|cc|}
\hline Surface & $\begin{array}{c}\tau_{s}(\mathbf{k P a}) \\
\text { from MTS test }\end{array}$ & ARF & $\begin{array}{c}\tau_{s} \mathbf{( k P a )} \\
\text { from VASTA }\end{array}$ & ARF \\
\hline Sandblasted Al & 447 & 1.00 & 766 & 1.00 \\
\hline Silicone R-2180 & 187 & 2.96 & 54.1 & 14.2 \\
\hline Silicone R-1009 & 23.8 & 18.8 & 70.9 & 10.8 \\
\hline
\end{tabular}

The results from the VASTA experiment show there is a larger difference between the sandblasted aluminum surface and the silicone coated surfaces. The higher reference value leads to higher ARFs using VASTA. For silicone R-1009, the manufacturer's published shear stress of $8 \mathrm{kPa}$ at $-11^{\circ} \mathrm{C}$ is closer using the MTS test while silicone R-2180 has a published adhesion strength of $37 \mathrm{kPa}$ and it is very close to the value obtained from the VASTA test. Ultimately the results obtained from the VASTA test show the temperature dependence of the ice adhesion 
strength and the test itself more closely simulates the actual de-icing condition on aircraft.

The difference in ice adhesion strength between the two experiments is likely caused by the testing method. The MTS test was displacement controlled while the VASTA test was force controlled. By controlling the displacement, the coating deforms under load which increases the measured ice adhesion strength for more elastic coatings as the bonds between the ice and the surface take longer to break. Silicone R-2180 is more likely to exhibit this behavior as it can elongate by twice that of the silicone R-1009 [72, 73]. By applying constant force, the bond between the ice and surface breaks once the critical force is exceeded. The VASTA test demonstrated that the critical force is a function of the temperature and that once the critical force is exceeded at the testing temperature, the bond breaks. All previous testing conducted with NuSil silicone coatings was done using an MTS testing method which corresponds to the results obtained from this work [18, 58] while force based testing has not been conducted for these coatings.

\subsection{Using Multiple Parameters to Evaluate Icephobic Surface Effectiveness}

The ice adhesion strength and ARF should not be the only factors that determine if a coating is suitable for aircraft applications. Other parameters including the durability, cost of material and application, and mass should be considered. Based on both the wear resistance and ARF, a schematic was created in order to aid the selection process of icephobic coatings for industrial applications. This plot is shown in Figure 53. Coatings in the contained region possess a high ARF and low wear rate relative to other tested coatings. This region was arbitrarily drawn to provide 
distinction between acceptable and unacceptable coatings. As more coatings are tested, the position of the line may change. Coatings outside of this region are not suitable for aircraft as they possess either an ARF that is low when compared to other coatings or can wear quickly, exposing the surface of the aircraft. Both the silicone R-1009 and ALG are suitable for this application in comparison with the other tested coatings. Silicone R-1009 has the highest ARF when being tested using the MTS while ALG has the best wear resistance.

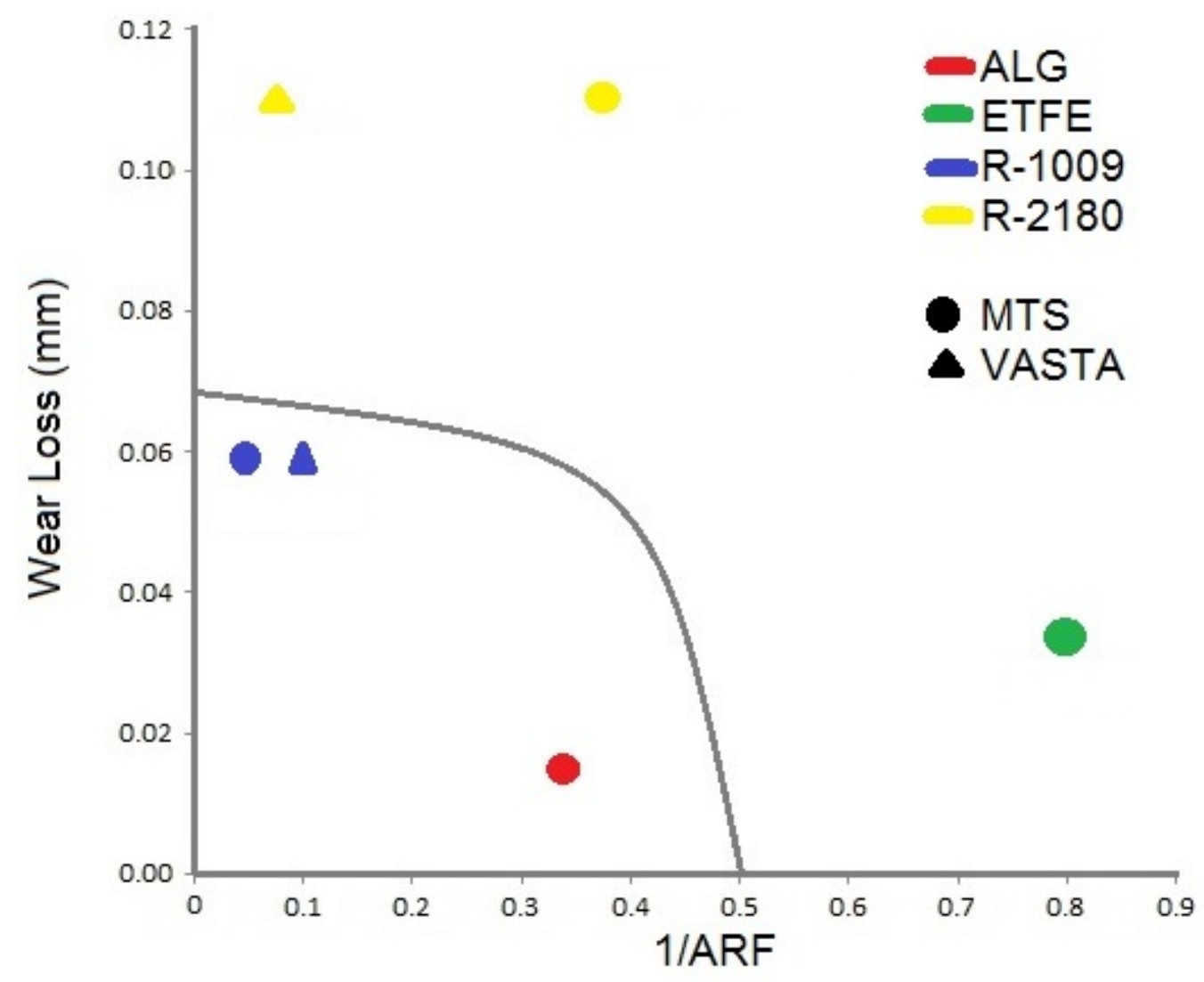

Figure 53: Composite plot aiding in the selection of icephobic coatings showing both the ARF and wear resistance.

An attempt to test the ice adhesion strength of ALG was made using the VASTA. The results were very inconsistent and no relationship between the ice adhesion strength and temperature could be obtained. Upon further inspection of the 
samples, cracking was discovered in the area where the droplets were placed. Figure 54 shows the cracking compared to an area where no cracks exist. This cracking allows for water droplets to embed themselves inside the cracks and form an interlocking structure which greatly increases the force required to eject the droplet. As the number of tests increased using the same sample, a higher temperature was required to eject the droplet at approximately the same shear stress. This shows that the number of cracks increased as more tests were conducted. This durability effect means that ALG is not an ideal coating for industrial applications where multiple freezing cycles will occur.

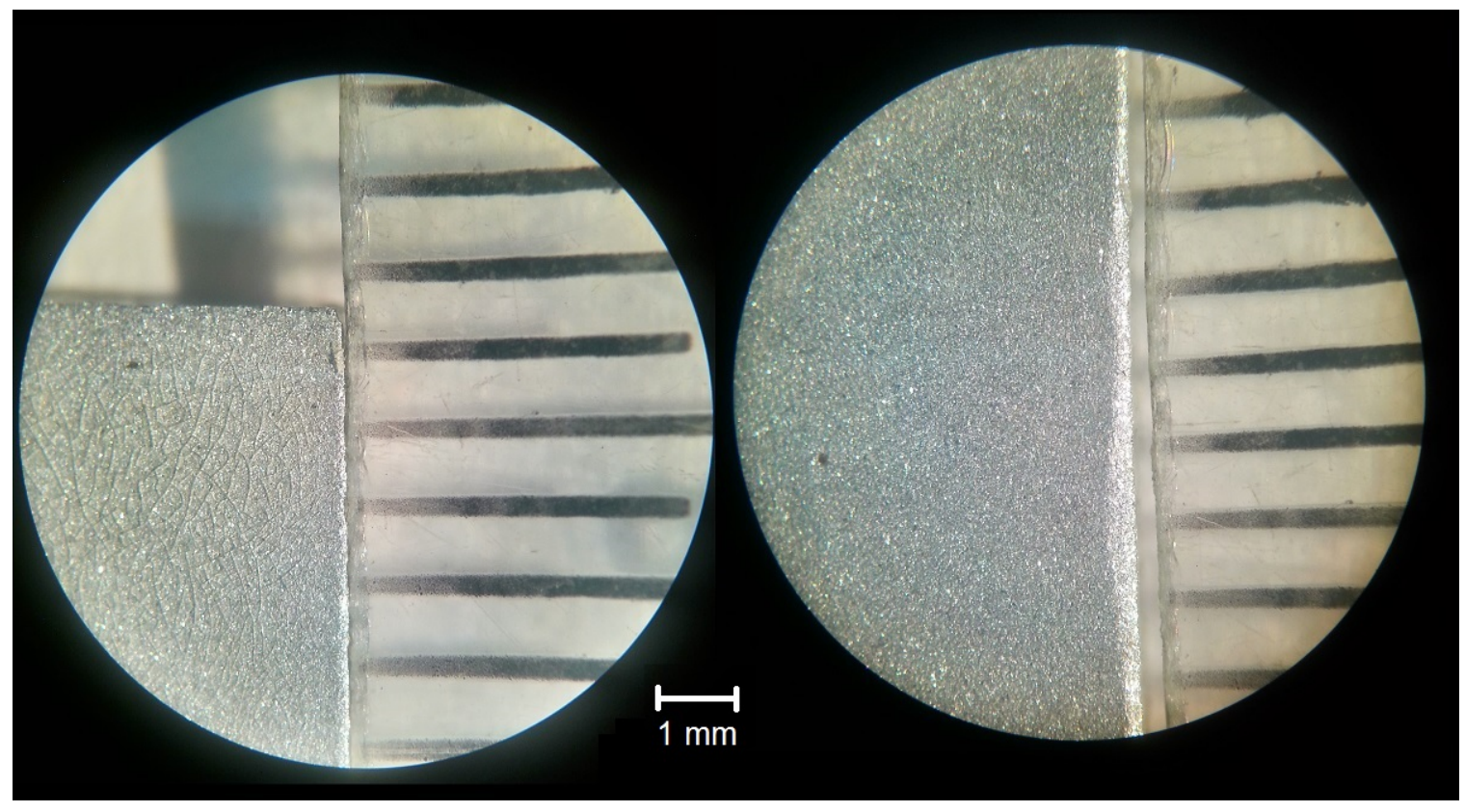

Figure 54: Cracks formed on the ALG surface (left) which raised the ice adhesion strength compared to the original surface (right). 


\subsection{Testing of Piezoelectric Actuators on an Alu- minum Plate}

The objective of this study is to find the resonance frequencies and quality factors corresponding to a plate having two piezoelectric actuators bonded to the back surface. One piezo acts as the actuator while the other is used as a sensor to measure the excitation. Ice delamination can then be attempted by applying a sufficient voltage at resonance modes to generate the desired response.

\subsubsection{Equipment Setup}

Using the sample shown in Figure 29 an electrical circuit is created using a power supply and waveform generator. The schematic for the setup is shown in Figure 55 while the individual components are shown in Figure 56. The power supply sends a voltage and current to the piezo actuator while being modulated by the waveform generator. The waveform generator varies the frequency at which the voltage is delivered and this is monitored and recorded using an oscilloscope controlled by a computer. The response measured by the piezo sensor is also measured and recorded as the response varies with the frequency. Using a laser vibrometer, the displacement at a point on the surface can be found in order to determine the mode shape. Finally a Hall-Effect current sensor was used to measure the current draw from the power supply. 


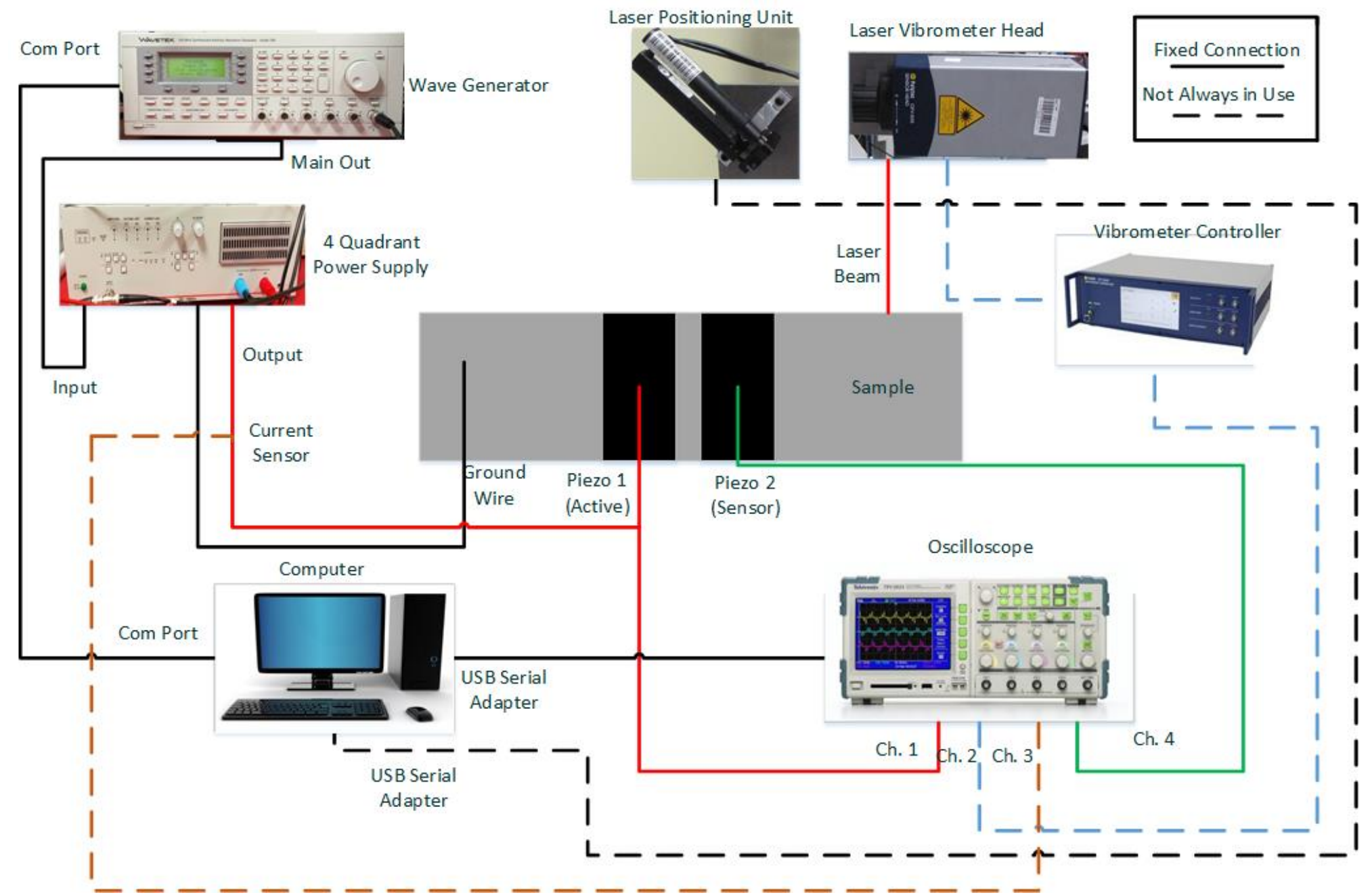

Figure 55: Schematic diagram showing all of the connections between the equipment used. 
(a)

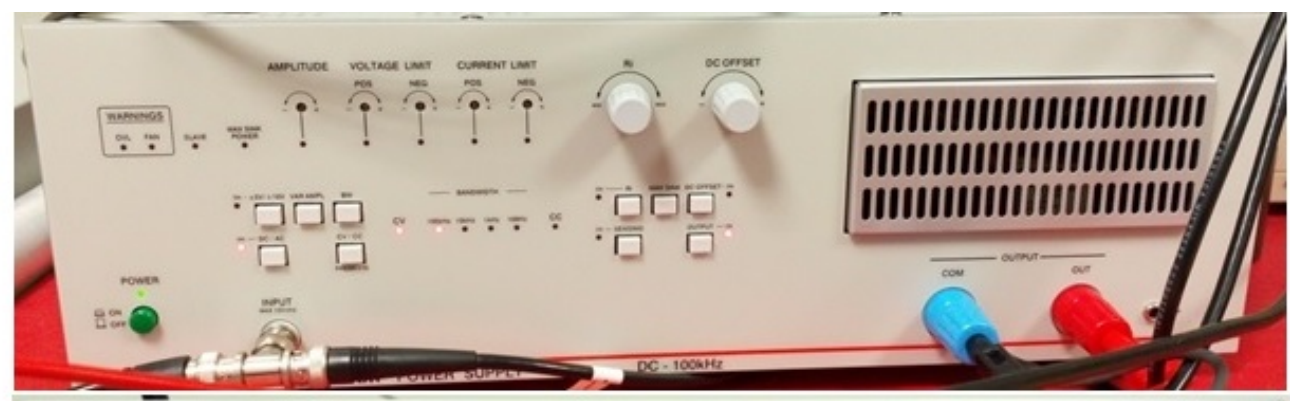

(b)

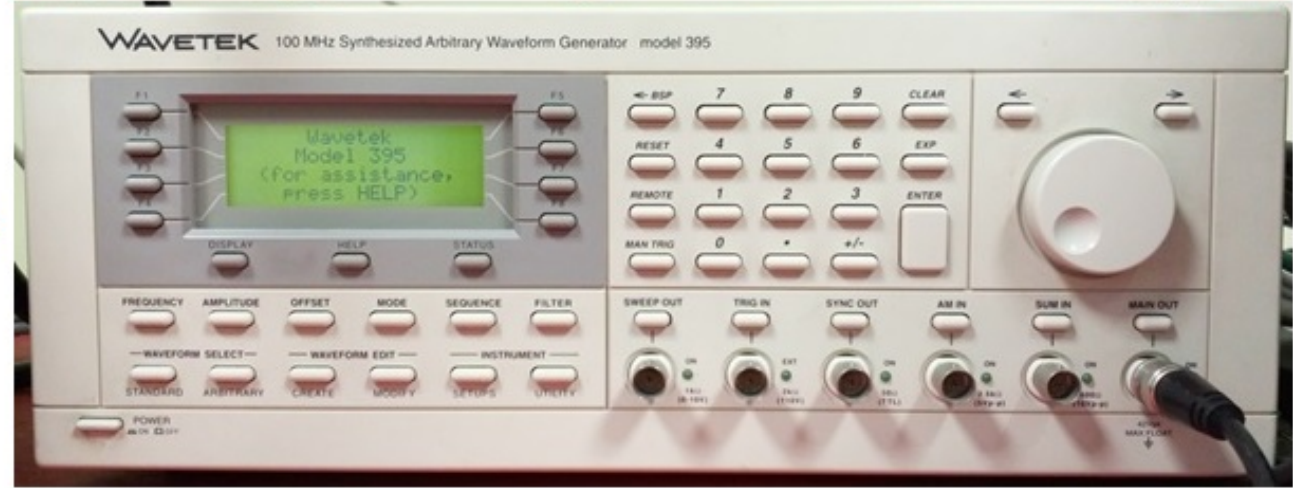

(c)

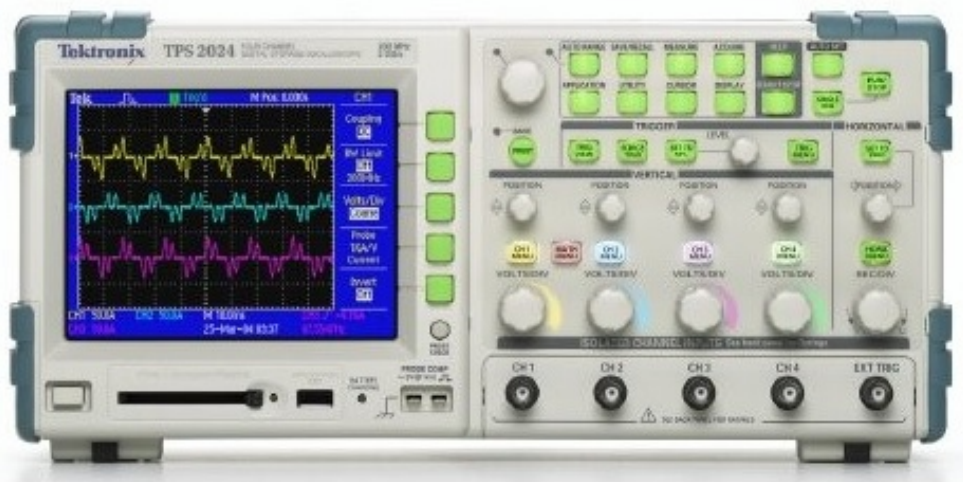

Figure 56: Equipment used in the experiment (a) the 4-quadrant power supply, (b) waveform generator, and (c) oscilloscope.

\subsubsection{Freezing Water onto the Plate}

Water was frozen onto the sample using the setup shown in Figure 57. Using a pivot vice, the sample could be leveled and then a precise amount of water can be added to ensure the correct ice thickness. A layer of scotch tape was placed around the outside of the outer edge of the sample to contain the water. After three hours, 
the sample would be removed and inspected to ensure that a continuous bond between the ice and the surface was achieved and that no water leaked out during the freezing process.

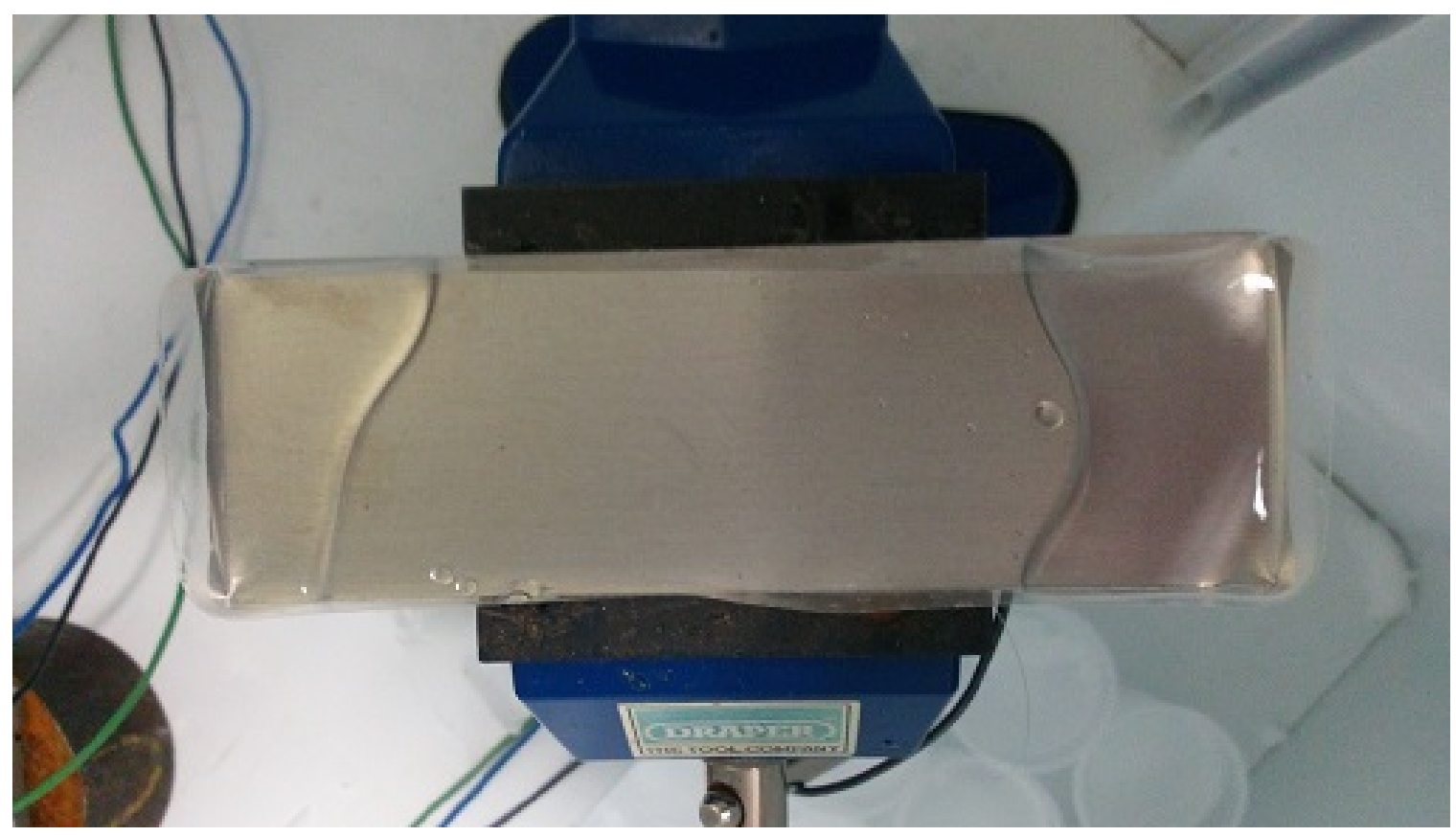

Figure 57: The sample is held level in the vice while the water freezes inside of a freezer.

\subsubsection{Discovery of Resonance Modes}

To find the resonance modes, a sweep is conducted by applying a constant voltage into the piezoceramic actuator and varying the frequency. The response is then measured using the piezoceramic sensor. The response from a typical sweep using an aluminum plate with a $2 \mathrm{~mm}$ thick sheet of ice is shown in Figure 58 . There are several flexural and extensional resonance modes found at lower frequencies as predicted by the numerical model as well as modes involving bending and torsion found in the 40 to $50 \mathrm{kHz}$ range. The largest response is measured at approximately $44 \mathrm{kHz}$ having a magnitude of around $40 \mathrm{~V}$. 


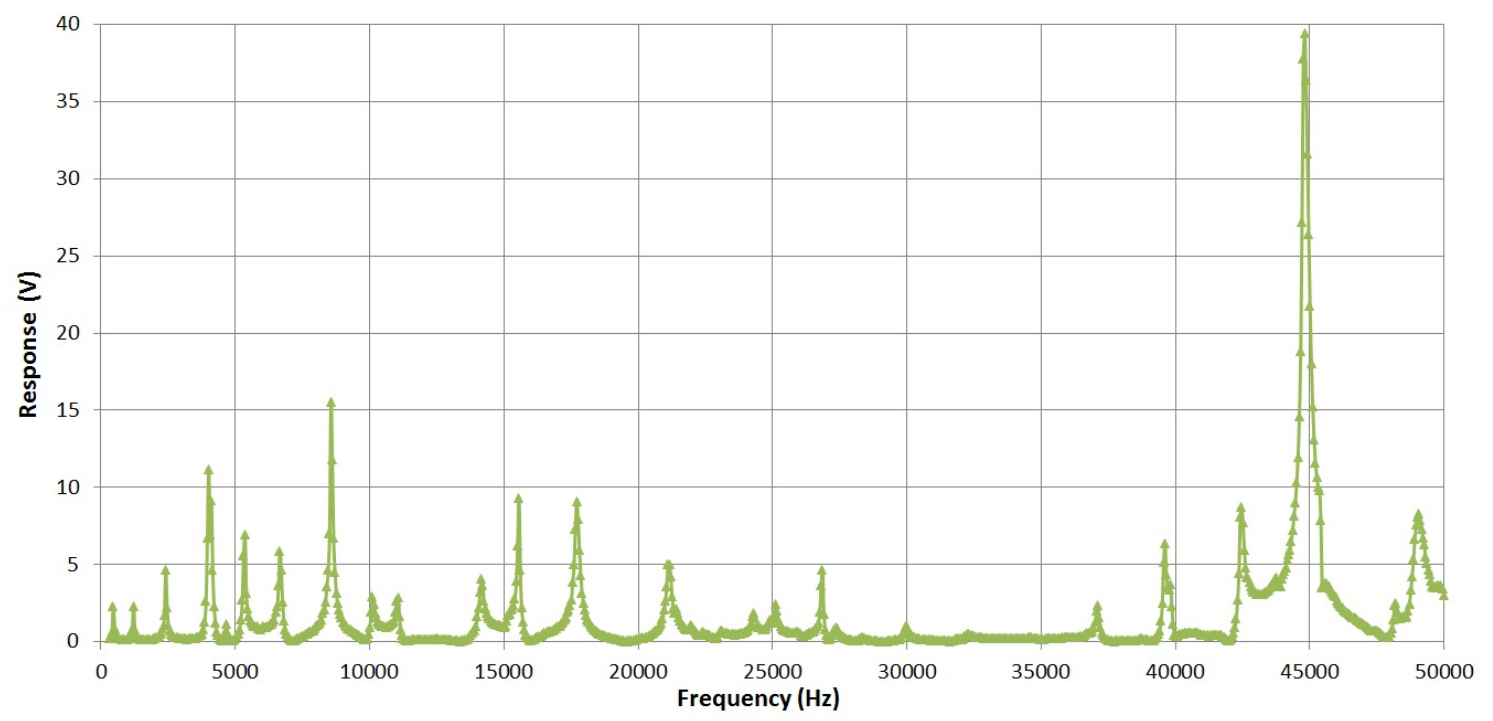

Figure 58: Response using a frequency sweep for a $2 \mathrm{~mm}$ thick sheet of ice.

There are small shifts in the resonance frequency between samples as the thickness of the ice sheet can vary slightly. If the stiffness to modal mass ratio changes, so do the modal frequencies. The temperature also has an effect on the stiffness to modal mass ratio. As the temperature decreases, the Youngs modulus increases due to the decreased molecular/atomic mobility at the microstructure level.

\subsubsection{Verification of Resonance Mode}

Although the numerical model may predict a resonance mode at a particular frequency, the mode may not be detected using the piezo-sensor configuration employed. To verify that the experimental mode matches the numerical model, a Polytec OFV-505 Laser Vibrometer was used to measure the displacement at points on the surface of the plate. The setup is shown in Figure 59. The laser measures one point at a time along the surface when being excited at the resonance frequency. Using a MATLAB GUI [79], an automatic grid search pattern can be generated to cover half of the plate. The laser travels along the search pattern and measures 


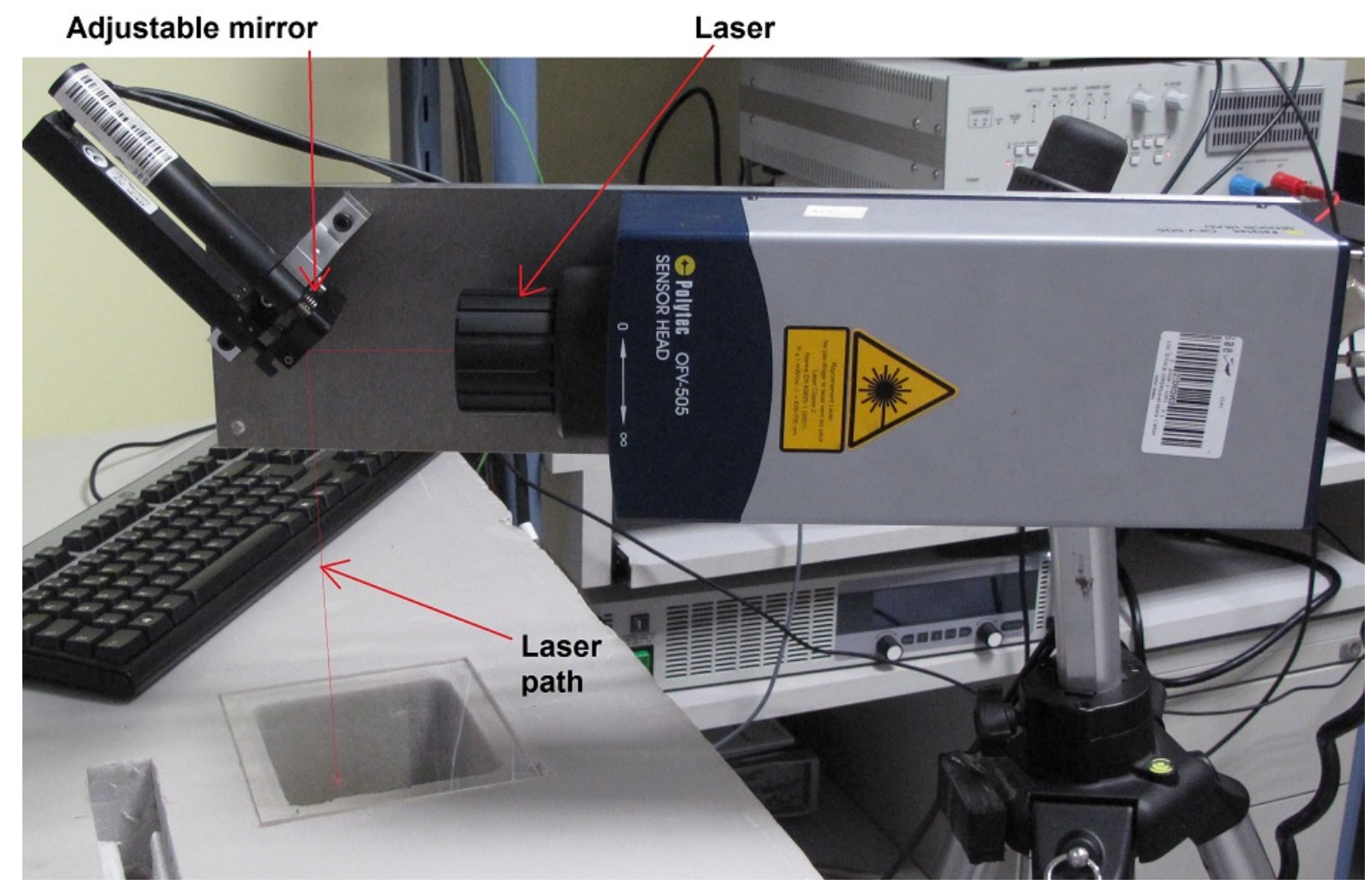

Figure 59: Setup of the scanning vibrometer.

the projected component of the surface velocity vector along the direction of the incident laser beam.

From the measurements taken by the laser vibrometer, a surface contour plot can be generated and compared to the results of the numerical model. Shown in Figure 60 is the contour plot obtained for the first flexural mode of the aluminum plate with an ice thickness of $2 \mathrm{~mm}$. There was a small amount of noise in the measurements using the vibrometer (as indicated by the spots in the surface contour plot), however, the measured pattern matched the predicted resonance mode. Modes at lower frequencies are better matched to the model due to the lower number of nodes, anti-nodes and their distribution. 

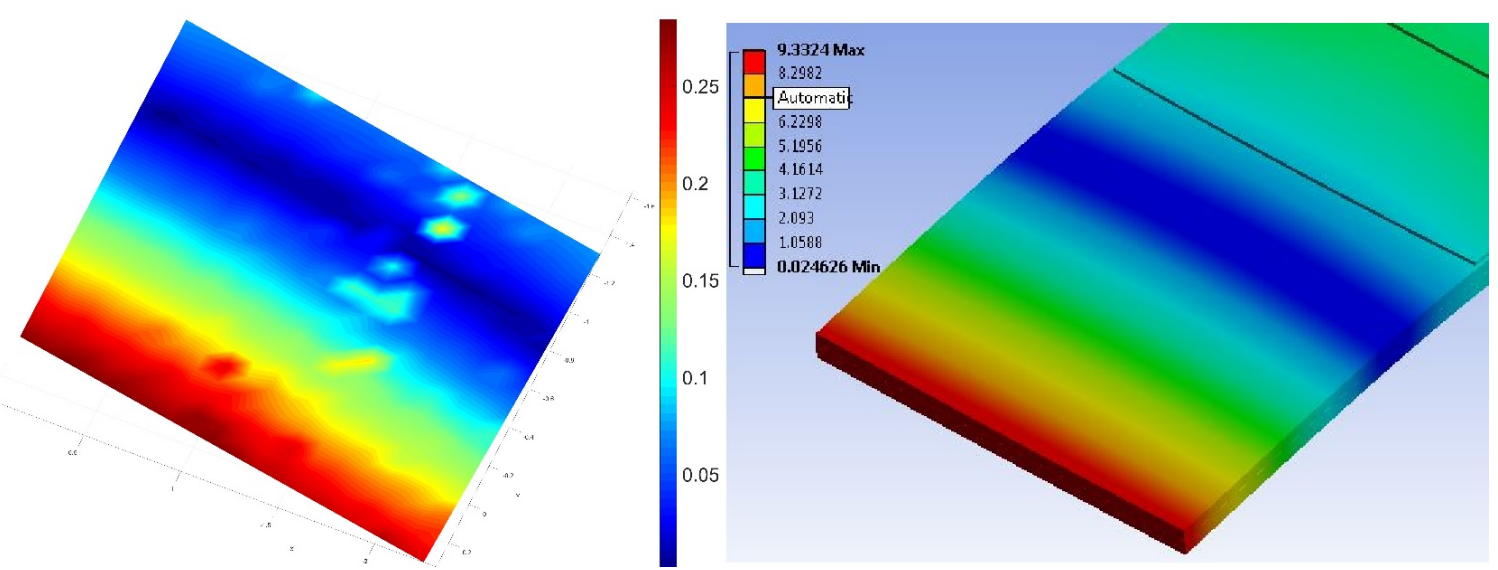

Figure 60: Surface contour plot (left) and the predicted deformation from the numerical model (right) for the first resonance mode.

\subsubsection{Behavior at a Resonance Mode}

As a resonance mode is approached, the current drawn by the actuator increases. As can be seen in Figure 61, the current drawn by the actuator follows the response from the sensor. The sweep was conducted downward, beginning at $45 \mathrm{kHz}$ and ending at $40 \mathrm{kHz}$.

The temperature of the plate followed the same trend as the current as shown in Figure 62. The temperature of the plate increases as a result of the increased motional current of the actuator as the resonance mode is approached. There is a larger delay in the temperature response as it takes several seconds for the heat to dissipate from the actuator. When at $42.7 \mathrm{kHz}$, the temperature of the plate increased from the initial freezer temperature of $-16{ }^{\circ} \mathrm{C}$ to $-7^{\circ} \mathrm{C}$. This change in temperature introduces a secondary mechanism for ice delamination. As presented in Section 5.3, the ice adhesion strength decreases linearly as the temperature increases. Due to the heat generated by the actuator, delamination may be further assisted by the reduced ice adhesion strength.

Measuring the current and temperature provide valuable alternatives to find 


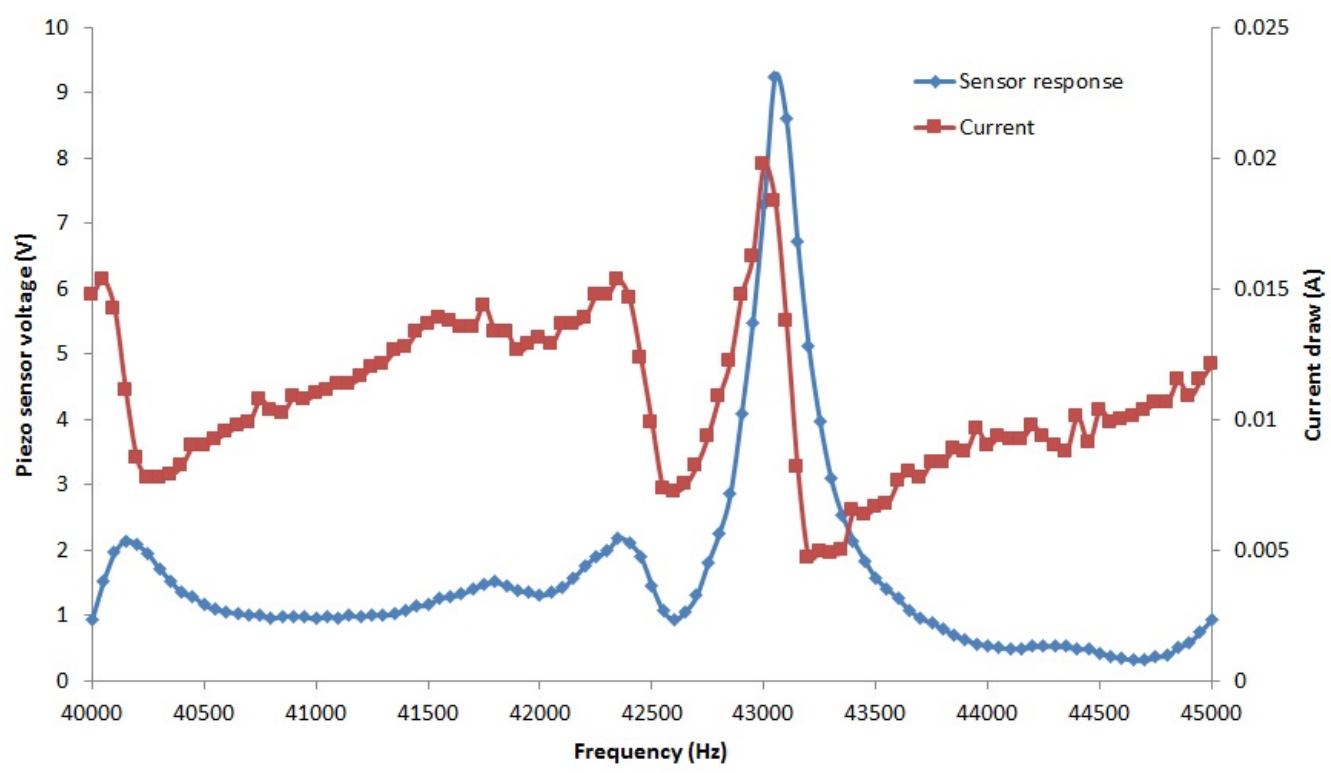

Figure 61: Sensor response and current draw for a sweep between $40 \mathrm{kHz}$ and $45 \mathrm{kHz}$ at $10 \mathrm{~V}$.

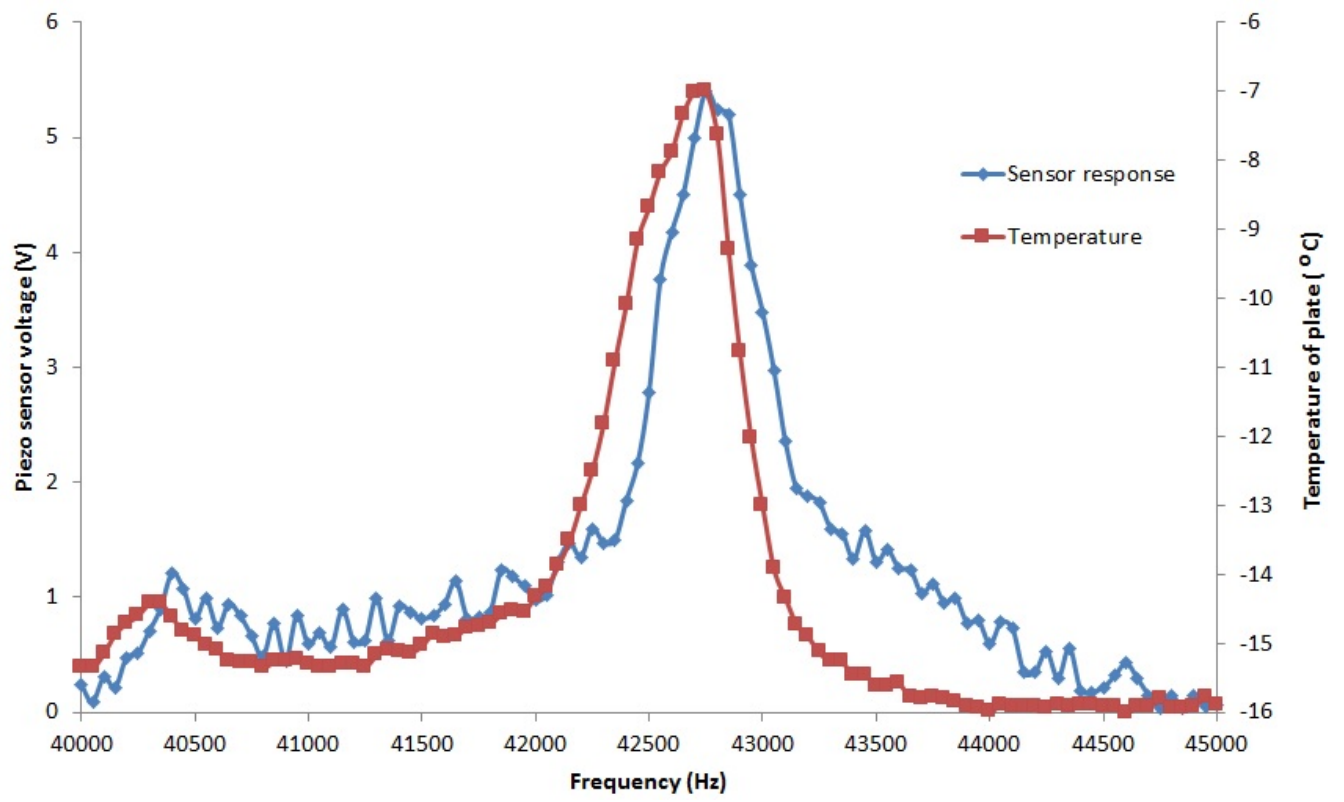

Figure 62: Sensor response and plate temperature for a sweep between $40 \mathrm{kHz}$ and $45 \mathrm{kHz}$ at $10 \mathrm{~V}$. 
resonance modes. Instead of using a physical sensor on the plate to measure the response, either the current or the temperature of the plate can be monitored in a non-contact manner.

\subsubsection{Measurement of Quality Factor}

The measurement of quality factor first requires a frequency sweep in order to find the resonance modes. To take the measurement, the frequency is slowly varied and the response of the sensor is recorded. From the acquired data, the peak value and the bandwidth are recorded and the quality factor can be calculated using Equation 1

At each resonance frequency, the quality factor was measured for different ice sheets. Figure 63 shows the quality factor measurements for six different $2 \mathrm{~mm}$ thick ice samples.

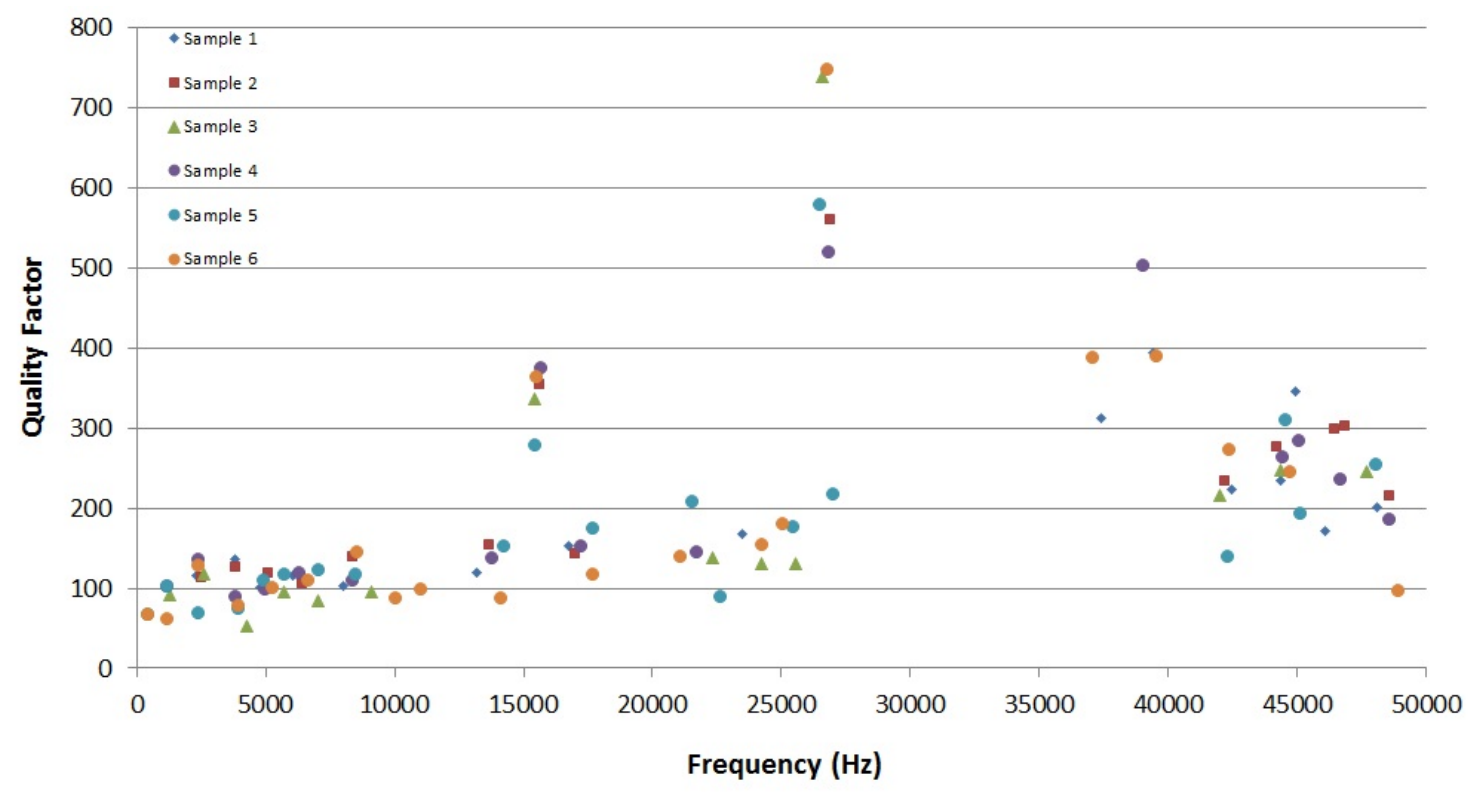

Figure 63: Quality factor measurements for a $2 \mathrm{~mm}$ thick sheet of ice.

At lower frequencies, the quality factor has a magnitude of approximately 100 
and the value increases in the range of 200 to 300 at a frequency of $50 \mathrm{kHz}$. The maximum quality factor of 752 is measured at $26.7 \mathrm{kHz}$. The quality factor is important as a linear increase in the quality factor causes a linear decrease in the voltage required for an ice sheet to delaminate. Based on the results obtained, the qualify factor is not affected by the ice thickness.

\subsubsection{Quality Factor Analysis}

After further analysis of the quality factor, four frequencies were determined to have quality factors that were higher than the trend. These four frequencies are listed in Table 16 ,

Table 16: Resonance modes with a high quality factor

\begin{tabular}{|c|c|}
\hline Frequency (kHz) & Quality Factor \\
\hline 15.547 & 361.6 \\
\hline 26.834 & 745.4 \\
\hline 37.110 & 386.6 \\
\hline 39.608 & 388.3 \\
\hline
\end{tabular}

From the numerical model, several modes exist at frequencies around those listed in Table 16 that are extensional modes as shown in Figure 64 . The theoretical first extensional mode as calculated by the 1D mathematical model developed by Budinger et al. occurs at a frequency of $15.0 \mathrm{kHz}$ [48]. Extensional modes can be identified in the numerical model. Extensional modes require a significant amount of current for de-icing and thus are not practical for application. Figure 64 shows the total deformation in the top image and the deformation in the z-axis in the lower image for each resonance mode. 


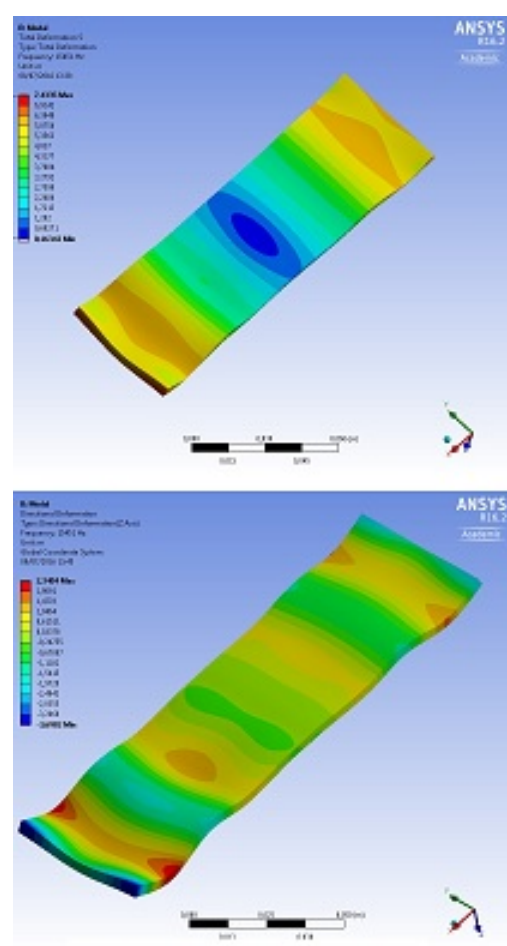

$f=15451 \mathrm{~Hz}$
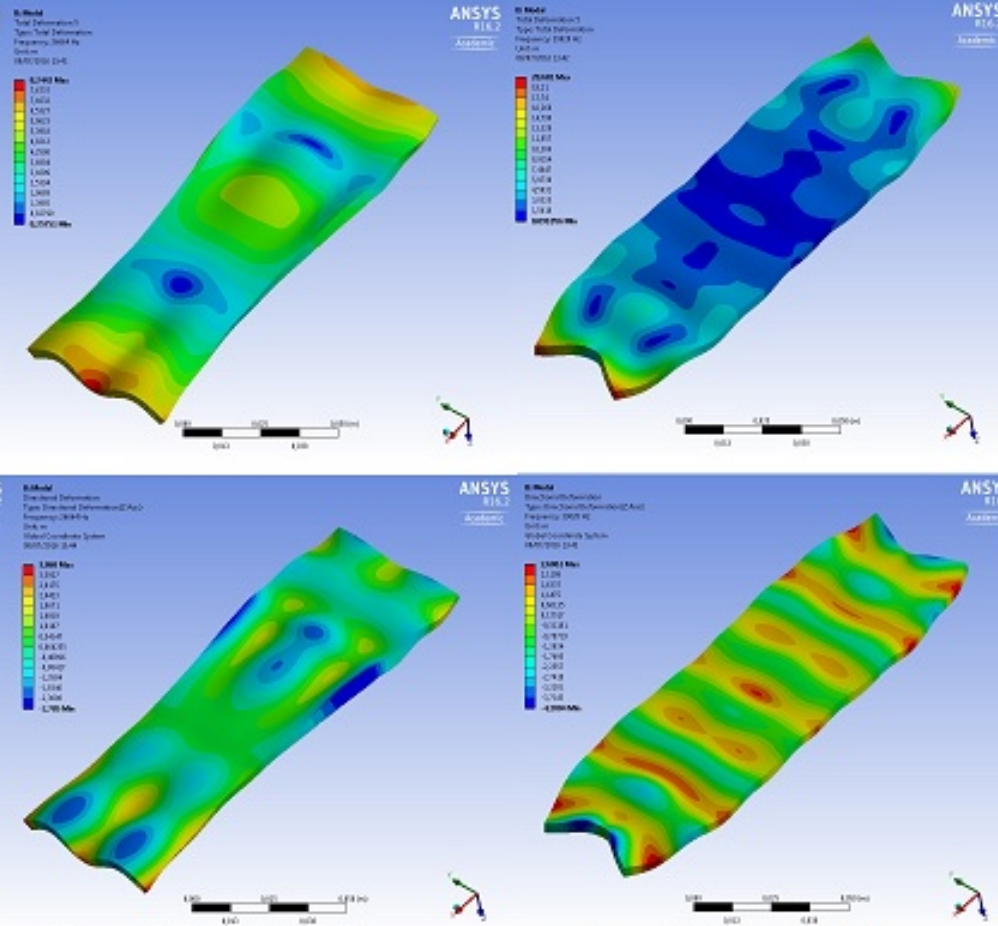

$f=26664 \mathrm{~Hz}$

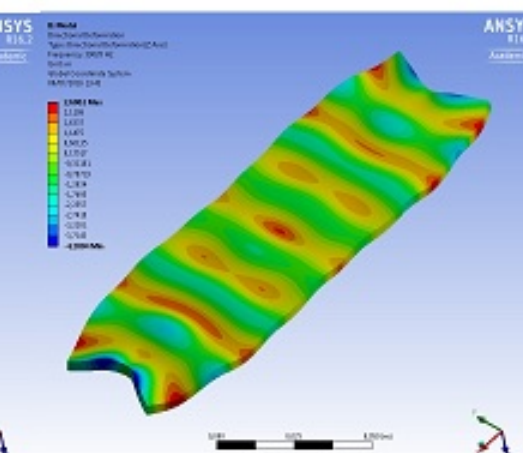

$f=39628 \mathrm{~Hz}$

Figure 64: Extensional resonance modes for the plate obtained from the numerical model with an ice thickness of $2 \mathrm{~mm}$.

Using the laser vibrometer, the deformation pattern was found for each of these modes experimentally. Figure 65 shows the contour map of the extensional mode compared with the extensional mode from the numerical model at $26.7 \mathrm{kHz}$. The nodes in the numerical model are shown in green and match the nodes from the experimental measurement in blue. In addition, the anti-nodes (red and blue in the numerical model) match those found in the experiment (red/orange). This allows for the conclusion that the observed modes with high quality factors are indeed extensional modes. When data points at these four frequencies are eliminated from the graph, it appears that a near-linear correlation exists between the frequency and quality factor as shown in Figure 66.

Being able to predict the quality factor for a given resonance frequency allows 


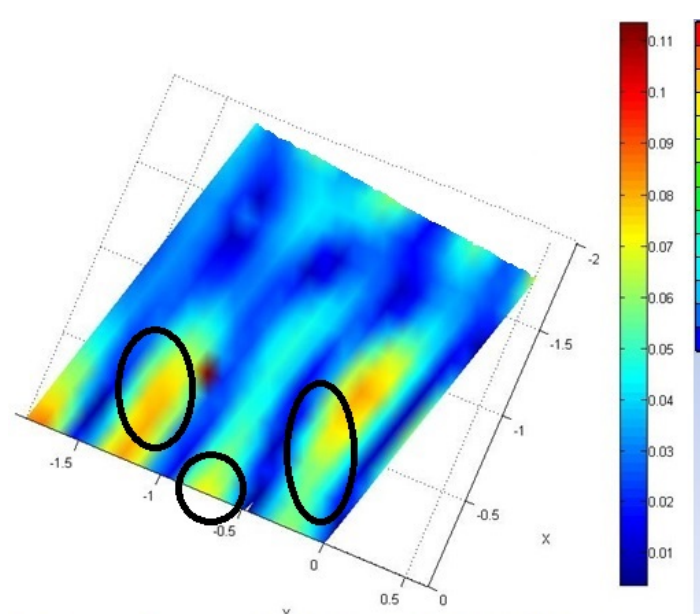

Experimental: $\mathrm{f}=\mathbf{2 6 8 9 4} \mathrm{Hz}$

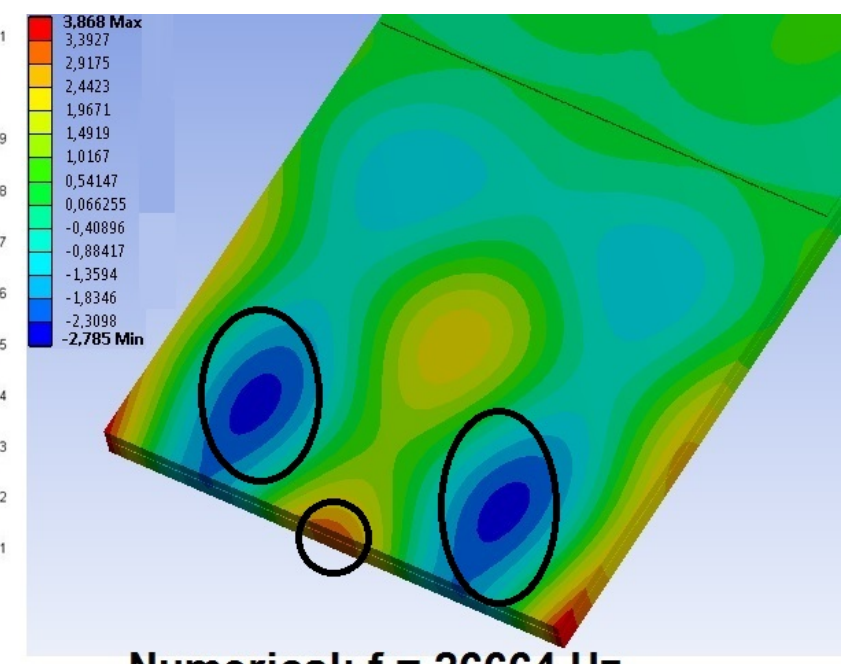

Numerical: $f=26664 \mathrm{~Hz}$

Figure 65: Experimental displacement (left) and displacement from the numerical model (right) for the extensional mode at $26.9 \mathrm{kHz}$.

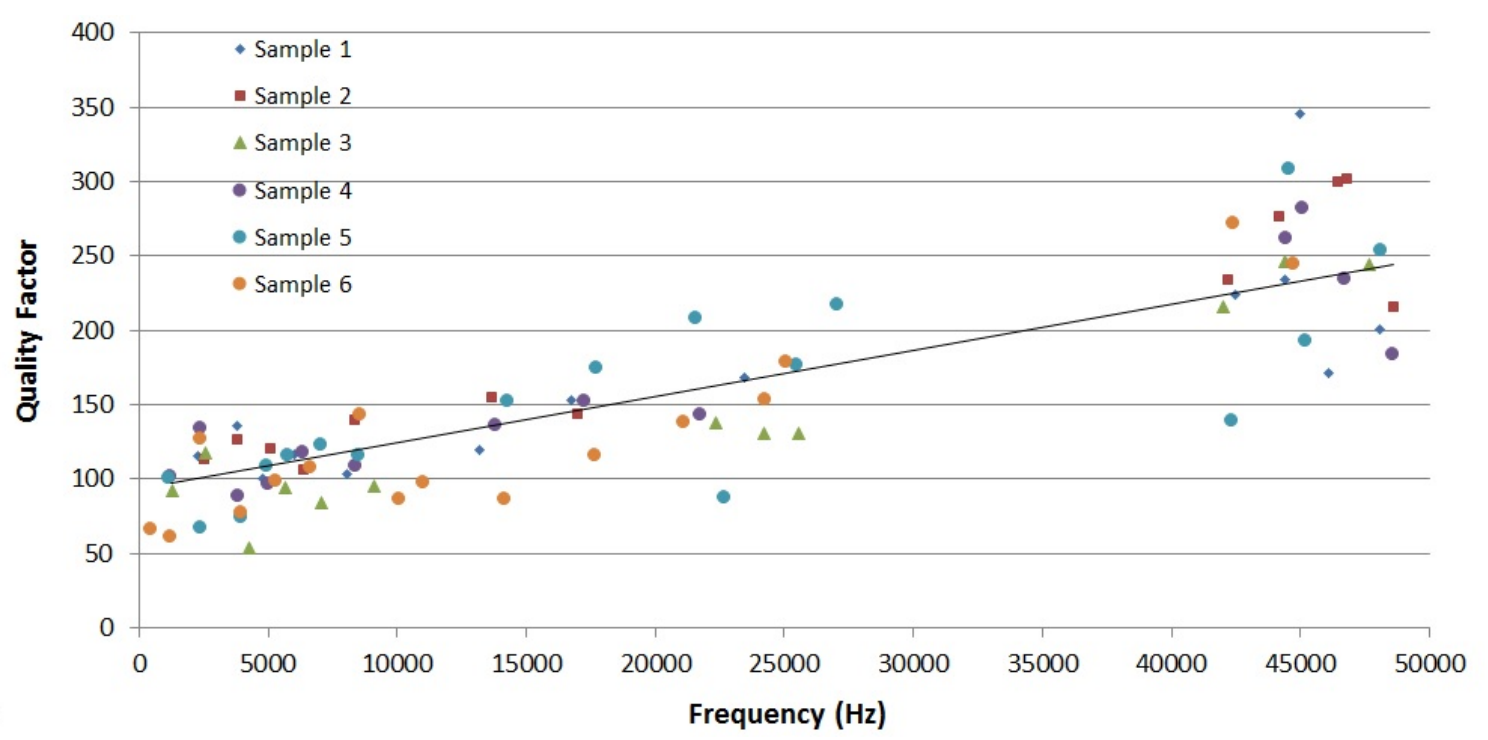

Figure 66: A linear correlation exists between the quality factor and resonance frequency when excluding extensional modes.

for significant time savings when determining if ice delamination can be attempted at a certain frequency. The previous procedure required a full frequency sweep and measurement of quality factor, inputting the measured quality factor into the numerical model and verifying the output would require a voltage below $100 \mathrm{~V}$ 
and a piezoceramic stress below $20 \mathrm{MPa}$. The new procedure uses a numerical model with an assumed quality factor of 100 (which can be revised accordingly based on experimental results) and the voltage is calculated from the measured quality factor at the frequency of interest.

\subsection{Comparing the Resonance Frequency of Coated Plates to Bare Aluminum}

\subsubsection{Using a Mechanically Activated Shaker}

Several plates with different coatings were tested to determine how the coating affects the resonance frequency of the plate. A shaker was placed under a bare aluminum, silicone R-1009 and ETFE coated plate and the laser vibrometer was used to measure the displacement at the tip of the plate. The setup of the shaker is shown in Figure 67. A hole was drilled in the centre of the plate and was then mounted to the shaker. The shaker allowed for quick measurements of the resonance frequencies to be found without needing to bond the piezoelectric patches to the plate.

To visualize the type of resonance mode, salt was sprinkled on the top surface of the plate and when a resonance frequency was reached, it would migrate to the nodes where there would be no displacement. The displacement on each plate in a range between 0 and $10 \mathrm{kHz}$ is shown in Figure 68. The measurement was taken by a single point vibrometer at the end of the plate as shown by the blue dot in Figure 67. The corresponding resonance modes are shown in Figure 69. This first mode is a flexural mode with four nodes while the other four modes contain both a flexural and torsional component. 


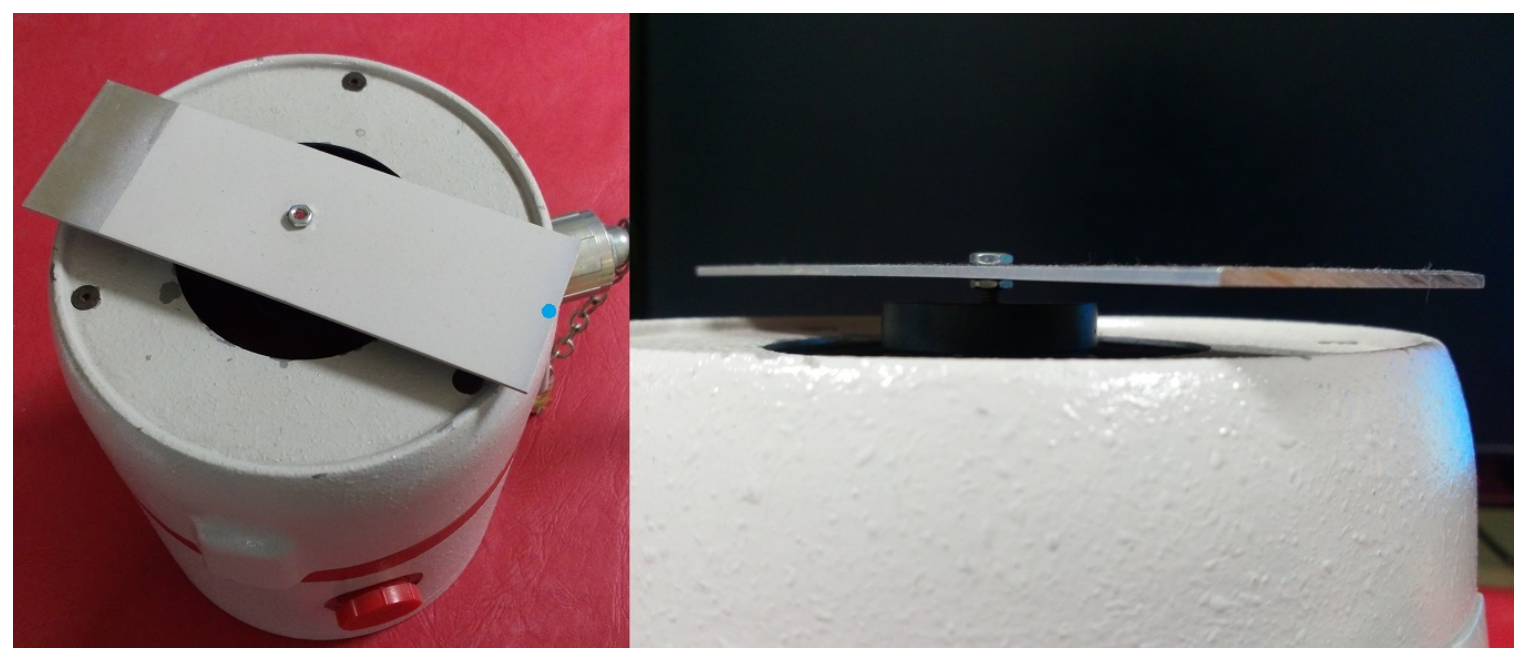

Figure 67: The shaker with a coated plate as seen from the top (left) and side views (right).

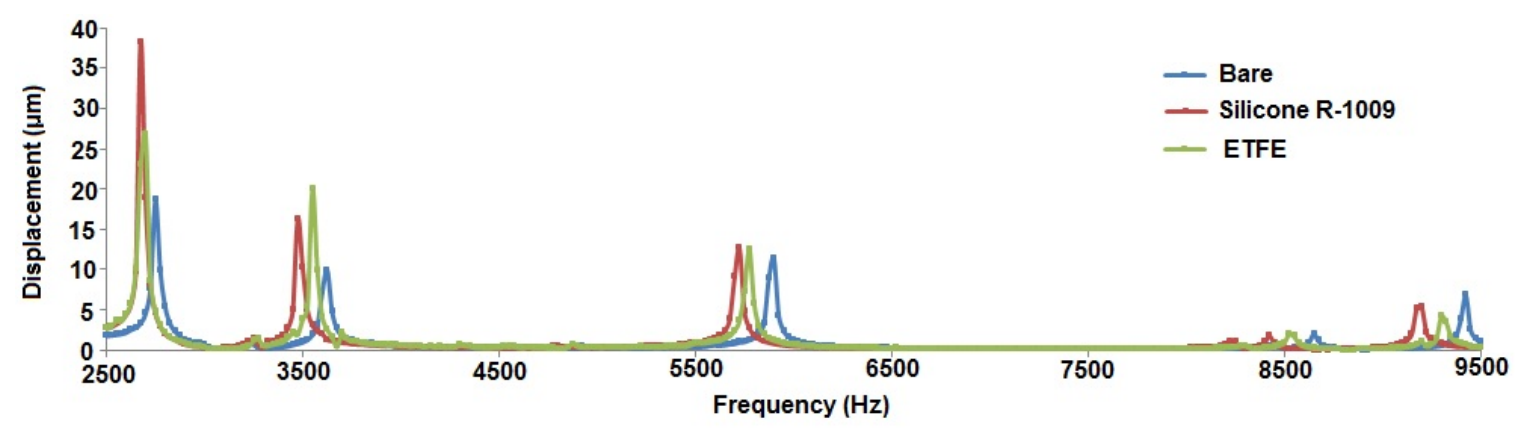

Figure 68: Sweep using the vibrometer and shaker on coated and uncoated plates.

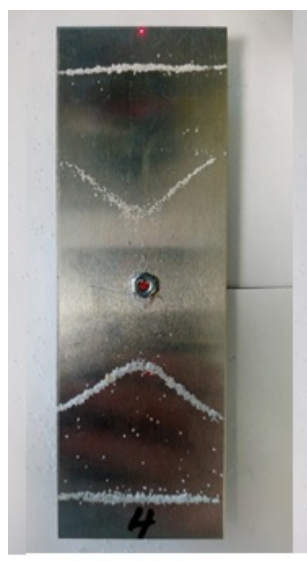

$f=2.7 \mathrm{kHz}$

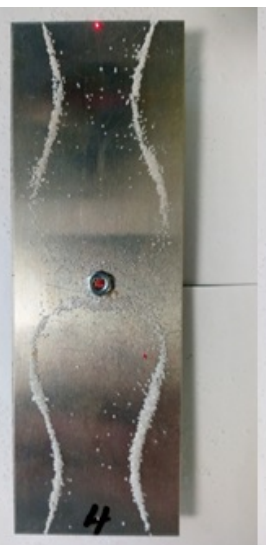

$f=3.5 \mathrm{kHz}$

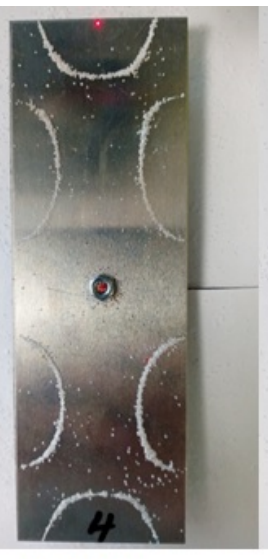

$f=5.8 \mathrm{kHz}$

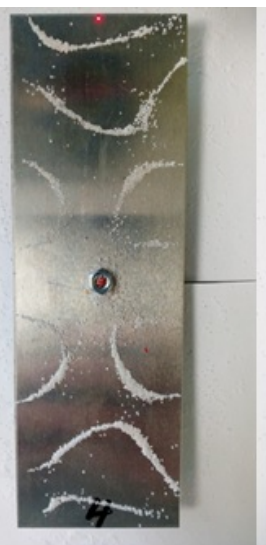

$f=8.5 \mathrm{kHz}$

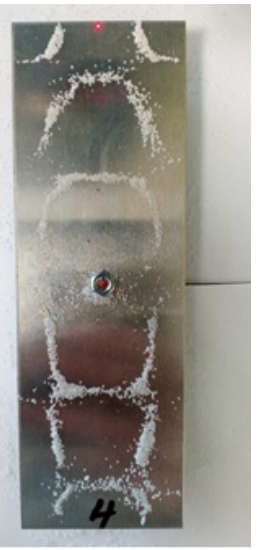

$\mathrm{f}=9.4 \mathrm{kHz}$

Figure 69: Corresponding resonance modes found using the shaker for the bare aluminum plate. 
Adding a coating with a lower elastic modulus causes the stiffness to mass ratio to decrease resulting in a lower resonance frequency. This decrease is greatest for the silicone R-1009 coating due to its low elastic modulus. At low frequencies, the larger mass results in a higher excitation force and larger displacement response. At higher frequencies, the displacement response with a coating is lower than that of the bare plate meaning that the coating adds additional damping to the plate.

\subsubsection{Using a Piezoceramic Actuator and Sensor}

In order to validate the observation from using a shaker, the samples were tested using with two piezoceramic patches; one used as an actuator and the other as a sensor. A similar sweep as the shaker was carried out on a bare aluminum and silicone R-1009 coated plate. The response from the sensor between 0 and $10 \mathrm{kHz}$ for the sweep are shown in Figure 70. The corresponding resonance modes that were consistent between the two samples are shown in Figure 71. The first two resonance modes are flexural modes with four and five nodes respectively. The third mode is a flexural mode with two nodes in the lateral direction while the fourth mode has flexural and torsional components.

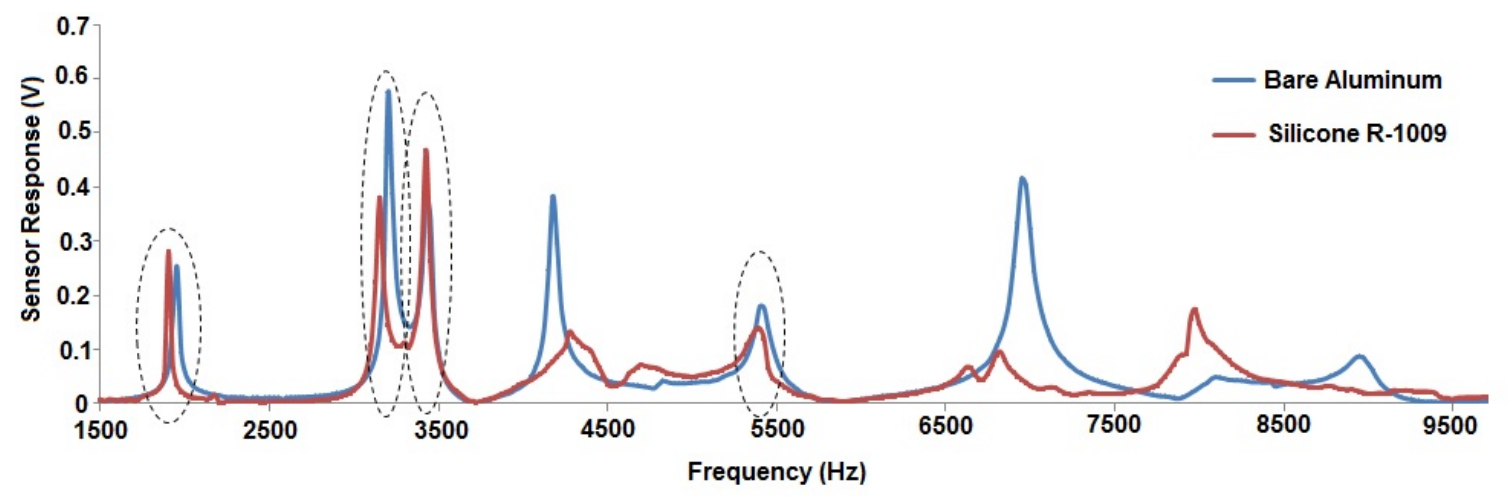

Figure 70: Sweep using the piezoelectric actuator and sensor on coated and uncoated plates where the circled peaks correspond to the resonance modes illustrated in Figure 71. 


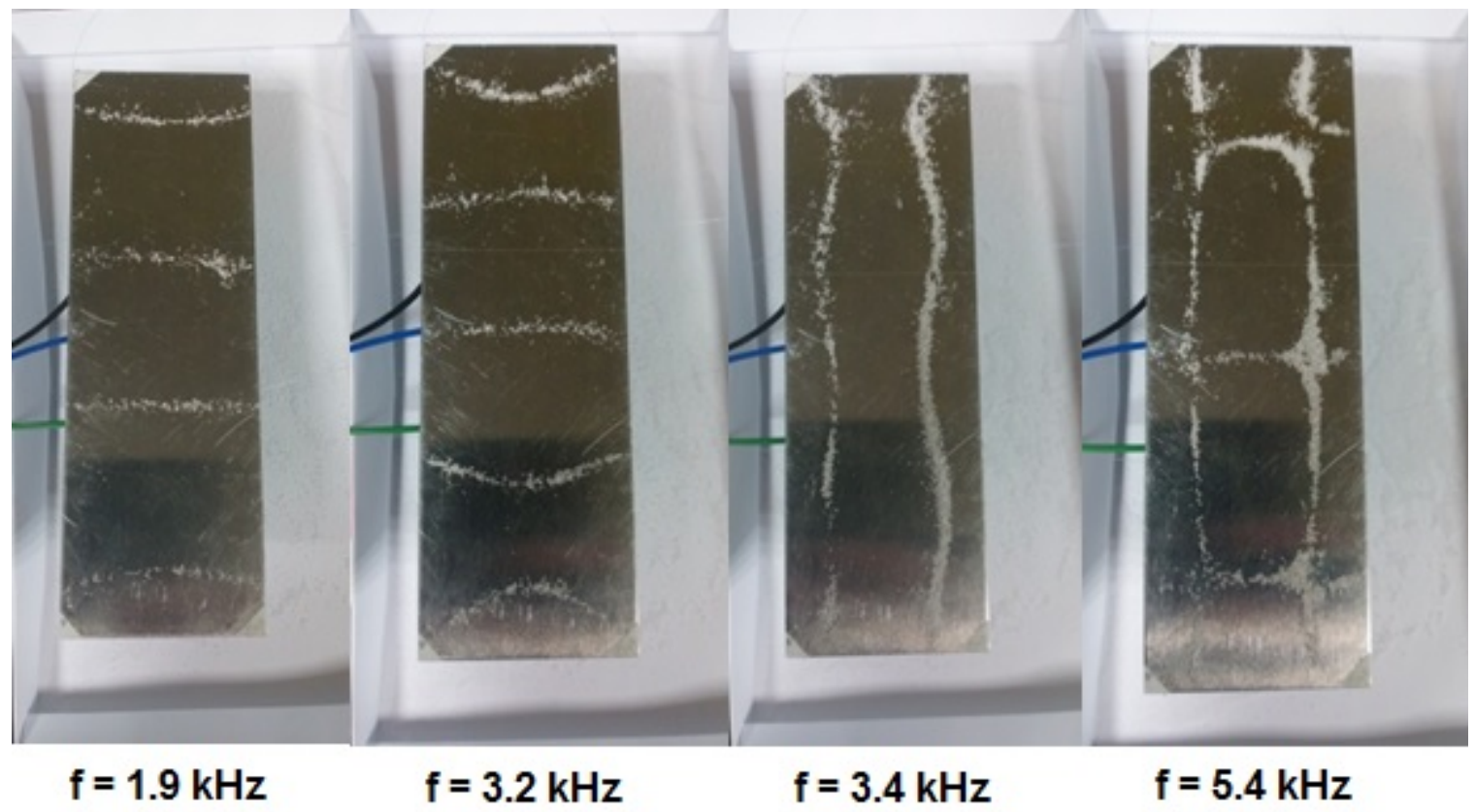

Figure 71: Corresponding resonance modes found using the piezoelectric actuator and sensor.

As was the case with the shaker, the resonance frequencies were lower for the coated sample than the bare sample. However, the response from the sensor was reduced for the silicone R-1009 coated sample compared to the bare sample.

The numerical model was then used to verify the modes found using the piezoelectric actuator and sensor. The resonance modes are shown in Figure 72. Each of the modes corresponds to the ones existing in Figure 71 . The resonance frequencies are also listed and are all higher than the ones found using the experiment by about $50 \mathrm{~Hz}$ showing that the model is an accurate simulation of the experiment. 


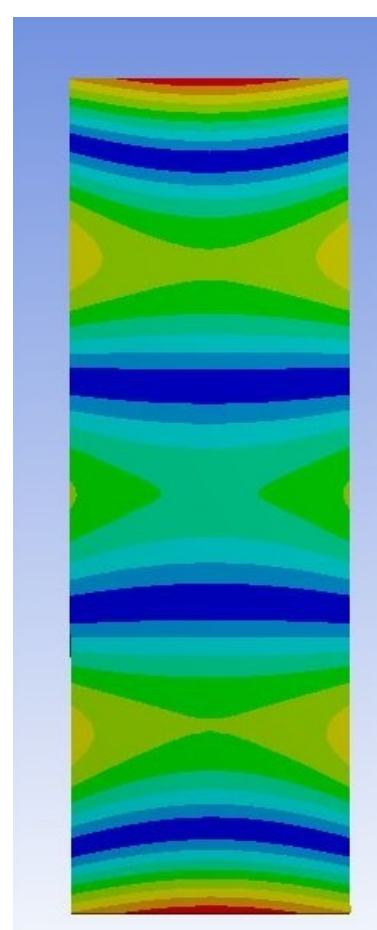

$f=1981 \mathrm{~Hz}$

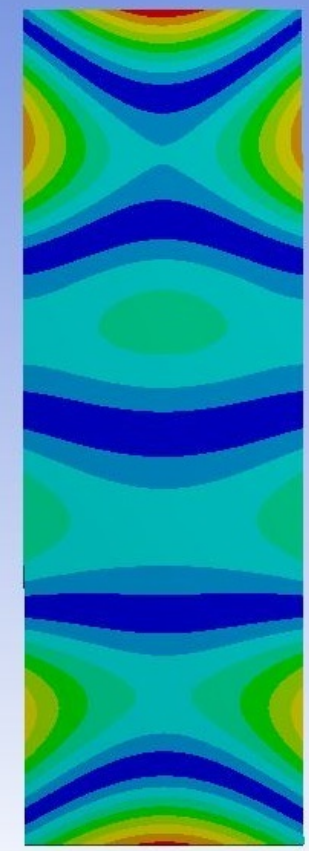

$f=3245 \mathrm{~Hz}$

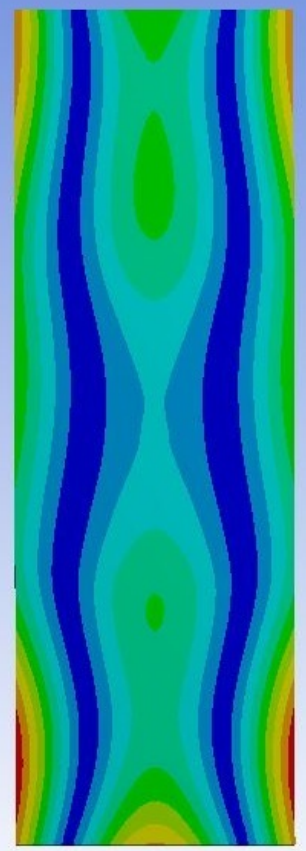

$f=3509 \mathrm{~Hz}$

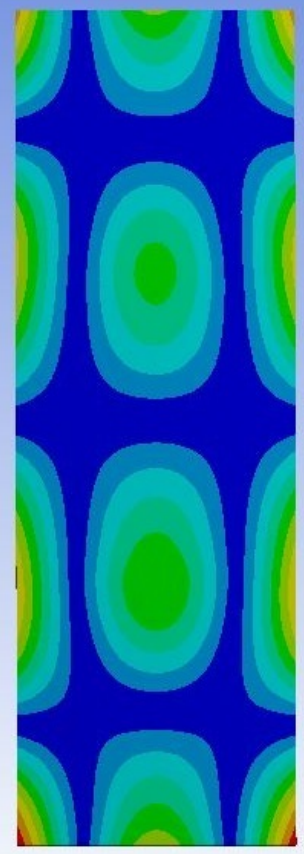

$f=5551 \mathrm{~Hz}$

Figure 72: Corresponding resonance modes found using the numerical model with no ice.

\subsubsection{Measuring the Quality Factor of Bare and Coated Samples}

The quality factor was measured for bare and coated samples using two different methods. Using the shaker and vibrometer, the quality factor was determined by measuring the displacement at the end of the plate. The quality factor for the modes shown in Figure 69 (measured with the shaker) at each resonance frequency is summarized in Figure 73 . These results show that the quality factor for the bare aluminum plate is usually higher than the coated plates. This demonstrates that adding a coating has the potential to increase the amount of damping in the structure. It has been shown that polymers have good damping properties due to their viscoelasticity [80]. As such every effort must be made to reduce the damping effect as much as possible. 


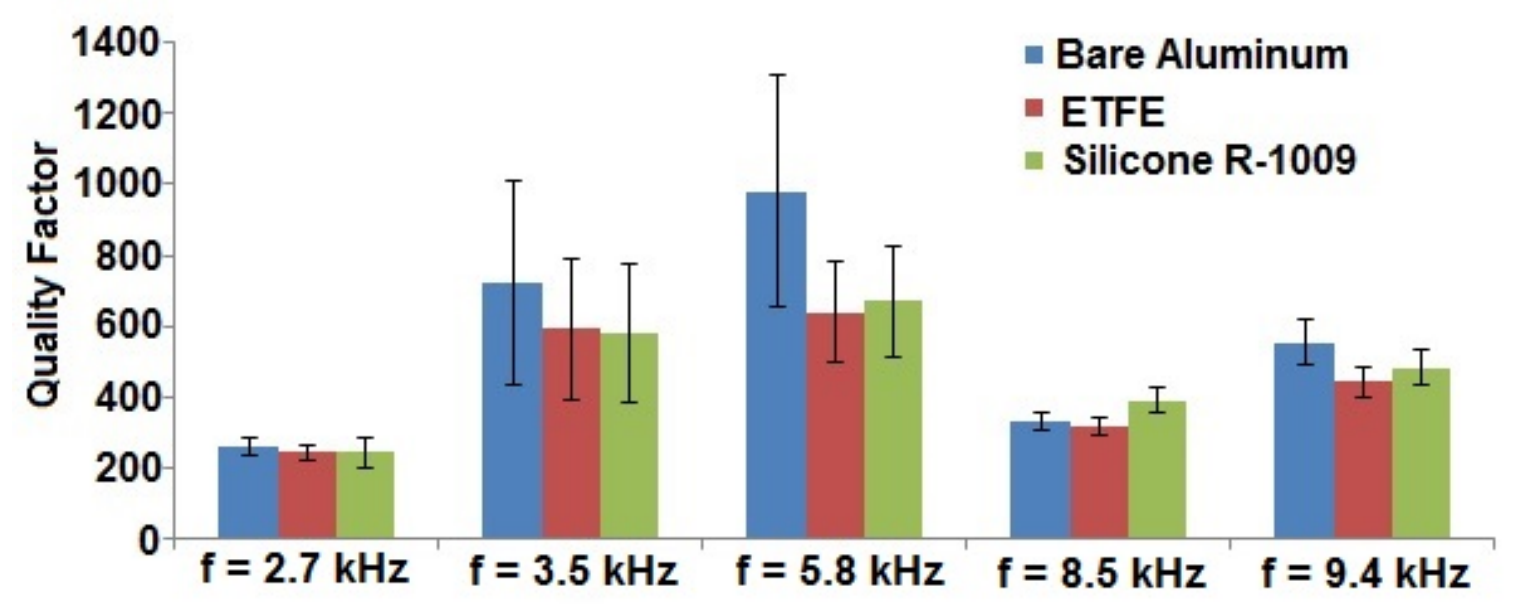

Figure 73: Quality factor for the bare aluminum (blue), ETFE (red), and silicone R-1009 (green) plates.

The quality factor measured using the PZT patch for the modes shown in Figure 71 is displayed in Figure 74 along with that measured with vibrometer. The quality factor for the uncoated plate is consistent for both measurement techniques. The plate coated with silicone R-1009 had a lower quality factor than the bare plate when measured with the ceramic patch, but had a higher quality factor when measured with the vibrometer.

The first mode found using both the shaker and patch have the same deformation pattern. When using the shaker, this mode has a quality factor of approximately 2.5 times that of the mode found with the piezoelectric patch. This shows that the coupling between the shaker and plate is greater than the patch which is bonded to the back of the plate. For the silicone R-1009 sample at $5.4 \mathrm{kHz}$, there was an anomaly for which the underlying reasons are being further analyzed at the moment.

By verifying that the quality factor is not significantly different for the coated plates compared to the bare aluminum plate, a coating can be used to decrease the ice adhesion strength of the ultrasonic de-icing system. If the increase in damping 


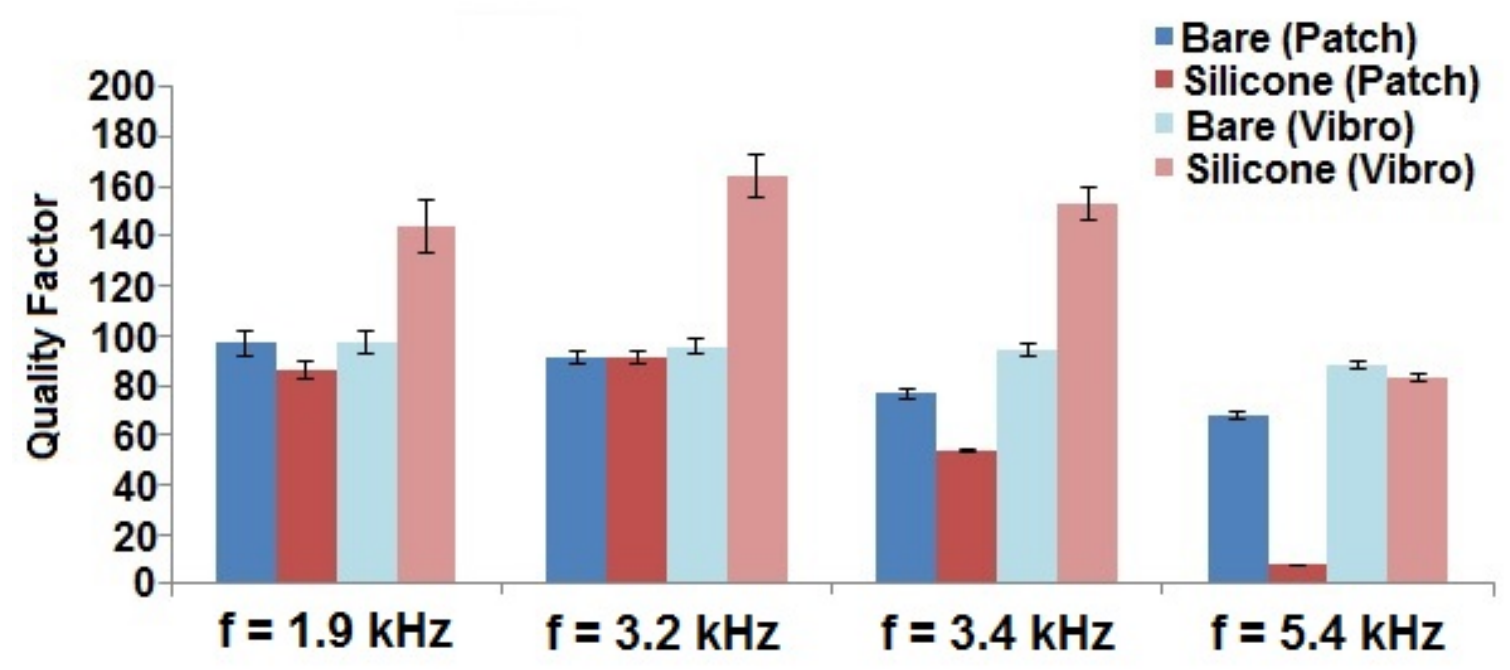

Figure 74: Quality factor for the bare aluminum and silicone R-1009 plates measured with the ceramic patch and vibrometer.

due to the addition of the coating was significant, a different coating/resonator would be required.

\subsection{Ice Delamination Testing}

To verify that the icephobic coating has the potential to decrease the power required to delaminate an ice sheet, bare aluminum and coated samples were tested inside a freezer with fixed temperature of $-16{ }^{\circ} \mathrm{C}$ and compared. The sample was suspended in a vertical configuration as was the case for the sweep.

\subsubsection{Bare Aluminum}

Delamination was attempted at the resonance mode causing the largest response around $43.3 \mathrm{kHz}$. Tests were conducted using pulses at $80 \mathrm{~V}$ (with each pulse supplied for 3 seconds) to see if the ice would break away from the plate. It was 
found that delamination was possible in several areas of the plate. Five delamination tests were attempted and produced different results as to the region where delamination would occur although the same resonance mode was used. The first attempt saw cracking in the bottom left corner followed by delamination on the top of the plate. The second attempt resulted in delamination on the sides of the sample while the third trial had cracking occur in the middle of the sample followed by delamination in this region. Tests four and five had delamination occur in the middle of the plate.

Figure 75 shows the sequence of events leading up to delamination of a $2 \mathrm{~mm}$ ice sheet on an aluminum plate. Initially $90 \mathrm{~V}$ was applied at a frequency of $42.6 \mathrm{kHz}$ which would cause a small area of delamination around the centre of the plate and several cracks would propagate outward from this area. After $80 \mathrm{~V}$ was applied for approximately 3 seconds, cracking and delamination would occur in conjunction and result in the second image. Further application of $80 \mathrm{~V}$ and $90 \mathrm{~V}$ for 2 to 3 second bursts would lead to cracking in the top and bottom portions of the plate and the ice in the corners would become delaminated as shown. Continuing to apply $90 \mathrm{~V}$ in short bursts lead to the image on the far right of Figure 75 . After the test was completed it was discovered that the ice sheet had delaminated, however, the mass of the remaining ice was not large enough to overcome the friction between the plate and the ice sheet.

As cracks form during the test, the resonant frequency of the mode of interest decreases. This trend shows that the stiffness to mass ratio decreases as the Young's modulus of the ice decreases due to the crack formation while there is no change in mass. The opposite is true for expulsion. As chunks of ice fall off, the resonant frequency increases due to the decrease in mass of the sample with the stiffness remaining relatively unchanged. 


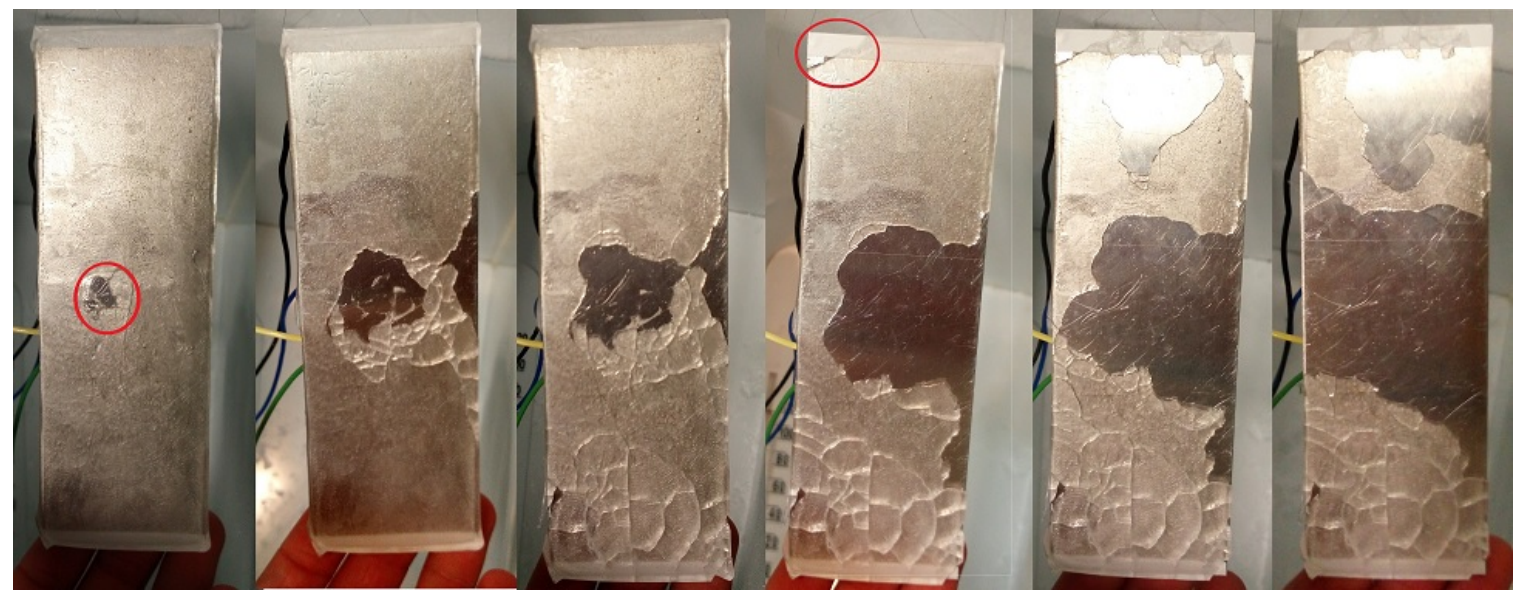

Figure 75: Sequence of delamination of a $2 \mathrm{~mm}$ sheet of ice off of an aluminum plate.

The test described earlier was repeated for an ice sheet with a thickness of $5 \mathrm{~mm}$. During the search for resonant frequencies of samples with $5 \mathrm{~mm}$ thick ice, one peak was found at $42750 \mathrm{~Hz}$ with an amplitude of $16.2 \mathrm{~V}$. It is reasonable that the amplitude measured by the sensor is less than that of the $2 \mathrm{~mm}$ ice sheet due to the decreased displacement as a result of the stiffness increase from the thicker ice sheet. De-icing was attempted at this frequency and the results are shown in Figure 76. During this test, a large crack formed along the centre of the plate. Several other cracks formed at the top and bottom sections of the sample. Delamination was detected as there was a colour change from clear to opaque in certain regions of the sample.

No chunks of ice were expelled as was the case for the $2 \mathrm{~mm}$ sheet of ice. When a crack forms, it does not necessary go through the entire thickness of the ice sheet. For thin ice sheets, the crack may pass all the way through while thicker sheets have some residual ice remaining as shown in Figure 77. Less force is then required to cause chunks to fall off of the sample with thinner ice sheets. 


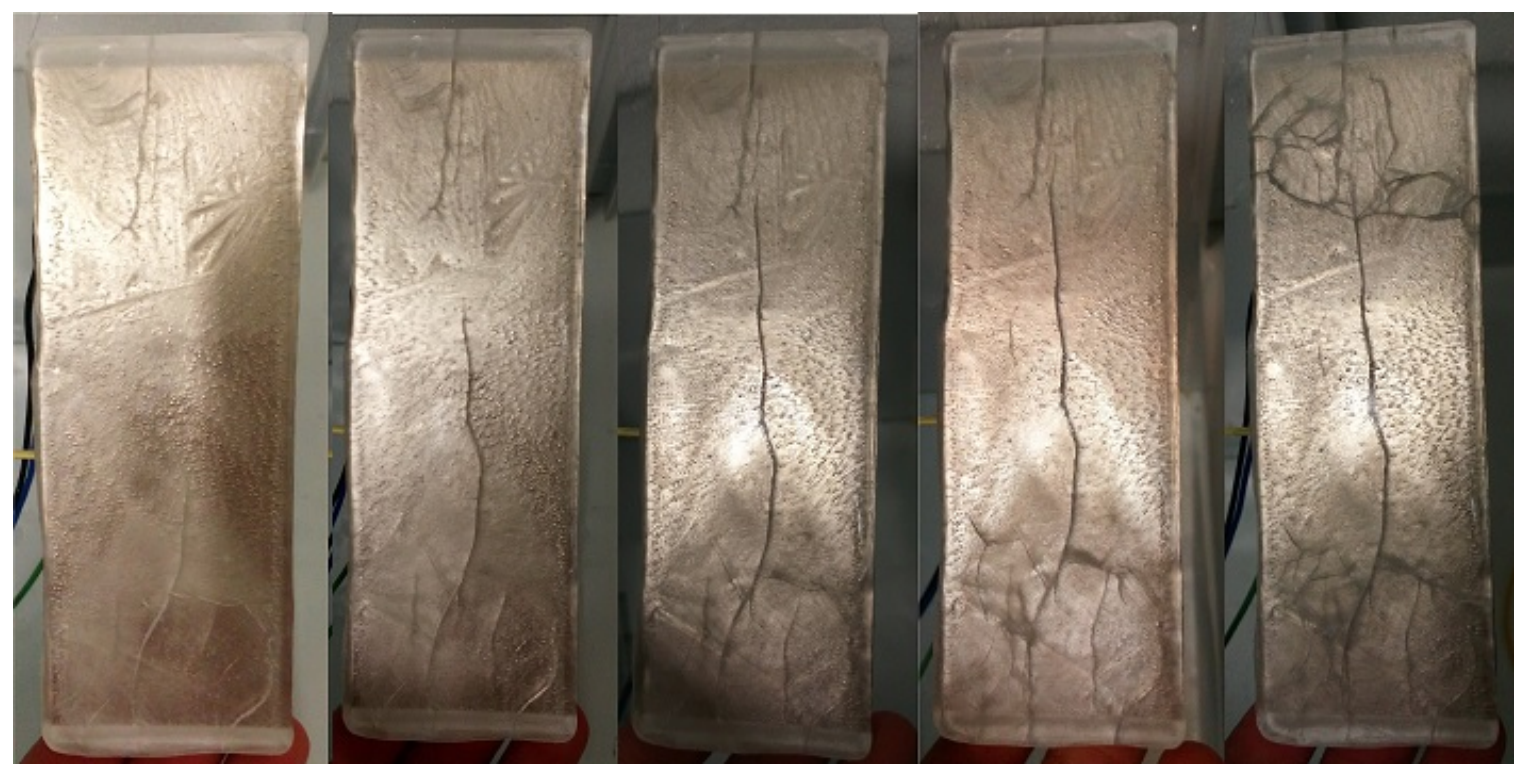

Figure 76: Delamination attempt for a $5 \mathrm{~mm}$ sheet of ice.

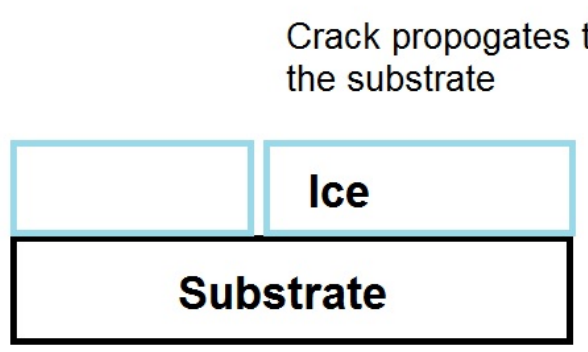

Thin Ice
Crack does not propogate to the substrate

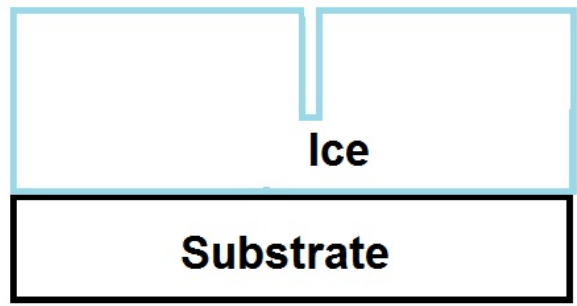

Thick Ice

Figure 77: Difference in crack depth depending on ice thickness.

\subsubsection{Silicone R-1009 Coated Plate}

Delamination was attempted for the plate coated with silicone R-1009. For the $2 \mathrm{~mm}$ ice thickness, a resonance mode causing a large response was discovered at $42 \mathrm{kHz}$. In an attempt to see if less power input is needed to shear ice on coated samples, a lower voltage was used. Tests were conducted using pulses at $70 \mathrm{~V}$ to 
see if the ice would break away from the plate. No cracks formed in the ice sheet and no chunks of ice were expelled. However, a visual change in colour from clear to opaque was observed in the ice sheet during the initial pulse. This colour change is indicative of a small gap formation between the ice sheet and the coating, hence ice delamination.

Although delamination occurred, the ice sheet did not slide off of the plate under its own mass when the plate was in a vertical orientation. If $50 \%$ of the ice sheet had delaminated, the shear stress due to gravity was estimated at $39 \mathrm{~Pa}$; three orders of magnitude below the ice adhesion strength of the silicone R-1009 coating. Thus the weight of ice alone is not sufficient to cause the ice sheet to fall off.

\subsubsection{Influence of Stiffness on Shear Stress}

The stiffness of the surface has an effect on the shear stress induced at the icecoating interface. Since silicone based coatings are elastomers, they have very low stiffness whereas aluminum has a relatively high stiffness. The normal and shear stress distribution for a composite beam in bending are shown in Figure 78. The image on the left depicts the normal and shear stress distribution for a bare sample whereas the right image shows the coated sample. Both the minimal value of the normal stress and the maximum value of the shear stress occur at the Neutral Axis (N.A.).

Based on the information in Table 17, the Young's moduli of ice and aluminum are separated by an order of magnitude so there is a small loss of shear stress at the ice-aluminum interface. When a low stiffness coating is added, there is a significant drop in the shear stress at the ice-coating interface. To minimize the effect of this shear stress loss, a stiffer coating (e.g., composite silicone coating with 


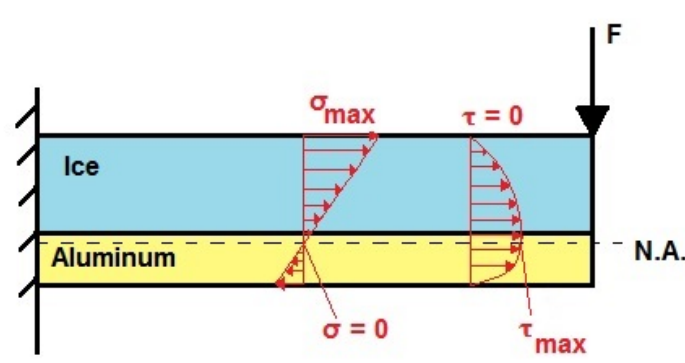

Without coating

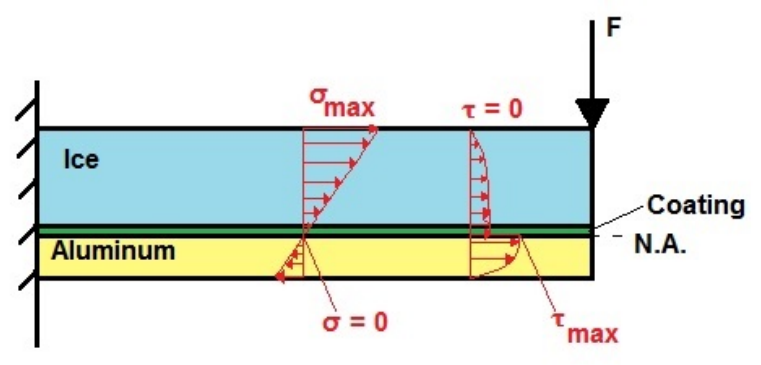

With coating

Figure 78: The normal and shear stress distributions in composite beams consisting of aluminum, coating and ice.

Table 17: Young's modulus for aluminum, ice and silicone rubber [72, 81]

\begin{tabular}{|l|c|}
\hline Material & $E \mathbf{~ ( G P a )}$ \\
\hline Aluminum & 71 \\
\hline Ice & 9.3 \\
\hline Silicone rubber & 0.001 \\
\hline
\end{tabular}

ceramic additives) shall be developed.

To verify that the low coating stiffness is a key contributing factor to the magnitude of interface shear stress, a simulation was setup using COMSOL Multiphysics [82]. A model was created containing the plate, coating and ice, similar to the model used in ANSYS. The model had a symmetric boundary condition on the left and was simply supported on the right. The first resonance frequency (flexural with two nodes) was found at $256 \mathrm{~Hz}$ and the deformation is shown in Figure 79 .

The interface shear stress was then found as a function of the position along the $x$-axis of the sample (longitudinal direction of the plate) as shown in Figure 80 Different values of the Young's modulus for the coating were input to see the effect of coating stiffness on the interface shear stress. It was found that a coating with a Young's modulus of $1 \mathrm{MPa}$ could transfer $10 \%$ of the shear stress that a 


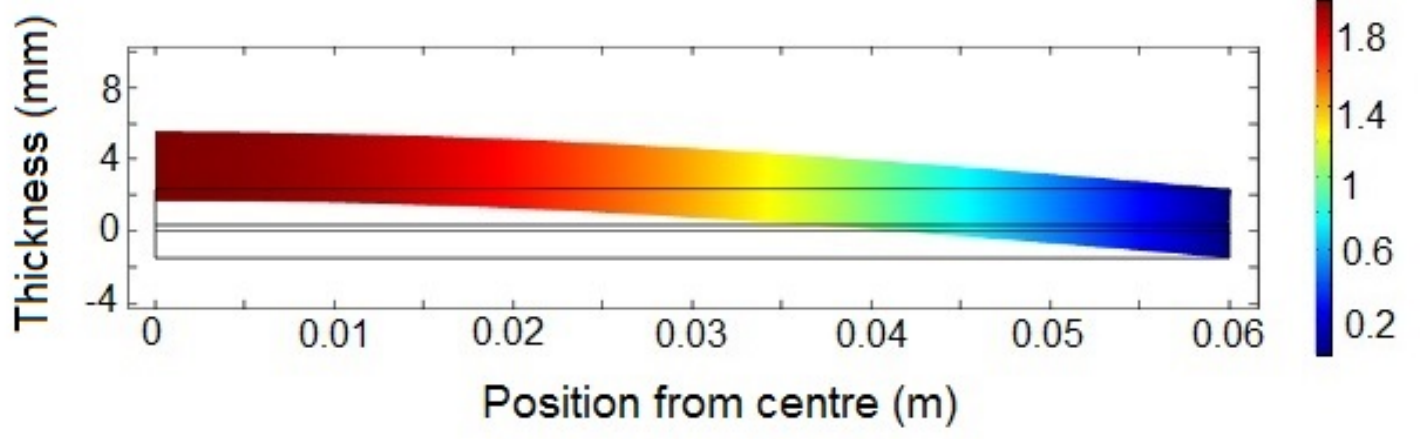

Figure 79: Deformation (in $\mathrm{mm}$ ) of the plate, coating and ice for the first flexural mode.

coating with $1 \mathrm{GPa}$ could. This simulation did not consider the effects of damping, however, lower modulus coatings would also have more damping which further reduces the interface shear stress. This study illustrates the importance of re-engineering existing coatings to maximize the shear stress transferred to the ice-coating interface.

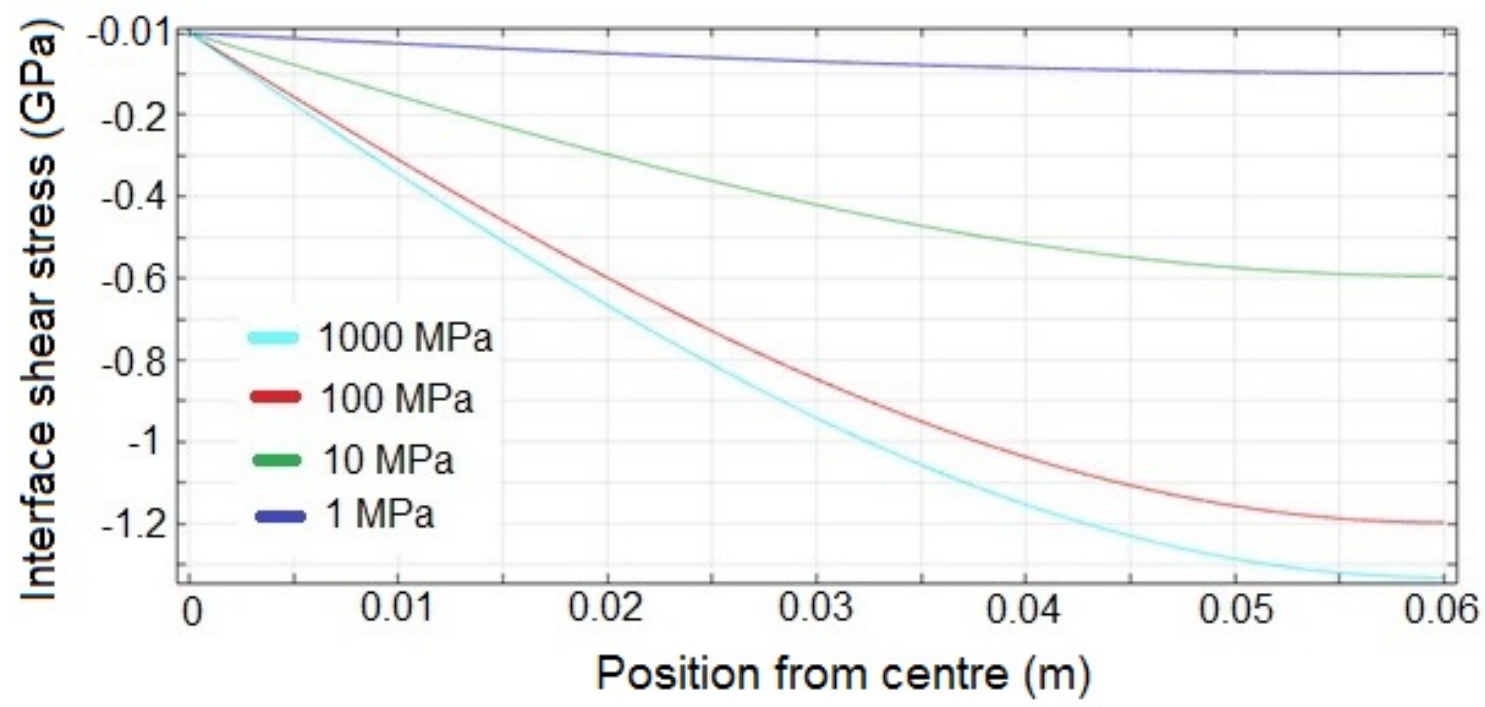

Figure 80: Interface shear stress between the ice and coating along the plate for different coating stiffnesses. 


\subsection{Summary of Results}

This research was initiated with the objective of designing a coupled de-icing system that has the capability to remove ice on an aircraft during flight. Numerous designs incorporating different surface features and vibration methods were carried out, along with numerical simulations to select adequate resonance frequencies and power requirements. Based on the experiment results obtained in this phase of the research, it was demonstrated that icephobic coatings lower the force required to break the adhesive bond between ice and a surface. It was also found that the temperature and ice adhesion strength have a linear relationship and that coated samples can cause ice delamination at lower temperatures than uncoated samples when the same force is applied.

Piezoelectric actuators were tested on aluminum plates to find the resonance frequencies, mode shapes and quality factors which in turn were used to conduct de-icing trials. Ice delamination testing showed that thinner ice sheets can be delaminated while more power is required to delaminate a thicker ice layer of $5 \mathrm{~mm}$; thus validating the preliminary numerical model.

When a coating was added, the same mode shapes were discovered and the resonance frequency was slightly below that of the uncoated plate due to the decrease in the stiffness to mass ratio of the structure. The resulting quality factor was not significantly different from that of the uncoated plate at various resonance modes. When conducting de-icing trials on a coated sample at a lower voltage $(70 \mathrm{~V})$, a colour change was observed in the ice sheet, indicating ice delamination from the coated surface. However, no ice spallation was realized. Although an experiment with further reduced voltage was not conducted, a comparison between the power used in the present study to delaminate ice from coated and uncoated plates is presented in Table 18. 
Table 18: Power required to delaminate ice on coated and uncoated plates

\begin{tabular}{|l|c|c|c|c|}
\hline Plate type & Voltage (V) & Current (A) & Power (W) & Power density $\left(\mathrm{kW} / \mathrm{m}^{2}\right)$ \\
\hline Bare & 80 & 0.6 & 48 & 6.2 \\
\hline Silicone R-1009 & 70 & 0.6 & 42 & 5.4 \\
\hline
\end{tabular}

The power density value was compared to measurements made by Strobl et al. [83] using a coupled system with a hydrophobic surface, heating element and piezoelectric actuators. Strobl et al. measured a power density of $2.74 \mathrm{~kW} / \mathrm{m}^{2}$ while this system required a power density of nearly double $\left(5.4 \mathrm{~kW} / \mathrm{m}^{2}\right)$. Palacios et al. [66] recorded a power density of $2.17 \mathrm{~kW} / \mathrm{m}^{2}$ on rotor blades where no icephobic coating was used.

While this work used a flat plate configuration, Strobl et al. and Palacios et al. had their respective systems on an airfoil. The configuration change as well as the effect of damping provided by the coating can be used to explain the difference in power densities between this work and previous researchers. Furthermore, in the work conducted by Strobl et al. and Palacios et al., the ice was formed in-situ in a wind tunnel while our samples were prepared with water directly placed on the surface. These would create differences in ice coverage and bonding strength on the surface, hence, the energy required to remove ice.

When applied onto aircraft, the induced vibrations from the actuator will interact with the pre-existing vibrations, however, the amplitude from the PZT is much smaller and will not be a significant contributor to structural performance. An ice detection system can be used to identify the presence of ice and the actuators can be activated to remove the ice formation. When operating at ultrasonic frequencies, passengers will not be able to hear any noise from the system. Further work will be conducted to assess the fatigue performance of piezoelectric de-icing systems. 


\section{Chapter 6}

\section{Concluding Remarks}

The aviation industry requires a solution to the ice accretion problem that balances effectiveness and energy efficiency. Existing IPS are often heavy, consume excessive power, and come with large footprints. Other chemical based systems have environmental concerns and require lab and material consumption for each icing event. The coupling of a passive icephobic coating and less intrusive active piezoelectric ice removal system has the potential to address the existing concerns.

\subsection{Contributions}

The following contributions to the field were achieved while carrying out this work:

1. Evaluated the potential feasibility and application methods of applying icephobic coatings onto aircraft surfaces.

2. Selected icephobic coatings based on ice adhesion and wear testing.

3. Developed a system that pairs icephobic coatings with piezoelectric actuators.

4. Used numerical modelling to find optimal resonance modes and validated them using experiments.

5. Demonstrated that the use of a coating can reduce the power consumption needed to delaminate ice. 
These contributions are further elaborated in the following sections.

\subsubsection{Feasibility of Coating Application}

Different coatings require different application methods including plasma spraying, dip coating and brush coating. While plasma spraying is impractical for parts already in service, brushing can be used to apply liquid coating onto flat and curved surfaces. Dipping has limitations including the size of the reservoir and the geometry of the part, leaving brush coating as the ideal application method as it can be used for parts of various sizes and geometries, in the shop or in the field.

The curing process is another consideration when selecting a coating. Some coatings require elevated temperature cures while others require a room temperature cure. Room temperature curing is preferred as no furnace is required and the coated part does not need to be removed from the larger system. This research deduced the most suitable application methods for selected coatings.

\subsubsection{Icephobic Coating Selection}

Icephobic coatings reduce the shear forces required to break the bonds between a layer of ice and a surface. Coatings that are resistant to all different types of icing conditions (frost, glaze or rime) typically have a low roughness which reduces the number of potential ice nucleation sites, delaying the freezing process. The contact angle of the droplet can also be observed to be greater than $90^{\circ}$. For these reasons, the primary coatings used in this study were silicone based due to the intrinsic low surface energy and also the elastic properties.

Both ice adhesion testing and wear testing were used to evaluate potential icephobic coatings. It has been concluded that the silicone R-1009 had the highest ARF of 18.8 which was six times greater than the next best coating (ALG). ALG 
had the best resistance to wear since it is a ceramic based coating but it develops cracks during icing and de-icing cycles. Ultimately, the silicone R-1009 was selected to use in the system as it is effective in reducing the shear stress required for delamination while being fairly resistant to wear. Another advantage of silicone R1009 is that it can be applied using brush coating and requires a room temperature cure.

Through this phase of the study, several deficiencies of existing coatings in the market were realized. When paired with piezoelectric actuators, a modified coating system is needed. We intend to develop new, engineered coating systems based on the following criteria:

- The ease of application and reapplication onto a surface.

- The adhesion reduction factor in the desired operating range.

- The wear rate and lifetime of the coating.

- A comparable stiffness to the substrate.

- A low damping coefficient.

\subsubsection{Computational Modelling of De-icing}

Using ANSYS software, a numerical model was created to simulate the delamination of an ice sheet from an aluminum substrate. Several systems with substrate, ice and coating were modelled and the resonance modes of the system were computed. At each mode, the minimum voltage to cause ice delamination was calculated as were the resulting displacement, piezoceramic stress, current and power.

Several factors were found to have a large influence on the power required for delamination. The ice thickness affects the resonance frequency as it alters the equivalent stiffness to mass ratio. The thinner the sheet of ice, the more potential resonance modes exist where delamination is possible. These modes also require less power for thinner sheets. 
The quality factor is a measure of the coupling between the resonator and the plate. As the quality factor increases, there is a linear decrease in both the voltage and power required for delamination. Although extensional modes have higher quality factors, it was determined that they should be avoided for de-icing purposes as they cause high stresses in the piezoceramic that will result in cracking.

The ice adhesion strength measured experimentally was input into the simulation. There is a linear relationship between the ice adhesion strength and the displacement, piezoceramic stress, voltage and current, while a squared relationship exists between the ice adhesion strength and power. As a result, measures taken to reduce reduce the ice adhesion strength (by using an icephobic coating) can lead to large decreases in the amount of power required by the system. In this study, it has been demonstrated that lower voltage was required to delaminate ice on coated surface. However, the extent of the reduction in power consumption has not been explored. Once the challenge in ice spallation after delamination has been resolved, further research will be conducted, in conjunction with modified coatings.

\subsubsection{Validation of the Ultrasonic De-icing System}

Using the same configuration as the model, the actual resonance frequencies were found using a frequency sweep response measurement. Employing a laser vibrometer, the displacement field was mapped at several resonance frequencies in order to validate the model. Quality factor measurements were taken at each resonance mode to use as an input to the model. It was concluded from this research that the quality factor increases linearly with resonance frequency when extensional modes are not considered.

A large response was measured at approximately $43 \mathrm{kHz}$ for both a $2 \mathrm{~mm}$ and 
$5 \mathrm{~mm}$ thick ice sheet. The quality factor was measured at 250 and the model was further updated. The numerical model predicted that delamination would be possible around $43 \mathrm{kHz}$ to ensure that the required voltage was below $100 \mathrm{~V}$ and resulting tensile stress in the piezoceramic did not exceed $24 \mathrm{MPa}$. Delamination was then tested using samples with both $2 \mathrm{~mm}$ and $5 \mathrm{~mm}$ thick ice sheets. It was observed that the $2 \mathrm{~mm}$ ice sheet was able to be delaminated using short bursts of $80 \mathrm{~V}$ while the $5 \mathrm{~mm}$ sheet would only crack at the centre.

Delamination was possible with the coated plate, however, the ice sheet did not break away (or spall) in chunks as was the case for the uncoated plate. The power required for delamination of the coated plate in our preliminary experiment was $12 \%$ less than that for the bare aluminum plate. The model predicted a significant power reduction for icephobic surfaces however, the combined effects of damping and a lower shear stress transfer through the coating prevented delamination at lower power levels. The resulting system requires a power density comparable to those obtained by other researchers. 


\subsection{Future Work}

The work completed in this thesis has shown that there is a great deal of promise for using icephobic coatings on aircraft for anti-icing and benefit ultrasonic deicing systems as a method to actively remove accumulated ice. As these systems are still in their infancy, there are multiple challenges that must be overcome for the systems to be put into service. These challenges include:

1. Coupling the actuator design and the coating development in order to have optimally matched performance.

2. An engineered surface shall be developed to further reduce the ice adhesion strength of a coating and increase the elastic modulus.

3. Using composite substrate materials to match the design of today's aircraft. This may require changes to the coating type and application method.

4. A further investigation into the parameters that affect the ice formation process as well as the transition from supercooled vapour to ice and study coupled anti-icing and de-icing strategies under different icing conditions.

5. Replacing the flat plate geometry with an airfoil and flexible actuators to determine resonance frequencies, mode shapes and delamination power requirements.

6. Performing dynamic wind tunnel testing to determine how ice builds up on icephobic surfaces at different temperatures and the ice removal characteristics with the activation of the ultrasonic de-icing system.

Each of these topics will need to be addressed in order to enable the coupled system to be employed on future aircraft. 


\section{List of References}

[1] K. Umemoto, E. Sugimura, S. de Gironcoli, Y. Nakajima, K. Hirose, Y. Ohishi, and R. M. Wentzcovitch, "Nature of the volume isotope effect in ice," Phys. Rev. Lett., vol. 115, 2015.

[2] A. Travesset, "The many phases of ice." http://www.physics.iastate.edu/ staff/travesset/phasesofice.doc, 2008. [Online; Accessed 12-June-2016].

[3] V. F. Petrenko and R. W. Whitworth, Physics of Ice. Clarendon Press, 1 ed., 1999.

[4] J. Petrovic, "Mechanical properties of ice and snow," Journal of Material Science, vol. 38, pp. 1-6, 2003.

[5] F. D. Haynes, "Effect of temperature on the strength of snow-ice," Tech. Rep. CRREL-78-27, U.S. Army Cold Regions Research and Engineering Laboratory, Hanover, New Hampshire 03755, December 1978.

[6] E. M. Schulson, "The structure and mechanical behavior of ice," Journal of the Minerals, Metals, Materials Society, vol. 51, pp. 21-27, 1999.

[7] J. Currier and E. Schulson, "The tensile strength of ice as a function of grain size," Acta Metallurgica, vol. 30, pp. 1511-1514, 1982.

[8] A. Mohamed and M. Farzaneh, "An experimental study on the tensile properties of atmospheric ice," Cold Regions Science and Technology, vol. 68, pp. 91-98, 2011.

[9] Department of the Army, U.S. Army Corps of Engineers, Washington, D.C., Ice Engineering, October 2002.

[10] I. A. Ryzhkin and V. F. Petrenko, "Physical mechanisms responsible for ice adhesion," Journal of Physical Chemistry, vol. 101, pp. 6267-6270, 1997. 
[11] J. L. Palacios, Design, fabrication, and testing of an ultrasonic de-icing system for helicopter rotor blades. PhD thesis, The Pennsylvania State University, 2008.

[12] M. Landy and A. Freiberger, "Studies of ice adhesion," Journal of Colloid and Interface Science, vol. 25, pp. 231-244, 1967.

[13] T. Bharathidasan, S. V. Kumar, M. Bobji, R. Chakradhar, and B. J. Basu, "Effect of wettability and surface roughness on ice-adhesion strength of hydrophilic, hydrophobic and superhydrophobic surfaces," Applied Surface Science, vol. 314, pp. 241-250, 2014.

[14] M. C. Chu and R. J. Scavuzzo, "Adhesive shear strength of impact ice," AIAA Journal, vol. 29, pp. 1921-1926, 1991.

[15] V. Hejaz, K. Sobolev, and M. Nosonovsky, "From superhydrophobicity to icephobicity: forces and interaction analysis," Scientific Reports, vol. 3, 2013.

[16] F. Arianpour, M. Farzaneh, and R. Jafari, "Hydrophobic and ice-phobic properties of self-assembled monolayers (sams) coatings on aa6061," Progress in Organic Coatings, vol. 93, pp. 41-45, 2016.

[17] M. Zou, S. Beckford, R.Wei, C. Ellis, G. Hatton, and M. Miller, "Effects of surface roughness and energy on ice adhesion strength," Applied Surface Science, vol. 257, pp. 3786-3792, 2011.

[18] C. Ryerson, "Ice protection of offshore platforms," Cold Regions Science and Technology, vol. 65, pp. 97-110, 2011.

[19] M. Susoff, K. Siegmann, C. Pfaffenroth, and M. Hirayama, "Evaluation of icephobic coatings-screening of different coatings and inuence of roughness," Applied Surface Science, vol. 282, pp. 870-879, 2013.

[20] C. Laforte and A. Beisswenger, "Icephobic material centrifuge adhesion test," in Proceedings International Workshop on Atmospheric Icing of Structures, (Montréal, Canada), June 2005.

[21] A. Heinrich, R. Ross, G. Zumwalt, J. Provorse, V. Padmanabhan, J. Thompson, and J. Riley, Aircraft Icing Handbook - Volume 3 of 3. Gates Learjet Corporation, 1991.

[22] J. Laforte, M. Allaire, and J. Laflamme, "State-of-the-art on power line deicing," Atmospheric Research, vol. 46, pp. 143-158, 1998. 
[23] R. Karmouch, S. Coudé, G. Abel, and G. Ross, "Icephobic ptfe coatings for wind turbines operating in cold climate conditions." INRS-Centre Énergie Matériaux Télécommunications, Varennes (Québec) J3X 1S2 Canada.

[24] G. A. Ruff and B. M. Berkowitz, "Users Manual for the NASA Lewis Ice Accretion Prediction Code (LEWICE)," Tech. Rep. NASA-CR-185129, Sverdrup Technology, Inc, Brook Park, Ohio, May 1990.

[25] H. Gao and J. L. Rose, "Ice detection and classifcation on an aircraft wing with ultrasonic shear horizontal guided waves," IEEE Transactions on Ultrasonics, Ferroelectrics, and Frequency Control, vol. 56, pp. 334-344, 2009.

[26] Y. Boluk, Adhesion of freezing precipitates to aircraft surfaces. Optima Specialty Chemicals and Technology, Montreal, Quebec, Canada, 1996.

[27] G. Mingione and M. Barocco, Flight in Icing Conditions Summary. La direction générale de l'Aviation civile.

[28] K. R. Petty and C. D. J. Floyd, "A Statistical Review of Aviation Airframe Icing Accidents in the U.S.," in 11th Conference on Aviation, Range, and Aerospace Meteorology, pp. 623-628, 2004.

[29] F. T. Lynch and A. Khodadoust, "Effects of ice accretions on aircraft aerodynamics," Progress in Aerospace Sciences, vol. 37, pp. 669-767, 2001.

[30] National Transportation Safety Board Bureau of Accident Investigation, Washington, D.C., Air Florida, Inc., Boeing 737-222, N62AF, Collision with 14th Street Bridge, Near Washington National Airport, January 1982.

[31] National Transportation Safety Board Bureau of Accident Investigation, Washington, D.C., In-flight Icing Encounter and Loss of Control Simmons Airlines, d.b.a. American Eagle Flight 4184 Avions de Transport Regional (ATR), 2002.

[32] AvStop.com Aviation Online Magazine, "NASA, Canadian Agency Renew Agreement To Reduce Aviation Icing Risks." http://avstop.com/may_2015/ nasa_canadian_agency_renew_agreement_to_reduce_aviation_icing_ risks. htm, May 2015. [Online; Accessed 12-June-2016].

[33] Y. Cao, C. Ma, Q. Zhang, and J. Sheridan, "Numerical simulation of ice accretions on an aircraft wing," Aerospace Science and Technology, vol. 23, pp. 296304, 2012. 
[34] J. Shin, B. Berkowitz, H. H. Chen, and T. Cebeci, "Prediction of ice shapes and their effect on airfoil drag," Journal of Aircraft, vol. 31, pp. 263-270, 1994.

[35] Association of European Airlines, Recommendations for De-Icing / Anti-Icing of Aircraft on the Ground, $23^{\text {rd }}$ ed., September 2008.

[36] United States Environmental Protection Agency, Washington, DC 20460, Environmental Impact and Benefit Assessment for the Final Effluent Limitation Guidelines and Standards for the Airport Deicing Category, April 2012.

[37] S. K. Thomas, R. P. Cassoni, and C. D. MacArthur, "Aircraft anti-icing and de-icing techniques and modeling," Journal of Aircraft, vol. 33, pp. 841-854, 1996.

[38] Australian Transport Safety Bureau, "Stall warning event involving a Raytheon B200, VH-ZCO." https://www.atsb.gov.au/media/5353729/ A0-2015-049\%20Final.pdf, 2015. [Online; Accessed 13-November-2016].

[39] M. Pourbagian and W. G. Habashi, "Aero-thermal optimization of in-ight electro-thermal ice protection systems in transient de-icing mode," International Journal of Heat and Fluid Flow, vol. 54, pp. 167-182, 2015.

[40] O. Parent and A. Ilinca, "Anti-icing and de-icing techniques for wind turbines: Critical review," Cold Regions Science and Technology, vol. 65, pp. 88-96, 2011.

[41] M. Mohseni and A. Amirfazli, "A novel electro-thermal anti-icing system for ber-reinforced polymer composite airfoils," Cold Regions Science and Technology, vol. 87, pp. 47-58, 2013.

[42] S. T. Buschhorn, N. Lachman, J. Gavin, B. L. Wardle, S. S. Kessler, and G. Thomas, "Electrothermal Icing Protection of Aerosurfaces Using Conductive Polymer Nanocomposites," in AIAA Paper 13-1729, 54 AIAA/ASME/ASCE/AHS/ASC Structures, Structural Dynamics, and Materials Conference, (Boston, Massachusetts, USA), 2013.

[43] Z. Goraj, "An overview of the deicing and antiicing technologies with prospects for the future," in $24^{\text {th }}$ International Congress of the Aeronautical Sciences, (Yokohama, Japan), 2004.

[44] K. Al-Khalil, "Thermo-Mechanical Expulsion Deicing System - TMEDS," in AIAA Paper 2007-692, 45 ${ }^{\text {th }}$ AIAA Aerospace Sciences Meeting and Exhibit, (Reston, Virginia, USA), 2007. 
[45] S. V. Venna, Y.-J. Lin, and G. Botura, "Piezoelectric transducer actuated leading edge de-icing with simultaneous shear and impulse forces," Journal of Aircraft, vol. 44, pp. 509-515, 2007.

[46] M. Budinger, V. Pommier-Budinger, G. Napias, and A. Costa da Silva, “Ultrasonic ice protection systems: Analytical and numerical models for architecture tradeoff," Journal of Aircraft, vol. 68, pp. 91-98, 2016.

[47] M. Endres, H. Sommerwerk, C. Mendig, M. Sinapius, and P. Horst, “Experimental Study of two Mechanical De-Icing Systems Applied on a Wing Section tested in an Icing Wind Tunnel," in German Aerospace Congress 2016, Braunschweig, (Braunschweig, Germany), September 2016.

[48] V. Pommier-Budinger, M. Budinger, N. Tepylo, and X. Huang, "Analysis of Piezoelectric Ice Protection Systems Combined with Ice-Phobic Coatings," in $8^{\text {th }}$ AIAA Atmospheric and Space Environments Conference, (Washington, D.C.), pp. 623-628, June 2016.

[49] S. Jung, M. Dorrestijn, D. Raps, A. Das, C. M. Megaridis, and D. Poulikakos, "Are superhydrophobic surfaces best for icephobicity?," Langmuir, vol. 27, pp. 3059-3066, 2011.

[50] H. Sojoudi, M. Wang, N. D. Boscher, G. H. McKinley, and K. K. Gleason, "Durable and scalable icephobic surfaces: similarities and distinctions from superhydrophobic surfaces," Soft Matter, vol. 12, pp. 1938-1963, 2016.

[51] K. Golovin, S. P. R. Kobaku, D. H. Lee, E. T. DiLoreto, J. M. Mabry, and A. Tuteja, "Designing durable icephobic surfaces," Science Advances, vol. 2, 2016.

[52] A. J. Meuler, J. D. Smith, K. K. Varanasi, J. M. Mabry, G. H. McKinley, and R. E. Cohen, "Relationships between water wettability and ice adhesion," ACS Applied Materials and Interfaces, vol. 2, pp. 3100-3110, 2010.

[53] A. J. Meuler, G. H. McKinley, and R. E. Cohen, "Exploiting topographical texture to impart icephobicity," ACS NANO, vol. 4, pp. 7048-7052, 2010.

[54] R. Menini and M. Farzaneh, "Elaboration of $\mathrm{al}_{2} \mathrm{O}_{3} /$ ptfe icephobic coatings for protecting aluminum surfaces," Surface and Coating Technology, vol. 203, pp. 1941-1946, 2009. 
[55] S. L. Sivas, B. Riegler, R. Thomaier, and K. Hoover, "A silicone-based ice-phobic coating for aircraft." http://www.thomasnet. com/pdf .php?prid= 100944. [Online; Accessed 12-June-2016].

[56] J. E. Mark, "Some interesting things about polysiloxanes," Accounts of Chemical Research, vol. 37, pp. 946-953, 2004.

[57] N. D. Mulherin and R. Haehnel, "Progress in Evaluating Surface Coatings for Icing Control at Corps Hydraulic Structures," Tech. Rep. Ice Engineering Information Exchange Bulletin, TN-03-4, U.S. Army Cold Regions Research and Engineering Laboratory, Hanover, New Hampshire 03755, 2003.

[58] NuSil Technology, Carpinteria, CA, Silicone Ice-phobic Coatings, 2011.

[59] R. C. Tucker, Jr., ASM Handbook, Volume 5: Surface Engineering, ch. Thermal Spray Coatings, pp. 497-509. ASM International, 1994.

[60] C. C. Ryerson, "Assessment of superstructure ice protection as applied to offshore oil operations safety," Tech. Rep. CRREL TR-09-4, U.S. Army Cold Regions Research and Engineering Laboratory, Hanover, New Hampshire 03755, April 2009.

[61] T. M. Schutzius, S. Jung, T. Maitra, P. Eberle, C. Antonini, C. Stamatopoulos, and D. Poulikakos, "Physics of icing and rational design of surfaces with extraordinary icephobicity," Langmuir, vol. 31, pp. 4807-4821, 2015.

[62] R. Gouni, "A new technique to study temperature effects on ice adhesion strength for wind turbine materials," Master's thesis, Case Western Reserve University, 2011.

[63] APC International Ltd., Piezoelectric Ceramics: Principles and Applications. Mackeyville, PA: APC International Ltd., 2 ed., 2011.

[64] V. Pommier-Budinger and M. Budinger, "Sizing optimization of piezoelectric smart structures with meta-modeling techniques for dynamic applications," International journal of applied electromagnetics and mechanics, vol. 46, pp. 195206, 2014.

[65] S. V. Venna and Y.-J. Lin, "Mechatronic development of self-actuating in-flight deicing structures," IEEE/ASME Transactions on mechatronics, vol. 11, pp. 585592, 2006. 
[66] J. Palacios, E. Smith, J. Rose, and R. Royer, "Instantaneous de-icing of freezer ice via ultrasonic actuation," AIAA Journal, vol. 49, pp. 1158-1167, 2011.

[67] J. L. Palacios and E. C. Smith, "Dynamic analysis and experimental testing of thin-walled structures driven by shear tube actuators," in $46^{\text {th }}$ AIAA/ASME/ASCE/AHS/ASC Structures, Structural Dynamics \& Materials Conference, (Austin, Texas), April 2005.

[68] S. Tarquini, C. Antonini, A. Amirfazli, M. Marengo, and J. Palacios, "Investigation of ice shedding properties of superhydrophobic coatings on helicopter blades," Cold Regions Science and Technology, vol. 100, pp. 50-58, 2014.

[69] A. Ibrahim, "Development and evaluation of anti-abrasion polymer coatings for circulation coins," Master's thesis, Carleton University, 2015.

[70] A. Acton, ed., Fluorinated HydrocarbonsAdvances in Research and Application. Atlanta, Georgia: ScholarlyEditions, 2013 ed., 2013.

[71] S. Laturkar and P. A. Mahanwar, "Superhydrophobic coatings using nanomaterials for antifrost applications review," Nanosystems: Physics, Chemistry, Mathematics, vol. 7, p. 650656, 2016.

[72] NuSil Technology, Carpinteria, CA, R-2180 Ice Phobic Coating, May 2014.

[73] NuSil Technology, Carpinteria, CA, R-1009 RTV Silicone Dispersion Coating, May 2014.

[74] DuPont, Washington, D.C., DuPont Teflon Nonstick \& Industiral Coatings, 2002.

[75] B. Xiao, "Development and evaluation of anti-corrosion and anti-bacterial polymer coatings for circulation coins," Master's thesis, Carleton University, 2015.

[76] PI Ceramic, Thuringia, Germany, Piezoelectric Ceramic Products: Fundamentals, Characteristics and Applications, 2016.

[77] B. Dixon, A. Walsh, B. Gall, and M. Goodwin, "Novel phase change material icephobic coating for ice mitigation in marine environments," in Green Ships, Eco Shipping, Clean Seas, 2014. The $12^{\text {th }}$ Annual General Assembly of IAMU.

[78] C. A. Schneider, W. S. Rasband, and K. Eliceiri, "NIH Image to ImageJ: 25 years of image analysis," Nature Methods, vol. 9, pp. 671-675, 2012.

[79] P. Rouset. Personal communication, June 2016. 
[80] D. Chung, "Review: Materials for vibration damping," Journal of Material Science, vol. 36, pp. 5733-5737, 2011.

[81] W. M. Haynes, CRC handbook of chemistry and physics: A ready-reference book of chemical and physical data. Boca Raton: CRC Press, 92 ${ }^{\text {nd }}$ ed., 2009.

[82] M. Budinger. Personal communication, March 2017.

[83] T. Strobl, S. Storm, M. Kolb, J. Haag, and M. Hornung, "Development of a hybrid ice protection system based on nanostructured hydrophobic surfaces," in $29^{\text {th }}$ Congress of the International Council of the Aeronautical Sciences, (St. Petersburg, Russia), 2014.

[84] D. Guyonar, G. Sebald, S. Pruvost, M. Lallart, A. Khodayari, and C. Richard, "Energy harvesting from ambient vibrations and heat," Journal of Intelligent Material Systems and Structures, vol. 20, pp. 609-624, 2009.

[85] E. Lefeuvre, A. Badel, C. Richard, L. Petit, and D. Guyomar, "A comparison between several vibration-poweredpiezoelectric generators for standalone systems," Sensors and Actuators A, vol. 126, pp. 405-416, 2006. 


\section{Appendix A}

\section{Derivation of the Numerical Model}

The numerical model uses ANSYS Modal to find the resonance frequencies of the system and their corresponding mode shapes. The model then computes the maximum displacement on the plate using the charge on the piezoceramic. The shear stress in the xy-plane is then found at the interface between the ice and plate. Using the measured quality factor and ice adhesion strength, the voltage and current can be computed for the interface shear stress to be equivalent to the ice adhesion strength.

\section{A.1 Resonance Frequency}

First the resonance modes can be found by solving the following eigenvalue problem:

$$
[K]\left\{\phi_{i}\right\}=\omega_{i}^{2}[M]\left\{\phi_{i}\right\}
$$

where:

$[K]=$ structural stiffness matrix,

$\left\{\phi_{i}\right\}=$ mode shape vector of mode $i$, 
$\omega_{i}=$ natural frequency of mode $i$, and

$[M]=$ structural mass matrix.

The model uses the Block Lanczos method to solve for the resonance modes. This method allows for a quick extraction of data in the user-specified frequency range.

\section{A.2 Extraction of Properties}

For a particular resonance mode, the charge on the surface of the piezoceramic $(q)$, the maximum displacement $\left(u_{\max }\right)$, the shear stress at the interface $\left(\tau_{z x}\right.$ and $\left.\tau_{y z}\right)$, and the maximum von Mises equivalent stress in the ceramic $(\sigma)$ can be calculated by the solver. The charge is later used for calculating the forcing factor of each mode. The maximum displacement is found by solving for the maximum displacement in the $\mathrm{z}$ direction of each node and then sorting the nodes by displacement magnitude.

The shear stress at the interface between the ice sheet and the plate is found at each node by computing the component in the zx direction and yz direction. The resultant shear stress $\left(\tau_{\text {int }}\right)$, can then be found using Equation 11 .

$$
\tau_{\text {int }}=\sqrt{\tau_{z x}^{2}+\tau_{y z}^{2}}
$$

The nodes are then sorted by interface shear stress and the median is found. The median value is then compared to the shear stress required for delamination found by experimental testing. This is done for each resonance mode.

The maximum von Mises equivalent stress in the ceramic is used to determine if the voltage required for delamination will cause cracking in the piezoelectric patch. If the stress is below $24 \mathrm{MPa}$, then cracking is avoided and delamination 
can be attempted. Both the actuator and sensor are checked using this criteria.

\section{A.3 Calculation of Vibrational Properties}

In vibration, there is a second order linear differential equation that governs the behavior of a spring-damper system given by:

$$
[M]\{\ddot{u}\}+[C]\{\dot{u}\}+[K]\{u\}=\{F\}
$$

where:

$[C]=$ structural damping matrix,

$\{u\}=$ nodal displacement vector,

$\{\dot{u}\}=$ nodal velocity vector,

$\{\ddot{u}\}=$ nodal acceleration vector,

$\{F\}=$ applied load vector.

The resonance frequency is a function of the equivalent mass and equivalent stiffness of the system as per Equation 10. It was found that the both of these parameters were a function of the maximum displacement. The mass is found using Equation 13 while the stiffness is calculated using Equation 14

$$
\begin{gathered}
M=\frac{1}{u_{\text {max }}^{2}} \\
K=\frac{\omega^{2}}{u_{\text {max }}^{2}}
\end{gathered}
$$

The governing equation for an electrical system is given by:

$$
i=N \dot{u}(t)-C_{0} \dot{V}(t)
$$


where $i$ is the current, $N$ is the force factor, $C_{0}$ is the capacitance of the piezoceramic and $V(t)$ is the applied voltage [64, 84, 85]. When Equation 15 is integrated with respect to time, it becomes:

$$
q=N u(t)-C_{0} V(t)
$$

where $q$ is the electrical charge on the piezoceramic. The force factor can be represented as:

$$
N=\frac{q}{u_{\max }}
$$

where both $q$ and $u_{\max }$ are found in the model. The capacitance is a function of the electrical permittivity, area and thickness of the piezoceramic as given by Equation 18

$$
C_{0}=\frac{\epsilon^{S} \epsilon_{0} A}{h}
$$

where $\epsilon^{S}$ is the ratio of permittivity between the piezoceramic and a vacuum, $\epsilon_{0}$ is the electrical constant, and $A$ and $h$ represent the area and thickness of the piezoceramic respectively.

\section{A.4 Calculation of Delamination Parameters}

Using the shear stress calculated at the interface as well as the maximum displacement, the shear coupling factor $k$ can be calculated using Equation 19 .

$$
k=\frac{\tau_{g e n}}{u_{\max }}
$$


where $\tau_{g e n}$ is the shear stress generated by the actuator. The shear coupling factor is the ratio of shear stress generated at the interface to the maximum displacement in the z-direction. This ratio is then used to find the displacement required for delamination:

$$
u_{d e l}=\frac{\tau_{d e l}}{k}
$$

where $\tau_{d e l}$ is the shear stress required for delamination and it is found using experimental testing for different types of surfaces.

The voltage required for delamination can be found using Equation 21;

$$
V_{\text {del }}=\frac{\tau_{\text {del }}}{\tau_{\text {med }}} \frac{u_{\text {max }} k}{N Q_{m}}
$$

where $\tau_{\text {med }}$ is the median value of shear stress exhibited between the ice and plate and $Q_{m}$ is the quality factor which is determined by experiments.

The current can also be calculated using Equation 22

$$
i_{\text {del }}=\frac{\tau_{\text {del }}}{\tau_{\text {med }}} u_{\text {max }} N \omega
$$

The power required for delamination is the product of the voltage and current. Finally, the stress in the piezoceramic can be calculated for each patch using Equation 23 ,

$$
\sigma_{d e l}=\frac{u_{d e l}}{u_{\max }} \sigma
$$

